NBER WORKING PAPER SERIES

\title{
INTERNATIONAL TRADE AND EARNINGS INEQUALITY: A NEW FACTOR CONTENT APPROACH
}

\author{
Rodrigo Adão \\ Paul Carrillo \\ Arnaud Costinot \\ Dave Donaldson \\ Dina Pomeranz \\ Working Paper 28263 \\ http://www.nber.org/papers/w28263 \\ NATIONAL BUREAU OF ECONOMIC RESEARCH \\ 1050 Massachusetts Avenue \\ Cambridge, MA 02138 \\ December 2020
}

We thank Thomas Bijl, Juan David Hernandez, Shanon Hsuan-Ming Hsu, Wouter Leenders, Antoine Levy, and Miguel Vazquez Vazquez for excellent research assistance, as well as Jonathan Vogel, Adrian Wood, our discussants Oleg Itskhoki and Ahmad Lashkaripour, and numerous seminar participants for helpful comments. We are grateful to the Centro de Estudios Fiscales and the Departamento de Control of the Ecuadorian Tax Authority for outstanding collaboration. In addition, this paper has benefited from funding from the National Science Foundation (grant SES-1559015), the CEPR and the UK Department for International Development (DFID) (under the 'Private Enterprise Development in Low-Income Countries' program, reference MRG004 3834), and the European Research Council under the European Union's Horizon 2020 research and innovation programme (grant agreement No 758984). The views expressed are not necessarily those of CEPR, DFID, or ERC. The views expressed herein are those of the authors and do not necessarily reflect the views of the National Bureau of Economic Research.

NBER working papers are circulated for discussion and comment purposes. They have not been peer-reviewed or been subject to the review by the NBER Board of Directors that accompanies official NBER publications.

(C) 2020 by Rodrigo Adão, Paul Carrillo, Arnaud Costinot, Dave Donaldson, and Dina Pomeranz. All rights reserved. Short sections of text, not to exceed two paragraphs, may be quoted without explicit permission provided that full credit, including $\odot$ notice, is given to the source. 
International Trade and Earnings Inequality: A New Factor Content Approach

Rodrigo Adão, Paul Carrillo, Arnaud Costinot, Dave Donaldson, and Dina Pomeranz

NBER Working Paper No. 28263

December 2020

JEL No. D3,F1,F6,J2

\title{
ABSTRACT
}

We develop a new factor content approach to study the impact of trade on inequality. Our analysis generalizes the theoretical results of Deardorff and Staiger (1988) and improves on past empirical implementations of these results. Combined with unique administrative data from Ecuador, our approach yields measures of individual-level exposure to exports and imports, for both capital and labor income, as well as estimates of the incidence of such exposure across the income distribution. We find that international trade raises earnings inequality in Ecuador, especially in the upper-half of the income distribution. However, the drop in inequality experienced by Ecuador over the last decade would have been less pronounced in the absence of trade.

\author{
Rodrigo Adão \\ Booth School of Business \\ University of Chicago \\ 5807 South Woodlawn Avenue \\ Chicago, IL 60637 \\ and NBER \\ rodrigo.adao@chicagobooth.edu \\ Paul Carrillo \\ George Washington University \\ 2115 G St. N.W. Suite 364 \\ Washington, DC 20052 \\ pcarrill@gwu.edu \\ Arnaud Costinot \\ Department of Economics, E52-534 \\ Massachusetts Institute of Technology \\ 77 Massachusetts Avenue \\ Cambridge, MA 02139 \\ and NBER \\ costinot@mit.edu
}

\author{
Dave Donaldson \\ Department of Economics, E52-554 \\ Massachusetts Institute of Technology \\ 77 Massachusetts Avenue \\ Cambridge, MA 02139 \\ and NBER \\ ddonald@mit.edu \\ Dina Pomeranz \\ University of Zurich \\ Schoenberggasse 1 \\ 8057 Zurich \\ Switzerland \\ dina.pomeranz@econ.uzh.ch
}




\section{Introduction}

Some individuals participate in the world economy. They own, work for, or sell to the supply chains of global firms that export and import. Others do not. What is the impact of such differences in trade exposure on earnings inequality? If a country's exports and imports were suddenly to drop to zero, because of some extreme policy or natural disaster, would its distribution of earnings become more or less equal? In the absence of trade, would the consequences of domestic shocks for inequality be magnified or dampened?

In this paper we offer a generalization of Deardorff and Staiger's (1988) factor content approach to address these questions. It maintains what we view as the main appeal of this approach-an intuitive supply and demand framework - while improving on its theoretical foundations and empirical implementation. The key input fed into our analysis is a unique administrative dataset from Ecuador that merges firm-to-firm transaction data, employer-employee matched data, owner-firm matched data, and firm-level customs transaction records. Together with theory, such information allows us to measure the export and import exposures of individuals-be they workers or capital owners-across the income distribution and, in turn, to infer the overall incidence of trade on earnings inequality.

Our main empirical finding is that international trade substantially raises earnings inequality in Ecuador, especially in the upper half of its income distribution. In the absence of trade, top-income individuals would be relatively poorer. However, our empirical analysis also implies that the drop in inequality that took place in Ecuador over the last decade would have been less pronounced if its economy had been subject to the same domestic shocks, but unable to trade with the rest of the world.

Section 2 lays out the theoretical foundations of our analysis. Our starting point is the observation that in economies with competitive factor markets, regardless of whether good markets are competitive as well, the earnings of individuals depend on the global demand for the factor services that they supply. While firms trade goods, not factors, international trade has an impact on inequality only insofar as it shifts the relative demand for the factor services embodied in those goods. This can occur through two channels: (i) foreign consumers and firms may demand domestic factor services in different proportions than domestic consumers and firms do, an export channel, or (ii) domestic consumers and firms may change their demand for domestic factor services in response to the availability of foreign factor services, an import channel. The overall impact of trade

on inequality then is the amount by which domestic factor prices need to adjust to bring factor markets to equilibrium in response to these two shifts in demand. 
The formal counterpart of this observation is a novel structural relationship between domestic factor prices, $w$, and two sufficient statistics of foreign shocks, $R E E$ and $w^{*}$ :

$$
R D\left(w, w^{*}\right) \times R E E=R S,
$$

where relative export exposure, $R E E$, can be measured directly via Leontief's (1953) factor content of exports, $w^{*}$ denotes foreign factor prices, $R D(\cdot, \cdot)$ is the domestic relative factor demand system, and $R S$ is domestic relative factor supply. This structural relationship summarizes how competitive markets determine domestic factor prices, regardless of whether an economy is open or closed, and provides the bedrock of our subsequent analysis. It underpins how we measure export and import exposure across individuals - by measuring the extent to which variation in REE and $w^{*}$ shift the demand for their factor services-as well as how we estimate the incidence of such exposure-by calculating the changes in factor prices that obtain when $R E E$ and $w^{*}$ are sequentially taken to their autarkic limits, $R E E \rightarrow 1$ (the export channel) and $w^{*} \rightarrow \infty$ (the import channel).

Section 3 introduces a model of Ecuador's domestic relative factor demand that can be built up from estimates based on firm-level micro-data. We assume that domestic consumers have nested CES demand for final goods, whereas firms have nested CES demand for intermediate goods and factors. However, this places no restriction on firm-level heterogeneity in demand for domestic and foreign factor services, or on firms' export behavior. As such, every individual's own exposure to exports and imports is similarly unrestricted, while the incidence of such exposure can be inferred in an intuitive manner from the extent to which consumers and firms reallocate expenditure in response to changes in good and factor prices.

Section 4 uses administrative tax data to measure these differences in trade exposure across Ecuador's income distribution from 2009-2015. Guided by the above structural relationship, we say that individuals are more exposed to exports if exports in the trade equilibrium raise the relative demand for their factor services-the labor they supply to firms, and the capital that they install in the firms they own-because those are disproportionately demanded abroad, either directly or indirectly, as in Leontief (1953). Likewise, we say that individuals are more exposed to imports if imports in the trade equilibrium lower the relative demand for their factor services because those are closer substitutes to foreign factor services. In our empirical model, these differences in substitutability can be measured directly from the covariance between factor shares embodied in different firms' domestic final sales and (direct and indirect) import cost shares at those same firms.

In Ecuador, we find that export exposure is broadly pro middle-class, in the sense that, 
on average, individuals in the middle of the income distribution export a higher fraction of their factor services, mostly labor, to the rest of the world. In contrast, import exposure tends to be pro-rich because Ecuadorian firms employing high-skill labor also import more intermediate goods. When imports become cheaper, those firms expand, and the relative demand for high-skill labor goes up, benefiting high-income individuals.

To go from exposure to incidence, Section 5 estimates our model of Ecuador's domestic relative factor demand. Domestic factor demand is a function of two micro-level demand elasticities: the elasticity of substitution between domestic factors of production, within each firm, and the elasticity of substitution between final goods, within each sector. To deal with potential simultaneity bias in the estimation of these demand parameters, we construct shift-share instrumental variables that leverage components of our measures of export and import exposure that are driven by foreign shocks. Combined with the rest of our micro-level dataset, IV estimates of these two parameters identify Ecuador's domestic relative factor demand.

Section 6 offers a battery of specification tests to strengthen the credibility of our empirical model. This includes macro-level tests that focus directly on the structural relationship between domestic factor prices $w$, relative export exposure $R E E$, and foreign factor prices $w^{*}$ emphasized by our theoretical analysis. Since we have estimated relative domestic factor demand indirectly through the estimation of two micro-level elasticities governing firm- and consumer-level responses, there is a priori no reason why the observed response of domestic factor prices to changes in our two sufficient statistics should coincide with the response predicted by our empirical model. In practice, preferences and technology may not be nested CES, and markets may not be competitive and adjust frictionlessly. Remarkably, however, under the same orthogonality conditions imposed to estimate micro-level elasticities, we cannot reject the null that observed and predicted responses of factor prices to foreign shocks are identical, up to a first-order approximation.

Section 7 concludes with a series of counterfactual exercises that combine measures of the two sufficient statistics, REE and $w^{*}$, with our estimates of domestic relative factor demand to compare the distribution of earnings in Ecuador with or without trade and, in turn, to evaluate its overall incidence on earnings inequality. Quantitatively, we find that the import channel dominates the export channel: international trade increases earnings inequality in Ecuador, especially in the upper-half of the income distribution. This is true both in our administrative data and in an augmented sample that includes individuals employed in informal firms.

Ultimately, we conclude that trade generates gains that are around 11\% larger for those at the 90th percentile than those at the median, and up to $27 \%$ larger in the case 
of Ecuador's top-percentile earners for whom capital ownership is particularly important. Nevertheless, we also find that openness had a tendency to magnify the decline in inequality caused by domestic shocks between 2009 and 2015. For example, in the absence of trade, the 90-10 ratio of Ecuador's earnings distribution would have decreased by $17 \%$ instead of the $32 \%$ observed in our dataset.

\section{Related Literature}

The literature on trade and inequality is rich and varied, from applied theory work (e.g., Stolper and Samuelson, 1941; Grossman and Rossi-Hansberg, 2008; Helpman et al., 2010) to reduced-form evidence (e.g., Hanson and Harrison, 1999; Attanasio et al., 2004; Autor et al., 2013) to structural empirical approaches (e.g., Artuc et al., 2010; Galle et al., 2017; Burstein and Vogel, 2017). A non-exhaustive list of recent surveys includes Goldberg and Pavcnik (2007), Feenstra (2010), Harrison et al. (2011), Helpman (2018), Muendler (2017), Pavcnik (2017), and Hummels et al. (2018).

Our analysis is most closely related to the factor content approach to trade and inequality, whose empirical application was popularized in the 1990s (Murphy and Welch, 1991; Borjas et al., 1992; Katz and Murphy, 1992; Wood, 1995; Borjas et al., 1997) despite being the subject of heated debate (Krugman, 2000; Leamer, 2000). ${ }^{1}$ The basic idea was to use a simple supply and demand framework to analyze changes in relative factor prices, with international trade acting as an implicit change in relative factor supply equal to the difference between factors used in exports and imports. In this paper we develop an alternative to the original factor content approach centered around a novel structural relationship between domestic factor prices and two sufficient statistics of foreign shocks that aims to maintain the same intuitive focus on factor supply and factor demand, but improves on what we view as three important limitations of the original approach.

On the theory side, Deardorff and Staiger (1988) provide micro-theoretical foundations for the original factor content approach. In a Heckscher-Ohlin model with CobbDouglas preferences and technology, they show that if all sectors are import-competing, then net exports of factor services are sufficient statistics for computing changes in relative factor prices resulting from a hypothetical move to autarky. Deardorff (2000) generalizes this result to the case of CES utility and production functions with equal elasticities. Our

\footnotetext{
${ }^{1}$ Throughout this paper, we use "inequality" and "earnings inequality" interchangeably. A number of papers have also studied, both theoretically and empirically, how international trade may affect the distribution of real income across individuals by differentially affecting the costs of living faced by individuals with heterogeneous or non-homothetic preferences (Porto, 2006; Fajgelbaum et al., 2011; Fajgelbaum and Khandelwal, 2016; Atkin et al., 2018; Borusyak and Jaravel, 2018; Faber and Fally, 2021). Our analysis has nothing to say about such cost-of-living considerations.
} 
novel structural relationship provides a non-parametric generalization of these results that dispenses with restrictions on preferences, technology, and good market structure. ${ }^{2}$ It stresses the importance of computing the factor content of gross rather than net exports as a measure of trade exposure. Net exports are sufficient statistics only if domestic and foreign factors are perfect substitutes, an unattractive assumption from an empirical standpoint. ${ }^{3}$ More generally, changes in relative factor prices depend on gross factor exports (our export channel) and the elasticity of domestic factor demand with respect to foreign factor prices (our import channel).

On the measurement side, we use our structural relationship to construct individual measures of export and import exposures. The original factor content approach focuses on a small number of factors of production, typically college and non-college graduates, and measures the factor content of exports and imports using coarse input-output matrices. ${ }^{4}$ It is well known that such data may mask tremendous heterogeneity, both in terms of factor price changes within groups as well as in terms of factor intensity within sectors, in particular between firms that are globally engaged and those that are not (Bernard and Jensen, 1999; Bernard et al., 2007b). In contrast, by combining data on firm-to-firm transactions and firm-level international transactions (as in Huneeus, 2018, Bernard et al., 2019, Demir et al., 2020, and Dhyne et al., 2021) with worker-firm and owner-firm matches, we are able to construct an individual-level version of the national income and product accounts and solve the previous factor content measurement issues. This granularity and inclusion of capital earnings also opens up the possibility to study the impact of trade on

\footnotetext{
${ }^{2}$ In earlier work on non-parametric counterfactual and welfare analysis in neoclassical environments Adao et al. (2017), we have followed a similar approach of focusing on aggregate factor demand, but maintained the assumption of perfectly competitive good markets. Since our focus in the present paper is on relative factor prices, not welfare, we can dispense with that assumption. Hence, our general results not only apply to recent neoclassical trade models with rich worker heterogeneity, such as Ohnsorge and Trefler (2007), Costinot and Vogel (2010), and Grossman et al. (2017), but also to recent monopolistically competitive models such as Yeaple (2005), Bernard et al. (2007a), and Fieler et al. (2018).

${ }^{3}$ Focusing on net exports also raises the question of how one should measure the domestic factor content of imports. In the empirically relevant case of no domestic production of some goods, there is no direct way to measure the domestic factors that would be needed to domestically produce imports under autarky. Wood $(1995,2012)$ offers important discussions of this issue as well as potential remedies.

${ }^{4}$ This is the same type of data used in Leontief's (1953) original factor content computations and in canonical Heckscher-Ohlin-Vanek tests (Bowen et al., 1987; Trefler, 1993, 1995; Davis and Weinstein, 2001). More recently, Borusyak and Jaravel (2018) use related data to construct measures of export and import earnings exposures across college and non-college graduates. They define one of these two groups as more exposed to exports (respectively, imports) if, in a small open economy version of a multi-sector Armington model, a small uniform decrease in trade costs imposed (respectively, faced) by the rest of the world raises the relative wage of that group. While we share a similar objective, our exposure measures are distinct: our export measure emphasizes factor content accounting so proceeds without restrictions on technology, preferences, or good market structure; neither our export nor our import measure requires the economy of interest to be small; and, when combined, our export and import measures summarize exposure to all foreign shocks, as captured by our two sufficient statistics, not just exposure to changes in trade costs.
} 
top income inequality (Piketty and Saez, 2003; Piketty et al., 2018; Smith et al., 2019).

On the estimation side, our structural relationship is valid both for an open and a closed economy. This allows us, before conducting counterfactual analysis by taking relative export exposure and foreign factor prices to their autarkic limit values, to test whether our empirical model can replicate, within sample, the observed response of domestic factor prices to changes in these two statistics. It also allows us to resolve a fundamental inconsistency of existing applications of the original factor content approach. The elasticity of substitution that enters Deardorff's (2000) formula is the elasticity of substitution between domestic factors in a hypothetical autarkic economy, not the elasticity of substitution in the observed trade equilibrium that has been estimated by Katz and Murphy (1992) among others. Indeed, for Deardorff's (2000) formula to be valid, the elasticity of substitution in the observed trade equilibrium should be infinite.

Along the way, we build a bridge between the original factor content approach and recent empirical work based on heterogeneous variation in exposure to a variety of trade shocks (e.g., Autor et al., 2014; Hummels et al., 2014; Pierce and Schott, 2016; Dix-Carneiro and Kovak, 2017). In contrast to more recent empirical work, and in line with the original factor content approach, we remain interested in the overall impact of trade on earnings inequality, rather than the impact of specific shocks. But in line with more recent empirical work, and in contrast to the original factor content approach, we give center stage to the observed response of factor prices to (sufficient statistics for) foreign shocks in order to strengthen the credibility of our empirical conclusions.

\section{The Simple Economics of Trade and Inequality}

\subsection{Factor Demand and Factor Supply}

Consider a world economy with many individuals and firms located either at Home or in the Rest of the World. Individuals are endowed with primary factors of production, indexed by $f$, that they sell to firms on perfectly competitive markets. Factors are partitioned into those located at Home, $f \in \mathcal{F}$, and those located in the Rest of the World, $f \in \mathcal{F}^{*}$. Under this convention, "college graduates at Home" and "college graduates in the Rest of the World" are therefore two distinct factors of production. $\bar{L}_{f}$ denotes the fixed world supply of factor $f \in \mathcal{F} \cup \mathcal{F}^{*}{ }^{5}$ Firms produce goods that they sell to indi-

\footnotetext{
${ }^{5}$ Economies with elastic labor supply are nested by treating leisure as an additional non-traded good. Roy models are also nested by treating workers with different productivity levels across sectors or occupations as distinct factors of production.
} 
viduals and other firms in potentially imperfectly competitive markets. In equilibrium, individuals maximize their utility, firms maximize their profits, and both good and factor markets clear. Appendices A.1.1 and A.2.1 provide formal definitions of the equilibria under perfect and imperfect competition in good markets, respectively.

Let $w \equiv\left\{w_{f}\right\}_{f \in \mathcal{F}}$ denote the vector of prices for domestic factors and $w^{*} \equiv\left\{w_{f}^{*}\right\}_{f \in \mathcal{F}^{*}}$ the prices for those in the Rest of the World. Factor " 0 " at Home is our numeraire. As shown in Appendices A.1.2 and A.2.2, given factor prices $\left(w, w^{*}\right)$, utility maximization by individuals, profit maximization by firms, and good market clearing determine the world demand $L_{f}^{W}\left(w, w^{*}\right)$ for any factor $f .{ }^{6}$ Factor prices in any given trade equilibrium, $w_{T} \equiv\left\{w_{f, T}\right\}_{f \in \mathcal{F}}$ and $w_{T}^{*} \equiv\left\{w_{f, T}^{*}\right\}_{f \in \mathcal{F}^{*}}$, then equalize world factor demand and supply,

$$
L_{f}^{W}\left(w_{T}, w_{T}^{*}\right)=\bar{L}_{f} \text { for all } f \in \mathcal{F} \cup \mathcal{F}^{*} .
$$

To analyze the role played by international trade in shaping domestic factor prices, we propose to decompose world factor demand into its domestic and foreign components,

$$
L_{f}^{W}\left(w, w^{*}\right)=L_{f}\left(w, w^{*}\right)+L_{f}^{*}\left(w, w^{*}\right)
$$

where $L_{f}\left(w, w^{*}\right)$ measures the total services of factor $f$ used to produce final goods consumed at Home and $L_{f}^{*}\left(w, w^{*}\right)$ measures the total services of factor $f$ used to produce goods that are exported to the Rest of the World. If there are no input-output linkages between firms, $L_{f}\left(w, w^{*}\right)$ and $L_{f}^{*}\left(w, w^{*}\right)$ simply correspond to the sum across all firms of the services of factor $f$ directly employed to produce final goods sold for consumers in Home and Rest of the World, respectively. If there are input-output linkages, $L_{f}\left(w, w^{*}\right)$ and $L_{f}^{*}\left(w, w^{*}\right)$ also include the services of factor $f$ indirectly used to produce intermediate goods to produce those final goods, to produce the intermediate goods to produce those intermediate goods, etc.- -as in Leontief's (1953) pioneering factor content calculations. The formal definitions of $L_{f}\left(w, w^{*}\right)$ and $L_{f}^{*}\left(w, w^{*}\right)$ can be found in Appendix A.1.3.

Using the previous decomposition, we can rearrange the market clearing conditions for domestic factors as follows.

Proposition 1. Suppose that factor markets are perfectly competitive. Then for given values of foreign factor prices $w_{T}^{*} \equiv\left\{w_{f, T}^{*}\right\}_{f \in \mathcal{F}}$ and export exposures $E E_{T} \equiv\left\{L_{f}^{*}\left(w_{T}, w_{T}^{*}\right) / L_{f}^{W}\left(w_{T}, w_{T}^{*}\right)\right\}_{f \in \mathcal{F}}$,

${ }^{6}$ For expositional purposes, we restrict attention in the main text to the case where $L_{f}^{W}\left(w, w^{*}\right)$ is a function rather than a correspondence. This is consistent with the factor demand system introduced in Section 3. The general case where $L_{f}^{W}\left(w, w^{*}\right)$ may be a correspondence is discussed in Appendix A. 
the vector of equilibrium domestic factor prices $w_{T} \equiv\left\{w_{f, T}\right\}_{f \in \mathcal{F}}$ solves

$$
R D_{f}\left(w_{T}, w_{T}^{*}\right) R E E_{f, T}=R S_{f} \text { for all } f \in \mathcal{F}, f \neq 0,
$$

where $R D_{f}\left(w, w^{*}\right) \equiv L_{f}\left(w, w^{*}\right) / L_{0}\left(w, w^{*}\right)$ is domestic relative factor demand, $R E E_{f, T} \equiv(1-$ $\left.E E_{0, T}\right) /\left(1-E E_{f, T}\right)$ is relative export exposure, and $R S_{f} \equiv \bar{L}_{f} / \bar{L}_{0}$ is relative factor supply.

Like equation (1), equation (2) is not an accounting identity. It is a structural relationship that, for given preferences, technology, and good market structure, summarizes how competitive factor markets determine factor prices. It stresses two sufficient statistics of foreign shocks: foreign factor prices, $w_{T}^{*}$; and relative export exposures, $R E E_{T} \equiv$ $\left\{R E E_{f, T}\right\}_{f \in \mathcal{F}}$, which can be directly measured via Leontief's (1953) factor content of exports. Compared to (1), the benefit of (2) is that it only requires information about the domestic factor demand system, $L_{f}\left(w, w^{*}\right)$, which only depends on technology, preferences and market structure at Home. Irrespective of the size of Home, it does not require knowledge of the global factor demand system, $L_{f}^{W}\left(w, w^{*}\right)$, which depends on the same considerations all around the world.

\subsection{Measuring The Impact of Trade on Inequality}

Proposition 1 provides the theoretical foundations for the rest of our analysis. Next, we use it to compare domestic factor prices observed in the trade equilibrium to those that would prevail in a counterfactual autarkic equilibrium.

As a matter of theory, this is a simple counterfactual exercise. Under autarky, foreign factor prices would move above their reservation values, which we denote by $w^{*}=\infty$, whereas domestic factor prices would adjust to equalize domestic factor demand and factor supply. In terms of relative domestic factor demand and supply, the autarkic equilibrium therefore requires that autarky factor prices $w_{A}$ satisfy

$$
R D_{f}\left(w_{A}, \infty\right)=R S_{f} \text { for all } f \in \mathcal{F}, f \neq 0 .
$$

When moving from the trade equilibrium described in equation (2) to autarky, domestic factor prices shift for two reasons. First, foreign demand for domestic goods and, in turn, the domestic factor services that they embody must go to zero. This is an export channel captured by the shift from the black relative supply curve (to the domestic market) to the red one in Figure 1 as $R E E_{f} \rightarrow 1$. Second, domestic demand for foreign goods and, in turn, the foreign factor services that they embody must go to zero. This is an import 


\section{Figure 1: The Simple Economics of Trade and Inequality}

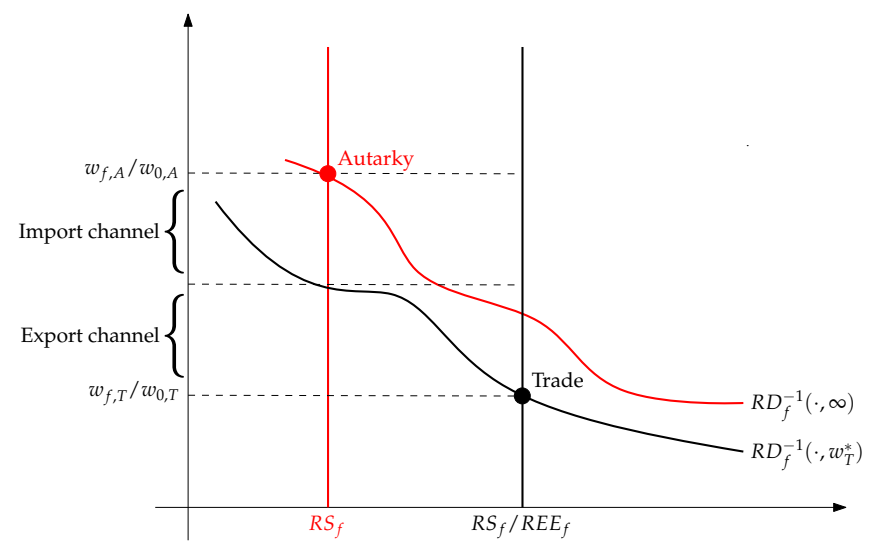

Notes: At the trading equilibrium, domestic and world factor prices $\left(w_{T}, w_{T}^{*}\right)$ equate relative domestic factor supply to relative world factor demand. The effect of eliminating trade (i.e. determining $w_{A}$ ) can be decomposed into an export channel $\left(R E E_{f} \rightarrow 1\right.$, at $\left.w^{*}=w_{T}^{*}\right)$ and an import channel $\left(w^{*} \rightarrow \infty\right.$, at $\left.R E E_{f}=1\right)$.

channel captured by the shift from the black relative demand curve to the red one in Figure 1 as $w^{*} \rightarrow \infty$.

Formally, let $(\Delta \ln w)_{\text {trade }} \equiv\left\{\ln \left(w_{f, T} / w_{f, A}\right)\right\}_{f \in \mathcal{F}}$ denote the vector of log-differences in domestic factor prices between the autarkic counterfactual equilibrium and the original trade equilibrium and let $R D\left(w, w^{*}\right) \equiv\left\{R D_{f}\left(w, w^{*}\right)\right\}_{f \in \mathcal{F}}$ denote the vector of domestic relative factor demand. Throughout our analysis, we assume that $\ln R D$ is continuously differentiable and that the matrix of domestic price elasticities $\partial \ln R D / \partial \ln w \equiv$ $\left\{\partial \ln R D_{f} / \partial \ln w_{g}\right\}_{(f, g) \in \mathcal{F} \times \mathcal{F}}$ is invertible. ${ }^{7}$ Starting from equation (2) and invoking the Implicit Function Theorem, we therefore obtain the following characterization of the changes in domestic factor prices between the autarkic and trade equilibria.

Proposition 2. Suppose that $\ln R D$ is continuously differentiable with respect to $\left(w, w^{*}\right)$ and that $\partial \ln R D / \partial \ln w \equiv\left\{\partial \ln R D_{f} / \partial \ln w_{g}\right\}_{(f, g) \in \mathcal{F} \times \mathcal{F}}$ is invertible for all $\left(w, w^{*}\right)$. Then differences

\footnotetext{
${ }^{7}$ We view these as mild technical assumptions. Although situations where goods and factors are perfect substitutes may (locally) violate these assumptions, one can always consider environments with close, but imperfect substitutes that satisfy them and whose implications for the impact of trade limit to those of environments with perfect substitutes.
} 
in domestic factor prices between the autarky and trade equilibria can be computed as

$$
\begin{aligned}
(\Delta \ln w)_{\text {trade }}= & \underbrace{-\int_{\left(u=0, v=\ln w_{T}^{*}\right)}^{\left(u=\ln R E E_{T}, v=\ln w_{T}^{*}\right)}\left(\frac{\partial \ln R D}{\partial \ln w}\right)^{-1} d u}_{\equiv(\Delta \ln w)_{\text {exports }}} \\
& \underbrace{-\int_{(u=0, v=\infty)}^{\left(u=0, v=\ln w_{T}^{*}\right)}\left(\frac{\partial \ln R D}{\partial \ln w}\right)^{-1}\left(\frac{\partial \ln R D}{\partial \ln w^{*}}\right) d v}_{\equiv(\Delta \ln w)_{\text {imports }}}
\end{aligned}
$$

where $\partial \ln R D / \partial \ln w^{*} \equiv\left\{\partial \ln R D_{f} / \partial \ln w_{g}^{*}\right\}_{\mathcal{F} \times \mathcal{F}^{*}}$ is the matrix of foreign price elasticities.

The formal proof can be found in Appendix A.3. Setting aside potential differences in domestic price elasticities, Proposition 2 implies that factors that benefit the most from opening up to trade are those that tend to be exported more-and hence have higher values of $R E E_{f, T}$ - and those that are less substitutable with foreign factor services-and hence have lower values of $\partial \ln R D_{f} / \partial \ln w_{g}^{*}$. We will use both observations to construct measures of export and import exposures across individuals in Section 4. Having specified a domestic factor demand system in Section 3 and estimated it in Section 5, we will then use Proposition 2 to compute the full incidence of trade on earnings inequality in Section 7. Before doing so, we now briefly discuss examples of factor demand systems in the literature and their implications for the relationship between trade and inequality.

\subsection{Examples}

Original Factor Content Approach. Like Stolper and Samuelson's (1941) Theorem, the original factor content approach pioneered by Deardorff and Staiger (1988) critically relies on the assumption that all imported goods are also produced at Home. Under this assumption, domestic firms are willing to produce the quantities imported by Home at the original trade prices, whereas domestic consumers are willing to consume their extra output, which makes the relative domestic factor demand curve perfectly elastic in the initial trade equilibrium. Factor prices under trade are thus equal to those that would prevail in a hypothetical autarkic equilibrium with factor supply adjusted by net export shares of each factor, $N E E_{f, T}$, and changes in factor prices between trade and autarky can be computed as the changes between two autarkic equilibria with factor supply $\bar{L}_{f}$ and $\bar{L}_{f}\left(1-N E E_{f, T}\right)$, as described in Figure $2 .^{8}$

\footnotetext{
${ }^{8}$ Net exports of factor $f$ are equal to its gross exports, $L_{f}^{*}$, minus the amount of factor $f$ that would be required to produce the vector of Home's imports.
} 


\section{Figure 2: Original Factor Content Approach}

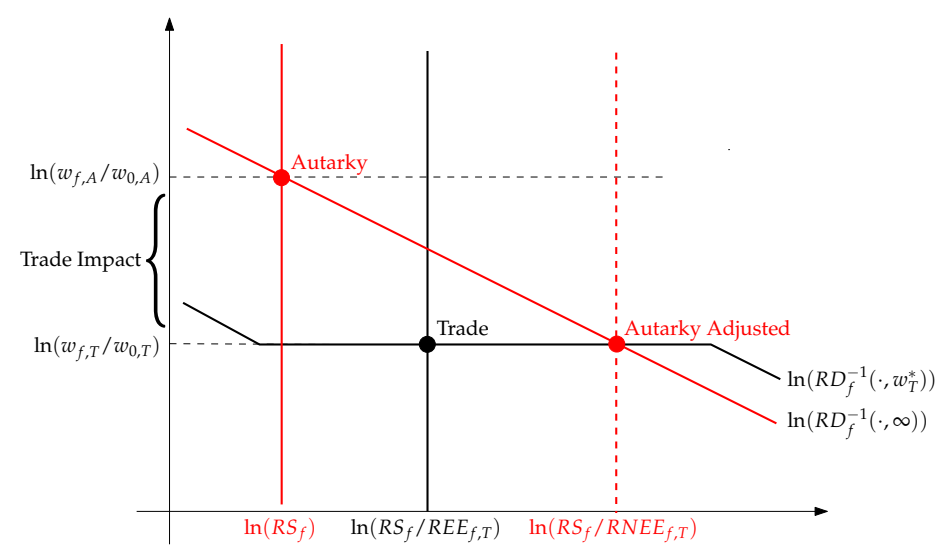

Notes: Following Deardorff and Staiger (1988), when Home produces all imported goods and hence $R D_{f}\left(w_{T}, w_{T}^{*}\right)$ is perfectly elastic around the trade equilibrium, the impact of trade on factor prices is equal to the effect in autarky, i.e. for $R D_{f}(w, \infty)$, of a hypothetical shift in $R S_{f}$ by the amount of the relative net export exposure $\left(R N E E_{f, T}\right)$. Illustrated for the Deardorff (2000) case in which $R D_{f}(w, \infty)$ is isoelastic.

Under the additional assumption that technology and preferences are Cobb-Douglas, as in Deardorff and Staiger (1988), or more generally CES with a common elasticity of substitution $\eta>0$, as in Deardorff (2000), the domestic factor demand system under autarky, $R D(w, \infty)$, is also CES with elasticity of substitution $\eta>0$. Hence the impact of trade on inequality in this case is equal to

$$
(\Delta \ln w)_{\text {trade }}=\ln \left(R N E E_{T}\right) / \eta
$$

with $R N E E_{T} \equiv\left\{\left(1-N E E_{0, T}\right) /\left(1-N E E_{f, T}\right)\right\}_{f \in \mathcal{F} .}{ }^{9}$ This is the limit of the general formula for $(\Delta \ln w)_{\text {trade }}$ presented in Proposition 2 in an environment with nested CES preferences, as the elasticity of substitution between goods from different countries is taken to infinity. For empirical purposes, the main issue with this formula is that $\eta$ is not the elasticity of substitution between factors in the trade equilibrium. Indeed, for the original factor content approach to be valid, the latter elasticity should be infinite. Instead, $\eta$ is the slope of $R D(w, \infty)$, the red demand curve in Figure 2 .

\footnotetext{
${ }^{9}$ Burstein and Vogel (2017) offer the following generalization of the previous formula. As a matter of accounting, they note that the value of payments received by a given factor are always equal to the payments made by firms to that factor. Since this accounting identity holds both under trade and autarky, it follows that changes in the payments received by a factor between trade and autarky can always be expressed as the changes in the payments made by firms to that factor. It also follows that if one decomposes the latter into Deardorff's (2000) original formula and a residual, then Deardorff's (2000) formula holds whenever that residual is zero. Compared to Burstein and Vogel (2017), who emphasize that the previous residual is non-zero in their structural model, one can view Proposition 2 as providing a general structural interpretation of that residual in any environment with perfectly competitive factor markets.
} 
Pure Export Channel. A pure export channel, $(\Delta \ln w)_{\text {imports }}=0$, arises whenever relative domestic factor demand is independent of foreign factor prices, $R D\left(w, w^{*}\right) \equiv R D(w)$. This occurs most notably in multi-factor extensions of Melitz (2003) such as Sampson (2014), Harrigan and Reshef (2016), and Antras et al. (2017a). When firms employ distinct types of workers, as in Antras et al. (2017a), the export channel takes a particularly simple form. In this case, CES demand for goods implies CES demand for domestic factor services for all values of $w^{*}$, not just in the limit $w^{*}=\infty$ as in Deardorff (2000). ${ }^{10}$ Applying Proposition 2 to the case of a CES factor demand system, we immediately obtain $(\Delta \ln w)_{\text {imports }}=0$ and

$$
(\Delta \ln w)_{\text {trade }}=\ln R E E_{T} / \eta,
$$

where $\eta$ denotes the elasticity of substitution between goods produced by different firms, and hence, the different factors they employ. Compared to the original factor content approach of Deardorff and Staiger (1988) and Deardorff (2000), it is gross rather than net export exposure that now determines the distributional impact of trade. ${ }^{11}$

Pure Import Channel. A pure import channel, $(\Delta \ln w)_{\text {exports }}=0$, may arise either when relative factor demand is perfectly elastic, as already illustrated in Figure 2, or when there is no variation in export exposure across factors, $R E E_{f, T}=1$. As an example of the latter, consider an economy where all goods are produced using the same factor intensity, with production requiring both primary factors of production and foreign intermediate goods, as in Burstein et al. (2013). Since all goods have the same factor intensity, export exposure is necessarily constant across all factors. It follows that $R E E_{f, T}$ is equal to one and that only the import channel is active. The magnitude of the import channel, in turn, depends on whether foreign inputs are closer substitutes to factor $f$ or factor 0. Following Krusell et al. (2000), Burstein et al. (2013) assume an aggregate nested CES production function, in which skilled workers are calibrated to be less substitutable with foreign factor services, so that the import channel increases the skill premium.

\footnotetext{
${ }^{10}$ Our discussion of Antras et al. (2017a) implicitly focuses on the special case of that model with inelastic labor supply. When labor supply is elastic, preferences over all goods, including leisure, are no longer CES.

${ }^{11} \mathrm{~A}$ pure export channel also arises in Matsuyama (2007). He considers an economy where goods have different factor intensity depending on the destination in which they are sold, all goods have the same factor intensity within a given destination, and there is no trade in intermediate goods. Under these assumptions, relative domestic factor demand again only depends on the relative price of domestic factors. This is also the channel emphasized in Verhoogen's (2008) partial equilibrium model.
} 


\section{An Empirical Model of Domestic Factor Demand}

Propositions 1 and 2 give center stage to the domestic factor demand system, $R D\left(w, w^{*}\right)$. We now describe an empirical version of the model in Section 2 that allows $R D\left(w, w^{*}\right)$ to be estimated from firm- and individual-level micro-data. Despite the parametric restrictions introduced, our model remains considerably more general than the original factor content approach: it does not require factor demand to be perfectly elastic; it does not impose any restriction on the heterogeneity in factor intensity across firms; and it allows arbitrary input-output linkages both between and within sectors. Most importantly, as we will show in Section 6, our model is, despite its restrictions, successful at matching macro-level responses of factor prices to foreign shocks.

\subsection{Micro-Level Demand for Goods and Factors}

Consider a parametric version of Section 2's environment in which Home's preferences and technology are nested CES and goods and factor markets are perfectly competitive.

Consumers. All domestic consumers have the same nested CES utility function over the goods produced by domestic firms $n \in \mathcal{N}_{k}$ in different sectors $k \in \mathcal{K}$,

$$
\begin{aligned}
U & =\prod_{k \in \mathcal{K}}\left(U_{k}\right)^{\alpha_{k}}, \\
U_{k} & =\left(\sum_{n \in \mathcal{N}_{k}} \theta_{n c}^{\frac{1}{\sigma}} \mathcal{C}_{n}^{\frac{\sigma-1}{\sigma}}\right)^{\frac{\sigma}{\sigma-1}},
\end{aligned}
$$

where $\alpha_{k}, \theta_{n c} \geq 0$ are exogenous preference parameters, with $\sum_{k \in \mathcal{K}} \alpha_{k}=1 ; \sigma>0$ is the elasticity of substitution between goods produced by different firms from the same sector; and $c_{n}$ denotes the quantity sold by firm $n$ to domestic consumers. ${ }^{12}$ Utility maximization implies that the total income $D_{n}$ spent by consumers on a domestic firm $n$ is equal to

$$
D_{n}=\frac{\alpha_{k} \theta_{n c} p_{n}^{1-\sigma} Y}{\sum_{r \in \mathcal{N}_{k}} \theta_{r c} p_{r}^{1-\sigma}} \text {, for all } n \in \mathcal{N}_{k} \text { and } k \in \mathcal{K},
$$

where $p_{n}$ is the price of goods produced by firm $n$ and $Y \equiv \sum_{f \in \mathcal{F}} w_{f} \bar{L}_{f}$ is the total income of domestic consumers. We let $d_{n k} \equiv D_{n} /\left(\sum_{r \in \mathcal{N}_{k}} D_{r}\right)$ denote the share of sector $k^{\prime} \mathrm{s}$

\footnotetext{
${ }^{12}$ Since we allow below for trade in intermediate goods, the assumption that foreign goods do not directly enter the utility function of domestic consumers is without loss of generality. Imports of final goods, if any, are captured by the sales of "domestic" firms that produce using zero domestic factors, zero domestic intermediate goods, and only foreign intermediate goods.
} 
domestic consumer expenditure devoted to domestic firm $n \in \mathcal{N}_{k}$.

Firms. All domestic firms have a nested CES production function over domestic factors $f \in \mathcal{F}$, the goods produced by domestic firms $n \in \mathcal{N}=\cup_{k \in \mathcal{K}} \mathcal{N}_{k}$, and the goods produced by foreign firms $n \in \mathcal{N}^{*}$,

$$
\begin{aligned}
q_{n} & =\varphi_{n}\left(l_{n}\right)^{\beta_{n}}\left(m_{n}\right)^{1-\beta_{n},}, \\
m_{n} & =\left(\prod_{r \in \mathcal{N}} m_{r n}^{\theta_{r n}}\right)^{\Theta_{n}}\left(\prod_{r \in \mathcal{N}^{*}} m_{r n}^{\theta_{r n}^{*}}\right)^{1-\Theta_{n},} \\
l_{n} & =\left(\sum_{f \in \mathcal{F}} \theta_{f n}^{\frac{1}{\eta}} l_{f n}^{\frac{\eta-1}{\eta}}\right)^{\frac{\eta}{\eta-1},}
\end{aligned}
$$

where: $\varphi_{n}, \beta_{n}, \Theta_{n}, \theta_{f n}, \theta_{r n} \geq 0$ are exogenous technology parameters, with $\beta_{n} \in[0,1]$, $\Theta_{n} \in[0,1]$, and $\sum_{r \in \mathcal{N}} \theta_{r n}=\sum_{r \in \mathcal{N}^{*}} \theta_{r n}^{*}=1 ; \eta>0$ is the elasticity of substitution between domestic factors; and $q_{n}$ and $m_{r n}$ denote the total output of firm $n$ and the quantity sold by firm $r$ to firm $n$.

Profit maximization implies that the total expenditure $X_{f n}$ by a domestic firm $n$ on a domestic factor $f$ is equal to

$$
X_{f n}=\frac{\theta_{f n} w_{f}^{1-\eta}}{\sum_{g \in \mathcal{F}} \theta_{g n} w_{g}^{1-\eta}} \beta_{n} R_{n}, \text { for all } f \in \mathcal{F} \text { and } n \in \mathcal{N},
$$

where $R_{n} \equiv p_{n} q_{n}$ denotes the total revenues of firm $n$. The associated share of firm $n$ 's costs from payments to factor $f$ is $x_{f n} \equiv X_{f n} / R_{n}$.

The total expenditure $X_{r n}$ by a domestic firm $n$ on an intermediate good $r$, in turn, is

$$
X_{r n}= \begin{cases}\left(1-\beta_{n}\right) \Theta_{n} \theta_{r n} R_{n}, & \text { for all } r \in \mathcal{N} \text { and } n \in \mathcal{N}, \\ \left(1-\beta_{n}\right)\left(1-\Theta_{n}\right) \theta_{r n}^{*} R_{n}, & \text { for all } r \in \mathcal{N}^{*} \text { and } n \in \mathcal{N} .\end{cases}
$$

We let $X_{n}^{*} \equiv \sum_{r \in \mathcal{N}^{*}} X_{r n}$ denote the total imports of foreign intermediate goods by any domestic firm $n$ and treat those imports as a composite of foreign factor services with price $w_{n}^{*} \equiv \prod_{v \in \mathcal{N}^{*}}\left(p_{v}^{*}\right)^{\theta_{v n}^{*}}$. From now on, we simply refer to the vector of firm-specific import prices, $w^{*} \equiv\left\{w_{n}^{*}\right\}_{n \in \mathcal{N}}$, as the vector of foreign factor prices. The associated shares of firm $n^{\prime}$ s costs are denoted $x_{r n} \equiv X_{r n} / R_{n}$ and $x_{n}^{*}=X_{n}^{*} / R_{n}$. 
Finally, zero-profits requires the firm's output price to be equal to its unit cost,

$$
p_{n}=\phi_{n}\left(\sum_{f \in \mathcal{F}} \theta_{f n} w_{f}^{1-\eta}\right)^{\frac{\beta_{n}}{1-\eta}}\left(\left(\prod_{r \in \mathcal{N}} p_{r}^{\theta_{r n}}\right)^{\Theta_{n}}\left(w_{n}^{*}\right)^{1-\Theta_{n}}\right)^{1-\beta_{n}}, \text { for all } n \in \mathcal{N}
$$

where $\phi_{n} \equiv \varphi_{n}^{-1}\left(\beta_{n}\right)^{-\beta_{n}}\left[\left(\Pi_{r \in \mathcal{N}}\left(\theta_{r n}\right)^{\theta_{r n}} \Theta_{n}\right)^{\Theta_{n}}\left(\Pi_{r \in \mathcal{N}^{*}}\left(\theta_{r n}^{*}\right)^{\theta_{r n}^{*}}\left(1-\Theta_{n}\right)\right)^{\left(1-\Theta_{n}\right)}\left(1-\beta_{n}\right)\right]^{-\left(1-\beta_{n}\right)}$ is an adjusted measure of firm $n^{\prime}$ s productivity.

Summarizing, our nested CES model does not restrict the levels of demand for any factor. Two elasticities, $\sigma$ and $\eta$, are unrestricted as well and form the basis of our estimation in Section 5. Upper-level elasticities-across sectoral outputs in consumption, across domestic suppliers in production, and across domestic and foreign inputs in production-are assumed to be unitary, a feature that will be consistent with the tests described in Section 6.

\subsection{Macro-Level Demand for Factors}

Relative Domestic Factor Demand. For given domestic and foreign factor prices, $w \equiv$ $\left\{w_{f}\right\}_{f \in \mathcal{F}}$ and $w^{*} \equiv\left\{w_{n}^{*}\right\}_{n \in \mathcal{N}}$, the domestic factor demand $L_{f}\left(w, w^{*}\right)$ measures the total services of factor $f$ used, both directly and indirectly, to produce final goods consumed at Home. As described in Appendix A.1.3, the value of domestic demand for domestic factors $f \in \mathcal{F}$ is

$$
\left\{w_{f} L_{f}\left(w, w^{*}\right)\right\}_{f \in \mathcal{F}}=A(w) B D\left(w, w^{*}\right)
$$

where $A(w) \equiv\left\{x_{f n}(w)\right\}_{(f, n) \in \mathcal{F} \times \mathcal{N}}$ is the domestic matrix of factor shares, $B \equiv(I-$ $M)^{-1}$ is the Leontief inverse associated with the domestic input-output matrix $M \equiv$ $\left\{x_{n r}\right\}_{(n, r) \in \mathcal{N} \times \mathcal{N}}=\left\{\theta_{n r} \Theta_{n}\left(1-\beta_{n}\right)\right\}_{(n, r) \in \mathcal{N} \times \mathcal{N}}$, and $D\left(w, w^{*}\right) \equiv\left\{D_{n}\left(w, w^{*}\right)\right\}_{n \in \mathcal{N}}$ is the vector of domestic consumer expenditures. ${ }^{13}$ Substituting for consumer expenditures using equation (4) and firm factor and intermediate shares using equation (6), this implies

$$
R D_{f}\left(w, w^{*}\right)=\left(\frac{w_{f}}{w_{0}}\right)^{-\eta} \frac{\theta_{f} \cdot Z\left(w, w^{*}\right)}{\theta_{0} \cdot Z\left(w, w^{*}\right)}
$$

\footnotetext{
${ }^{13}$ The parametric model of Section 3.1 corresponds to the special case of the general model of Appendix A.1 in which each domestic good $g \in \mathcal{G}$ is produced by a single domestic firm $n \in \mathcal{N}$, each firm produces a single good, and $\mathcal{G}=\mathcal{N}$. The facts that the domestic matrix of factor shares is independent of foreign factor prices and the Leontief inverse is independent of all prices derive from our Cobb-Douglas assumptions.
} 
where $\cdot$ denotes the inner product of two vectors, $\theta_{f} \equiv\left\{\theta_{f n}\right\}_{n \in \mathcal{N}}$ captures the propensity of factor $f$ to be employed by different domestic firms, and $Z\left(w, w^{*}\right) \equiv\left\{Z_{n}\left(w, w^{*}\right)\right\}_{n \in \mathcal{N}}$ captures the propensity of factors employed by those firms to be absorbed domestically:

$$
Z_{n}\left(w, w^{*}\right)=\beta_{n}\left(w_{n}^{D}(w)\right)^{\eta-1} \sum_{k} \sum_{r \in \mathcal{N}_{k}} b_{n r}\left(\frac{p_{r}\left(w, w^{*}\right)}{P_{k}\left(w, w^{*}\right)}\right)^{1-\sigma} \alpha_{k} \theta_{r c} .
$$

This term itself depends on the elements $b_{n r}$ of the Leontief inverse $B$; the CES price index for firm $n^{\prime}$ s domestic factors, $w_{n}^{D}(w) \equiv\left(\sum_{f \in \mathcal{F}} \theta_{f n} w_{f}^{1-\eta}\right)^{\frac{1}{1-\eta}}$; the CES price index in firm $n^{\prime}$ s sector, $P_{k}\left(w, w^{*}\right) \equiv\left(\sum_{n \in \mathcal{N}_{k}} \theta_{n c} p_{n}^{1-\sigma}\left(w, w^{*}\right)\right)^{\frac{1}{1-\sigma}}$; and the vector of firm-level prices $p\left(w, w^{*}\right) \equiv\left\{p_{n}\left(w, w^{*}\right)\right\}_{n \in \mathcal{N}}$ given by the solution to $(7)$,

$$
\ln p_{n}\left(w, w^{*}\right)=\sum_{r \in \mathcal{N}} b_{r n}\left(\ln \phi_{r}+\beta_{r} \ln w_{r}^{D}(w)+x_{r}^{*} \ln w_{r}^{*}\right) .
$$

Foreign Price Elasticities. Two types of elasticities enter Proposition 2: the elasticities of relative factor demand with respect to domestic factor prices $\partial \ln R D / \partial \ln w$, which affect both the export and import channels, and the elasticities of relative demand with respect to foreign factor prices $\partial \ln R D / \partial \ln w^{*}$, which only affect the import channel. Our next proposition, whose proof can be found in Appendix A.4, describes the economic considerations that shape $\partial \ln R D / \partial \ln w^{*}$.

Proposition 3. For any domestic factor $f \in \mathcal{F}$, the elasticity of relative demand with respect to the price of a foreign factor $w_{n}^{*}$ is

$$
\frac{\partial \ln R D_{f}}{\partial \ln w_{n}^{*}}=(\sigma-1)\left(I E_{f n}-I E_{0 n}\right),
$$

with the measure of import exposure, $I E_{f n}$, such that

$$
I E_{f n} \equiv-\sum_{k \in \mathcal{K}} \sum_{m \in \mathcal{N}_{k}} s_{f m} \times\left(\bar{x}_{n m}^{*}-\sum_{r \in \mathcal{N}_{k}} d_{r k} \bar{x}_{n r}^{*}\right),
$$

where $s_{f m} \equiv \sum_{r \in \mathcal{N}} x_{f r} b_{r m} D_{m} / w_{f} L_{f}$ is the share of factor f's domestic demand embodied in firm $m^{\prime}$ s final sales and $\bar{x}_{n m}^{*} \equiv b_{n m} x_{n}^{*}$ is the share of firm m's costs spent, both directly and indirectly, on firm n's imports of foreign factor services.

Changes in the price of a foreign factor $w_{n}^{*}$ affect the relative demand for domestic factors through expenditure switching by domestic consumers, which is captured by $I E_{f n}$ and whose magnitude depends on the elasticity of substitution between firms $\sigma$. This 
is a smoother version of the standard import competition mechanism emphasized by Stolper and Samuelson's (1941) Theorem and the original factor content approach where domestic and foreign firms are implicitly assumed to be perfect substitutes $(\sigma=\infty)$. When the price of a foreign factor $w_{n}^{*}$ increases, each firm $m$ experiences a price increase proportional to its share of total spending, both direct and indirect, on that foreign factor, $\bar{x}_{n m}^{*}=b_{n m} x_{n}^{*}$. In the empirically relevant case of $\sigma>1$, domestic consumers therefore spend less on the domestic firms whose technologies are more intensive in that foreign input than that of their industry competitors, i.e. the firms $m$ for which $\bar{x}_{n m}^{*}-\sum_{r \in \mathcal{N}_{k}} d_{r k} \bar{x}_{n r}^{*}$ is high. This triggers a contraction in the demand for the domestic factors that tend to be employed by the firms more exposed to the import price shock, i.e. the factors $f$ for which $\sum_{k \in \mathcal{K}} \sum_{m \in \mathcal{N}_{k}} s_{f m} \times\left(\bar{x}_{n m}^{*}-\sum_{r \in \mathcal{N}_{k}} d_{r k} \bar{x}_{n r}^{*}\right)$ is high.

In the absence of intermediate goods, $I E_{f n}$ takes a particularly simple form. In this case, firms have strictly positive employment of domestic factors $\left(s_{f m}>0\right)$ if, and only if, they have zero expenditure on foreign inputs $\left(\bar{x}_{n m}^{*}=0\right)$. Thus, import exposure reduces to $I E_{f}=\sum_{k \in \mathcal{K}} \bar{s}_{f k} d_{k}^{*}$, where $\bar{s}_{f k} \equiv \sum_{r \in \mathcal{N}_{k}} s_{f r}$ is the share of factor $f^{\prime}$ s domestic demand employed in sector $k$ and $d_{k}^{*}$ is the share of expenditure on imports in that sector. That is, factors exposed to import competition are those that tend to be employed in sectors where spending shares on imports are higher.

Domestic Price Elasticities. Let us now turn to the matrix of domestic price elasticities $\partial \ln R D / \partial \ln w$, which determines by how much domestic factor prices must adjust in response to a change in relative export exposure $R E E$ or foreign factor prices $w^{*}$ to bring back the domestic factor market to equilibrium. As shown in Appendix A.5, the domestic price elasticities can be decomposed as follows.

Proposition 4. For any domestic factor $f \in \mathcal{F}$, the elasticity of relative demand with respect to the price of a domestic factor $w_{g}$ is equal to

$$
\frac{\partial \ln R D_{f}}{\partial \ln w_{g}}=-\eta \mathbb{1}_{g}(f)+(\eta-1)\left(D E F_{f g}-D E F_{0 g}\right)+(\sigma-1)\left(D E C_{f g}-D E C_{0 g}\right)
$$

with the two measures of domestic exposures, $D E F_{f g}$ and $D E C_{f g}$, such that

$$
\begin{aligned}
D E F_{f g} & \equiv \sum_{k \in \mathcal{K}} \sum_{m \in \mathcal{N}_{k}} r_{f m} \times x_{g m}^{D}, \\
D E C_{f g} & \equiv-\sum_{k \in \mathcal{K}} \sum_{m \in \mathcal{N}_{k}} s_{f m} \times\left(\bar{x}_{g m}-\sum_{r \in \mathcal{N}_{k}} d_{r k} \bar{x}_{g r}\right),
\end{aligned}
$$

where $r_{f m} \equiv x_{f m}\left(\sum_{v \in \mathcal{N}} b_{m v} D_{v}\right) / w_{f} \bar{L}_{f}$ is the share of factor f's domestic demand employed by 
firm $m, x_{g m}^{D} \equiv x_{g m} / \sum_{f \in \mathcal{F}} x_{f m}$ is the share of firm $m$ 's factor costs devoted to factor $g$, and $\bar{x}_{g m} \equiv \sum_{n \in \mathcal{N}} b_{n m} x_{g n}$ is the share spent, both directly and indirectly, on that factor.

As one would expect, the elasticity of substitution between domestic factors $\eta$ now also plays a central role, as reflected in the first two terms $-\eta \mathbb{1}_{\{f=g\}}+(\eta-1)\left(D E F_{f g}-\right.$ $\left.D E F_{0 g}\right)$. It controls the magnitude of expenditure switching across factors within each firm. The third term in Proposition 4 has the same interpretation as in the case of the foreign price elasticity of Proposition 3; it captures how changes in domestic factor prices affect expenditure by consumers across domestic firms in a sector.

It is important to note that although the micro-level demand for factors within each firm is CES, the macro-level demand generically is not. ${ }^{14}$ Hence, our analysis allows for departures from the Independence of Irrelevant Alternatives. For instance, if $\eta>1$, then an increase in the price of factor $g$ leads to an equal amount of expenditure switching towards all other factors within each firm. However, if factor $f$ is employed in firms that are on average more intensive in factor $g$, i.e. in firms $m$ for which $x_{g m}^{D}$ is relatively high, such reallocations increase the aggregate relative demand for factor $f$. This is the effect captured by $D E F_{f g}$. It implies that trade may not only affect factor prices because different factors have different export and import exposures, which we will focus on in the next section, but also because they are more or less impacted by changes in the prices of other domestic factors, an equilibrium feature that will be active in the empirical and counterfactual exercises of Sections 6 and 7.

\section{Export Exposure, Import Exposure, and Earnings}

We now build on the theoretical results of Sections 2 and 3 to estimate the impact of trade on inequality in Ecuador, a country whose unique administrative records provide the requisite data. The goal of this first empirical section is to construct measures of export and import exposure at different points of Ecuador's income distribution. Prior to the estimation of its domestic factor demand system in Section 5, this will allow us to evaluate whether poor or rich individuals experience larger shifts in the demand for their factor services because of international trade and, in turn, whether they are more or less likely to benefit from it.

\footnotetext{
${ }^{14}$ The only exception is the Cobb-Douglas case: $\eta=\sigma=1$. Note that this special case differs from the environment studied in Deardorff and Staiger (1988) who assume that goods produced by domestic and foreign firms are perfect substitutes within each sector-in our notation, this corresponds to $\sigma=\infty$.
} 


\subsection{Data}

Our primary dataset covers the universe of Ecuador's formal economy from 2009 to 2015. It includes all incorporated and non-incorporated firms that file a corporate tax or social security form, or are named as a supplier in the returns of other firms. To those we match all individuals that earn labor income from these firms, or own a share of these firms, or both, over that same period. This gives us an average of 2.9 million individuals per year who are engaged in 1.5 million firms. ${ }^{15}$ By its nature, this administrative data provides a comprehensive picture of Ecuador's formal economy alone, but Section 7.2 introduces a survey-based extension that covers informal activities as well. Here we describe the key features of our data construction and report further details in Appendix B. While all measures described below are annual, we suppress time subscripts until they are necessary.

Corporate Income Tax Data. We use annual corporate income tax forms to measure the revenues $R_{n}$, the total costs $C_{n}$, the exports $E_{n}$, and the imports $X_{n}^{*}$ of domestic firms $n \in \mathcal{N}$. This allows us to compute import shares $x_{n}^{*}=X_{n}^{*} / R_{n}$ for all domestic firms.

Value Added Tax Data. We use tax records related to Ecuador's valued added tax (VAT) system to measure spending $X_{r n}$ by a domestic firm $n$ on intermediate goods from any other domestic domestic firm $r$. This allows us to compute the domestic firm-to-firm input-output matrix $M$ with elements $x_{r n}=X_{r n} / R_{n}$, as well as the share of any firm $r$ in the total purchases of domestic inputs by firm $n, \theta_{r n}=X_{r n} / \sum_{m \in \mathcal{N}} X_{m n}$. By subtracting total sales of intermediate goods and exports from total revenues, we measure sales to domestic consumers as $D_{n}=R_{n}-\sum_{m \in \mathcal{N}} X_{n m}-E_{n} \cdot{ }^{16}$ This allows us, in turn, to compute domestic consumer expenditure shares across sectors, $\alpha_{k}=\sum_{r \in \mathcal{N}_{k}} D_{r} / \sum_{r \in \mathcal{N}} D_{r}$, as well as across firms within sectors, $d_{n k}=D_{n} / \sum_{r \in \mathcal{N}_{k}} D_{r}$, with each sector $k \in \mathcal{K}$ corresponding to one of 62 divisions that firms $r \in \mathcal{N}_{k}$ report as their main activity based on the 2-digit ISIC revision 3.1 classification. ${ }^{17}$

\footnotetext{
${ }^{15}$ While all such firms enter our analysis, the vast majority of these are non-incorporated and/or selfemployed individuals, as further detailed below. In the small number of cases for which firms are owned by a holding company, we group them into a single firm.

${ }^{16}$ Whenever this leads to $D_{n}<0$, we raise the revenues of firm $n$ to $R_{n}=\sum_{m \in \mathcal{N}} X_{n m}+E_{n}$ so that $D_{n}=0$.

${ }^{17}$ We aggregate firms in two out of those 62 sectors, the public and financial sectors, into a single consolidated firm because of differences in tax treatment in those sectors. By construction, this consolidated firm covers all state-owned firms. We also create a 63rd sector with a single consolidated residual firm whose sales and costs are used to balance all accounting identities in the model, and a 64th unclassified sector including all firms for which we do not have information on their main activity.
} 
Social Security Data. We use social security records that link individuals to firms via labor payments to measure spending $X_{f n}$ by a domestic firm $n$ on different labor groups $f \in \mathcal{F}_{\mathrm{L}, \mathrm{SS}}$. We split workers into 73 labor groups. We begin with the three-level classification of education that is known for each worker-less than high school, high school graduate, and college graduate-and then further augment that by the 24 provinces of Ecuador in which each worker earns his or her primary income. ${ }^{18}$ This results in 72 labor groups in the social security database. We then create an additional labor group that covers all employed individuals with missing information or those not appearing in social security records, $\mathcal{F}_{\mathrm{L}, \mathrm{NSS}}$.

From the corporate tax forms, we know the total wage payments $W_{n}=\sum_{f \in \mathcal{F}_{\mathrm{L}}} X_{f n}$ of each firm $n$, with $\mathcal{F}_{\mathrm{L}}=\mathcal{F}_{\mathrm{L}, \mathrm{SS}} \cup \mathcal{F}_{\mathrm{L}, \mathrm{NSS}}$. For each individual $i$ in the social security dataset, we also know the wage payments $W_{i n}$ that he or she has received from each firm $n$, as well as the labor group $\mathcal{I}_{f}$ to which he or she belongs. For each firm $n$, we can therefore compute the share of labor payments associated with a particular factor $f \in \mathcal{F}_{\mathrm{L}, \mathrm{SS}}$ as $\sum_{i \in \mathcal{I}_{f}} W_{i n} / \sum_{i \in \mathcal{I}} W_{i n}$ and, in turn, $X_{f n}=\left(\sum_{i \in \mathcal{I}_{f}} W_{i n} / \sum_{i \in \mathcal{I}} W_{i n}\right) W_{n}$. Payments to the residual group of workers not in the social security system are $X_{R n}=W_{n}-\sum_{f \in \mathcal{F}_{\mathrm{L}, S \mathrm{~S}}} X_{f n}$.

For each individual $i$, we let $Y_{f i}$ denote the labor payments associated with any factor $f \in \mathcal{F}_{\mathrm{L}}$. This is either equal to zero, if $i \notin \mathcal{I}_{f}$, or to the sum of labor payments received by individual $i$ across all domestic firms, $Y_{f i}=\sum_{n \in \mathcal{N}}\left(W_{i n} / \sum_{j \in \mathcal{I}} W_{j n}\right) W_{n}$, if $i \in \mathcal{I}_{f}$.

Firm Ownership Data. We refer to any factor of production not in $\mathcal{F}_{\mathrm{L}}$ as capital and let $\mathcal{F}_{\mathrm{K}}$ denote the set of such factors. Further, we assume the existence of two types of capital: "Oil" $\left(K_{\text {oil }}\right)$, which is specific to the oil sector, and "Not oil" ( $\left.K_{\text {not oil }}\right)$, which is freely mobile across all other sectors. We think of the former type of capital as oil resources, an important source of exports for the Ecuadorian economy whose returns are unlikely to be correlated with the returns to structure and equipment in other sectors. For any firm $n$ we measure its profits as the difference, $R_{n}-C_{n}$, between its revenues and costs (payments to labor and intermediate inputs). ${ }^{19}$ If the firm hires no employees beyond the firm's owner itself, we treat the firm's profits as labor income, $X_{f n}=R_{n}-C_{n}$, accruing to the labor group of the (essentially self-employed) owner. Otherwise, the firm's profits accrue to $K_{\text {oil }}$ or $K_{\text {not oil }}$ depending on the firm's sector.

\footnotetext{
${ }^{18} \mathrm{~A}$ province in Ecuador is roughly equivalent to a commuting zone in the United States. In terms of area, Ecuador is about the size of Colorado. It comprises 24 provinces and 17 million individuals compared to 17 commuting zones and 5.8 million individuals for Colorado.

${ }^{19}$ Whenever this leads to negative profits, we raise firm $n$ 's revenues to $C_{n}$ in order to bring $R_{n}-C_{n}$ to zero. Those additional sales are then imputed to the residual consolidated firm. This procedure guarantees the existence of the Leontief inverse matrices used below.
} 
By dividing factor spending by total revenue, we obtain the domestic matrix of factor cost shares $A$ with elements $x_{f n}=X_{f n} / R_{n}$ for all domestic factors $f \in \mathcal{F}=\mathcal{F}_{\mathrm{L}} \cup \mathcal{F}_{\mathrm{K}}$. The share of firm $n$ 's costs attributable to primary factors is then given by $\beta_{n}=\sum_{f \in \mathcal{F}} x_{f n}$.

For each individual $i$, we then measure capital payments using a unique ownership database that reports the personal tax IDs of each of a firm's owners, as well as their corresponding ownership shares. Using those reported shares, we compute the share of each individual $i$ in the capital payments of firm $n, \vartheta_{n i}$. The capital payments of individual $i$ associated with the oil sector are $Y_{K_{\text {oil }}}=\sum_{n \in \mathcal{N}_{\text {oil }}} \vartheta_{n i} X_{f n}$, whereas her capital payments associated with the rest of the economy are $Y_{K_{\text {not oil }} i}=\sum_{n \notin \mathcal{N}_{\text {Oil }}} \vartheta_{n i} X_{f n}$. The total income of individual $i$ is then given by $Y_{i}=\sum_{f \in \mathcal{F}} Y_{f i}$, with $\omega_{f i}=Y_{f i} / Y_{i}$ denoting the share of her earnings associated with factor $f .{ }^{20}$

Customs Data. For estimation purposes in Section 5, we also use international trade data from two sources: (i) Ecuadorian firm-level customs transaction records, available from 2009-2011; and (ii) country-level trade from CEPII's BACI dataset, available from 2009-2015. Both datasets report trade flows at the HS6 digit level. Ecuador's main export item is crude oil, which accounts for 55\% of total exports in 2009-2011. Besides oil, Ecuadorian exports are biased towards other basic products, such as bananas (10\%), fishing products $(9 \%)$, and flowers (4\%). Ecuador's imports derive predominantly from manufactured products, with the most important products being machinery and equipment $(21 \%)$, chemicals $(13 \%)$, and vehicles $(13 \%)$, as described in Figure B.3.

Summary Statistics. Appendix B.2.2 presents additional statistics regarding the distribution of earnings among individuals in 2012, the midpoint of our sample, as well as how their sources of earnings vary. ${ }^{21}$ Our sample reflects well the high level of income inequality in Ecuador. While annual income was $\$ 4,874$ for the median individual, it was $\$ 25,881$ and $\$ 187,165$ for the individuals in the 90th and 99th percentiles of the income distribution. $^{22}$ Also apparent is the importance of educational attainment and capital earnings in accounting for total earnings inequality in Ecuador. The share of income of those with less than a college degree declines substantially above the median of the income distribu-

\footnotetext{
${ }^{20}$ Since each individual is in only one labor group, she has at most three positive values of $\omega_{f i}$ : that associated with her labor group and those associated with the two types of capital. In 2012, 7.1\% of individuals had positive amounts of both labor and capital income, and this number rises to $42.6 \%$ among the top 5\% of the income distribution. In the oil sector, only $12 \%$ of total capital payments accrue to individuals in our sample, with the rest of those payments received by public firms owned by the central government.

${ }^{21}$ For the purposes of calculating these statistics, we restrict attention to individuals with strictly positive income for whom we have both location and education information.

${ }^{22}$ All nominal values are reported in US dollars (the official currency of Ecuador since 2000).
} 
tion. Capital income is especially relevant among the highest earners: those in the top 1\% of the income distribution, on average, derive $85.3 \%$ of their income from capital.

\subsection{Export Exposure Across the Distribution of Earnings}

From Factor to Individual Export Exposure. For each domestic factor $f \in \mathcal{F}$, the foreign factor demand $L_{f}^{*}\left(w, w^{*}\right)$ measures the total services of factor $f$ used, both directly and indirectly, to produce exported goods. As described in Appendix A.1.3, the value of foreign demand for domestic factors $f \in \mathcal{F}$ is equal to $\left\{w_{f} L_{f}^{*}\right\}_{f \in \mathcal{F}}=A B E$, where $A=\left\{x_{f n}\right\}_{(f, n) \in \mathcal{F} \times \mathcal{N}}$ is the domestic matrix of factor cost shares, $B=\left\{b_{n r}\right\}_{(n, r) \in \mathcal{N} \times \mathcal{N}}$ is the Leontief inverse associated with the input-output matrix $M=\left\{x_{n r}\right\}_{(n, r) \in \mathcal{N} \times \mathcal{N}}$, and $E \equiv\left\{E_{n}\right\}_{n \in \mathcal{N}}$ is the vector of exports. Factor $f^{\prime}$ s export exposure, defined as $E E_{f}=$ $L_{f}^{*} / L_{f}^{W}$ in Proposition 1, is therefore equal to

$$
E E_{f}=\left(\sum_{n \in \mathcal{N}} x_{f n} \sum_{r \in \mathcal{N}} b_{n r} E_{r}\right) /\left(\sum_{n \in \mathcal{N}} X_{f n}\right) .
$$

In turn, we define the export exposure of an individual $i \in \mathcal{I}$ as

$$
E E_{i}=\sum_{f \in \mathcal{F}} \omega_{f i} \times E E_{f}
$$

where $\omega_{f i}=Y_{f i} / Y_{i}$ is the share of individual i's earnings associated with factor $f$.

Our export exposure measure corresponds to the share of an individual's earnings that derives, either directly or indirectly, from exports rather than domestic consumption. It does not rely on any of the parametric assumptions introduced in Section 3-as discussed in Section 2, it is simply the granular counterpart of Leontief's (1953) factor content of exports. By construction, individuals with higher export exposure $E E_{i}$ tend to face higher demand in the trade equilibrium relative to autarky. We therefore expect higher demand, in turn, to lead to higher factor prices and earnings for these individuals under trade.

Results Figure 3 plots (in the solid blue line) the relationship between $E E_{i}$ and (total) income in our sample in 2012. ${ }^{23}$ Export exposure in Ecuador is pro middle-class. The average share of (direct plus indirect) exports in total earnings varies between 16\% and $17 \%$ among individuals between the 10th and 50th percentiles of the income distribution. As we move to income percentiles above the median of the income distribution, the share

\footnotetext{
${ }^{23}$ The corresponding figures for all other years in our sample can be found in Appendix C.2. Table C.1 also reports moments of the distribution of export exposure across individuals.
} 
Figure 3: Distribution of Export Exposure Across Individuals, 2012

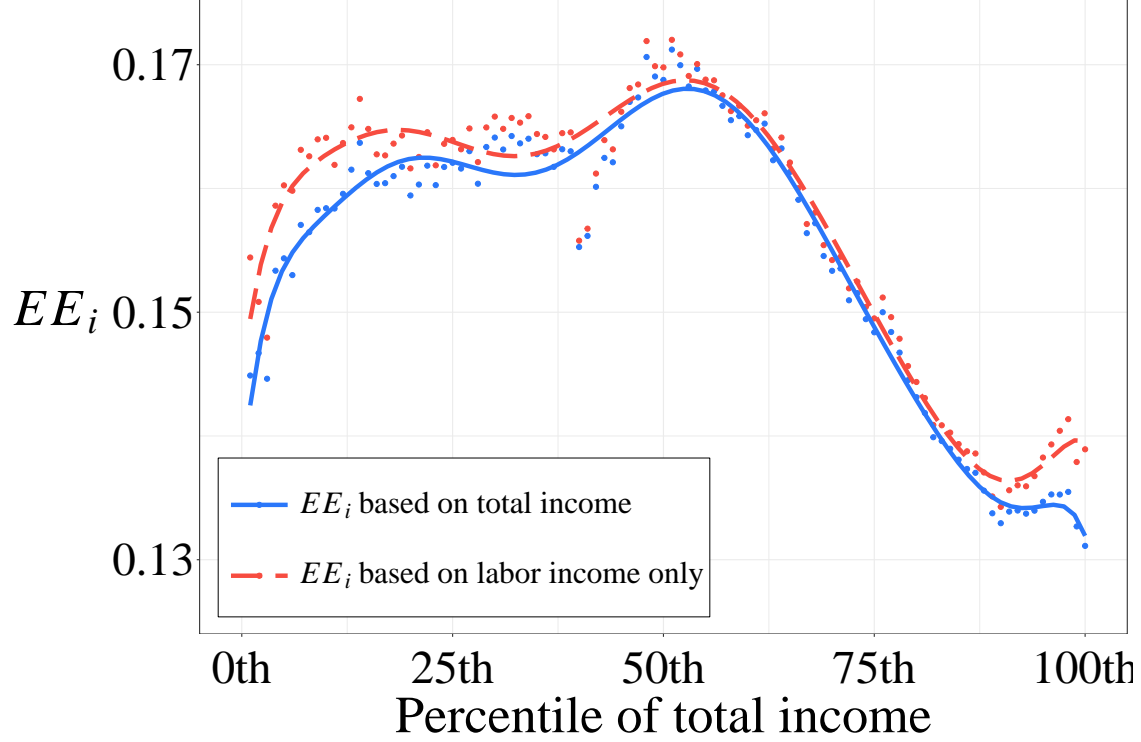

Notes: The blue dots report the average value of $E E_{i}$, computed as in equation (10), across all individuals in 2012 whose total income lies within each percentile of the total income distribution. The solid blue line indicates a fitted $10^{\text {th }}$-order polynomial. The red dots (and dashed red line) are analogous but use a measure of $E E_{i}$ that is computed while giving no weight to capital in individuals' income and among individuals with positive labor income.

of exports in total income consistently falls. It is only $13.3 \%$ among those with the $10 \%$ highest earnings in our sample.

Figure 3 also shows (in the dashed red line) the distribution of export exposure of labor income-that is, computed using only the export exposure of the labor type owned by each individual, excluding capital income. The fact that the red line is consistently above the blue line indicates that labor earnings are, on average, more exposed to exports than are capital earnings. The difference is clearer at the top of the income distribution because the richest individuals earn relatively larger shares from capital. However, the small difference between the two curves indicates that the export exposure of capital is just slightly lower than that of the labor factors of those in high-income percentiles.

Qualitatively, the fact that the richest individuals in Ecuador are the least exposed to exports resonates well with classical Heckscher-Ohlin predictions. Since Ecuador is scarce in high-skilled workers relative to the rest of the world, one expects the factor services of these workers, who are prevalent at the top of the income distribution, to be exported less. It is worth emphasizing that this occurs even though we do not restrict exporting firms to have the same skill-intensity as other firms in a given industry, unlike in standard factor content computations. 


\subsection{Import Exposure Across the Distribution of Earnings}

From Factor to Individual Import Exposure. To explore how import exposure varies across the income distribution, we focus on the impact of a uniform change in foreign factor prices: $d \ln w_{n}^{*}=d \ln w^{*}$ for all $n \in \mathcal{N}$. For such a shock, Proposition 3 implies that

$$
\frac{d \ln R D_{f}}{d \ln w^{*}}=(\sigma-1)\left(I E_{f}-I E_{0}\right),
$$

where $I E_{f} \equiv \sum_{n \in \mathcal{N}} I E_{f n}$ and $\left\{I E_{f n}\right\}_{n \in \mathcal{N}}$ is described in Proposition 3. To go from factor exposure to individual exposure, we again take averages across factors, weighted by each individual's factor income shares,

$$
I E_{i}=\sum_{f \in \mathcal{F}} \omega_{f i} \times I E_{f}
$$

In the empirically relevant case of $\sigma>1$, individuals with higher import exposure $I E_{i}$ tend to experience a decrease in the domestic relative demand for their factors when moving from the trade equilibrium, with $w^{*}<\infty$, to the autarky equilibrium, with $w^{*} \rightarrow \infty$. We expect lower relative demand, in turn, to lead to lower relative factor prices and relative earnings for these individuals.

Results. Figure 4 reports the average import exposure for individuals in different percentiles of the income distribution. ${ }^{24}$ The downward-sloping solid blue line indicates that low-income individuals are more exposed to import competition than are high-income individuals. Qualitatively, this contrasts with classical Heckscher-Ohlin predictions-where high-skill, high-income individuals would be those facing more import competition-and arises because much of Ecuador's imports are intermediate goods used by firms employing high-skill workers. Quantitatively, import exposure ranges from 0.045 at the bottom to 0.03 at the top. For an elasticity of substitution $\sigma$ around 2, as we estimate in Section 5, this implies that a $10 \%$ increase in the price of foreign factors would increase the relative demand for low-income individuals by about $0.15 \%$.

Note that the red dashed curve is steeper than the blue solid curve. This reflects the fact that capital is more exposed to import competition than the labor factors owned by individuals at the top of the income distribution and less exposed than those owned by individuals at the bottom. The proximity of the two curves, however, again indicates small differences between the import exposures of workers and capital owners.

\footnotetext{
${ }^{24}$ Again, Appendix C.2 reports the corresponding figures for all other years, along with summary statistics of the import exposure distribution across individuals.
} 
Figure 4: Distribution of Import Exposure Across Individuals, 2012

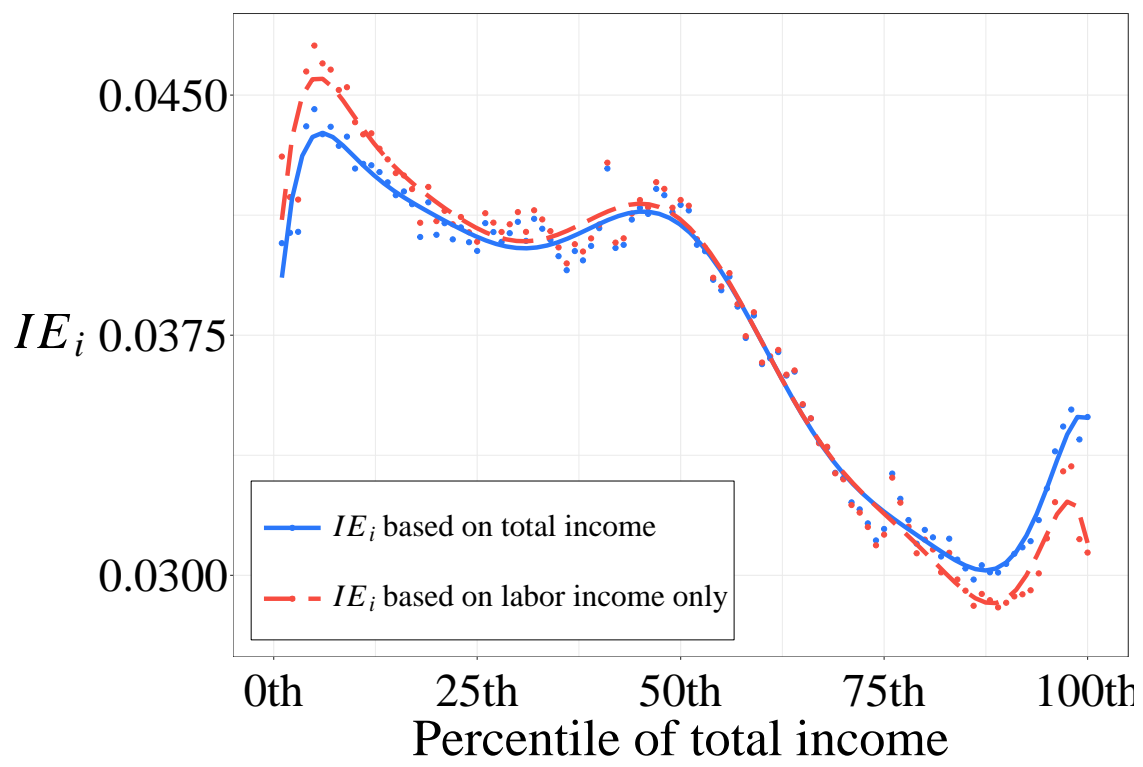

Notes: The blue dots report the average value of $I E_{i}$, computed as in equation (12), across all individuals in 2012 whose total income lies within each percentile of the total income distribution. The solid blue line indicates a fitted $10^{\text {th }}$-order polynomial. The red dots (and dashed red line) are analogous but use a measure of $I E_{i}$ that is based on labor income alone, like in Figure 3.

Overall, Figures 3 and 4 paint a nuanced picture of the exposure to international trade across Ecuador's income distribution. Export exposure is broadly pro-poor, in the sense that, on average, poorer individuals export a disproportionate fraction of their factor services, as one might have expected in a country abundant in less-skilled workers. Import exposure, on the other hand, is broadly anti-poor in the sense that cheaper imports tend to reduce disproportionately the domestic demand for the factor services of poor individuals. To evaluate the overall incidence of these differences in export and import exposures, we require an estimate of Ecuador's factor demand system, to which we now turn.

\section{Estimating Micro-Level Elasticities}

We now estimate Ecuador's factor demand system, which will allow us to quantify the incidence of differences in export and import exposures across individuals. The model in Section 3 describes an economy in which $R D\left(w, w^{*}\right)$ takes a nested CES form featuring two micro-level elasticities of substitution: that between primary factors in domestic production $(\eta)$ and that between firms' products in domestic consumption $(\sigma)$. The analysis in this section uses firm-level micro-data to obtain estimates of these two parameters. 


\subsection{Elasticity of Substitution Between Domestic Factors}

Empirical Specification. Equation (5) implies a log-linear relationship between factor expenditure, $X_{f n, t}$, and factor price, $w_{f, t}$, within each firm $n$,

$$
\ln X_{f n, t}=(1-\eta) \ln w_{f, t}+\zeta_{n, t}+\ln \theta_{f n, t}
$$

where $\zeta_{n, t} \equiv \ln \left(\beta_{n} \theta_{f n} R_{n} / \sum_{f \in \mathcal{F}} \theta_{f n} w_{f}^{1-\eta}\right)$ collects firm-year specific terms and $\eta$ is the elasticity of substitution across factors to be estimated. For the purposes of estimating $\eta$, we let the demand shock $\theta_{f n, t}$ be a function of a factor-specific term, $\zeta_{f}$, a vector of observables that we denote Controls $_{f, t}$ and to which we return below, and a residual productivity shock, $\epsilon_{f n, t}$,

$$
\ln \theta_{f n, t}=\zeta^{\prime} \operatorname{Controls}_{f, t}+\zeta_{f}+\epsilon_{f n, t} .
$$

Combining the two previous equations, we obtain our empirical specification,

$$
\ln X_{f n, t}=(1-\eta) \ln w_{f, t}+\zeta^{\prime} \text { Controls }_{f, t}+\zeta_{n, t}+\zeta_{f}+\epsilon_{f n, t}
$$

where firm-level factor expenditures $X_{f n, t}$ are given by the procedure from Section 4.1; the wages $w_{f, t}$ of each labor group $f \in \mathcal{F}_{L}$ are obtained by dividing total payments by the total number of workers in that group, $w_{f, t}=\left(\sum_{n \in \mathcal{N}} X_{f n, t}\right) / L_{f, t} ;$ and the price of each type of capital $f \in \mathcal{F}_{\mathrm{K}}$, is measured as the total factor payments $w_{f, t}=\sum_{n \in \mathcal{N}} X_{f n, t}$, since we have no physical measure available for the supply of capital. ${ }^{25}$

IV Strategy. OLS estimates of $\eta$ based on equation (13) suffer from the simultaneity bias that typically arises when estimating a demand relationship. We therefore develop instrumental variables (IVs) based on the differential exposure of factors to foreign shocks.

Our IVs take the commonly used "shift-share" form, based here on differential exposure of factors and firms to foreign shocks at the product $v$ level. In particular, we define the following shift-share variables:

$$
\begin{aligned}
\hat{E}_{f, t} & =\sum_{v \in \mathcal{H} \mathcal{S}} E E_{f v} \times(\text { Export Shock })_{v t^{\prime}} \\
\hat{I}_{f, t} & =\sum_{v \in \mathcal{H} \mathcal{S}} I E_{f v} \times(\text { Import Shock })_{v t^{\prime}}
\end{aligned}
$$

where $\mathcal{H S}$ denotes the set of all 6-digit HS products.

${ }^{25}$ This implies that capital supply shocks, if any, will also be part of the error term. 
In this notation, the "share" terms are $E E_{f v}$ and $I E_{f v}$, respectively. These are the product-level analogs of the factor trade exposures presented in Section 4. That is, $E E_{f v}$ is the share of product $v$ exports in factor $f^{\prime} s$ income in the initial period $t_{0}$, given by $E E_{f v}=\left(\sum_{n \in \mathcal{N}} x_{f n, t_{0}} \sum_{r \in \mathcal{N}} b_{n r, t_{0}} E_{r v, t_{0}}\right) /\left(\sum_{n \in \mathcal{N}} X_{f n, t_{0}}\right)$, where $E_{r v, t_{0}}$ denotes exports of firm $r$ in product $v$ at time $t_{0}$. $I E_{f v}$ is defined analogously as $I E_{f v}=\sum_{n \in \mathcal{N}} I E_{f n, t_{0}} \theta_{v n, t_{0}}^{*}$, where $I E_{f n, t_{0}}$ is the exposure of factor $f$ to import price shocks in firm $n$ at time $t_{0}$, and $\theta_{v n, t_{0}}^{*}$ is the share of product $v$ in firm $n$ 's imports at time $t_{0}$.

Turning to the "shifters", we seek determinants of the relative export and import growth of each variety $v$ that are plausibly derived from global shocks. To this end, we set (Export Shock) $)_{v t}$ equal to the log of global total export value (from all origins and destinations other than Ecuador) for each product $v \in \mathcal{H S}$ at date $t$ minus the average of the same variable across all products at that date. Similarly we set (Import Shock) $)_{v t}$ as the global average of log unit values of imports (again, across all origins and destinations excluding Ecuador) for each product $v \in \mathcal{H S}$ at date $t$ minus the average of the same variable across all products at that date. ${ }^{26}$

By demeaning both export and import shocks, we aim to isolate variation in shock realization across products, as discussed in Adao et al. (2019) and Borusyak et al. (2021). For the same reason, we include in the vector Controls $f, t$ each factor $f^{\prime}$ 's overall exposure to exports at date $t_{0}, E E_{f}=\sum_{v \in \mathcal{H S}} E E_{f v}$, interacted with a time dummy as well as each factor $f^{\prime}$ 's overall exposure to imports at date $t_{0}, I E_{f}=\sum_{v \in \mathcal{H}} I E_{f v}$, interacted again with a time dummy. This guarantees that our estimates are unaffected by domestic shocks that might disproportionately affect factors that are more exposed to international trade.

Given the controls in our specification, the exclusion restriction that underpins our IV estimates of $\eta$ is that productivity shocks in Ecuador-formally, the structural residuals $\epsilon_{f n, t}$ of (13) - are uncorrelated with product-level export and import shocks, an assumption that we believe is reasonable given the small size of Ecuador's economy. The logic of our IV strategy also requires that (Export Shock) $v t$ and (Import Shock) $v_{v t}$ do affect the export values and import unit values of different products in Ecuador, a fact that we verify in the zeroth-stage regressions presented in Appendix C.3.

Results. Table 1 reports our IV estimates of $\eta$. For our baseline estimate, reported in column (1), we use a balanced panel of incorporated firms that employ at least one worker

\footnotetext{
${ }^{26}$ Many others have used import and export shocks in the rest of the world as part of their shift-share IV strategies. On the export side, our shock is similar to the measures used in Aghion et al. (2018) and Huneeus (2018). On the import side, Hummels et al. (2014) have used growth in export supply to the rest of the world for product-country pairs as the shifter in a firm-level shift-share IV for imported input costs. Our focus on the unit values of imported inputs by firms is similar to Amiti et al. (2016) and Huneeus (2018).
} 
Table 1: Estimates of $\eta$

\begin{tabular}{|c|c|c|c|c|c|c|c|c|}
\hline & \multirow{2}{*}{$\begin{array}{c}\text { Baseline } \\
(1)\end{array}$} & \multicolumn{7}{|c|}{ Alternative Specifications } \\
\hline & & (2) & (3) & (4) & (5) & (6) & (7) & (8) \\
\hline Estimate of $\eta$ & $\begin{array}{c}2.09 \\
(0.35)\end{array}$ & $\begin{array}{c}2.15 \\
(0.65)\end{array}$ & $\begin{array}{c}2.13 \\
(0.48)\end{array}$ & $\begin{array}{c}2.02 \\
(0.73)\end{array}$ & $\begin{array}{c}2.06 \\
(0.32)\end{array}$ & $\begin{array}{c}2.11 \\
(0.33)\end{array}$ & $\begin{array}{c}2.10 \\
(0.59)\end{array}$ & $\begin{array}{c}3.29 \\
(2.51)\end{array}$ \\
\hline First-stage F statistic & 10.1 & 5.1 & 19.4 & 3.0 & 10.4 & 8.7 & 18.3 & 5.2 \\
\hline Factor-firm-year obs. & 625,024 & 625,024 & 625,024 & 625,024 & 512,915 & 861,747 & 536,795 & 446,169 \\
\hline Number of factors & 75 & 75 & 75 & 75 & 75 & 75 & 75 & 75 \\
\hline Alternative: & $\begin{array}{l}- \\
- \\
-\end{array}$ & $\begin{array}{c}\text { Drop } \\
\text { extra } \\
\text { controls }\end{array}$ & $\begin{array}{l}\text { Export } \\
\text { IV } \\
\text { only }\end{array}$ & $\begin{array}{c}\text { Import } \\
\text { IV } \\
\text { only }\end{array}$ & $\begin{array}{c}\text { Firms } \\
\mathrm{w} />5 \\
\text { workers }\end{array}$ & $\begin{array}{c}\text { Un- } \\
\text { balanced } \\
\text { panel }\end{array}$ & $\begin{array}{l}\text { Years } \\
2010- \\
2015\end{array}$ & $\begin{array}{l}\text { Years } \\
2011- \\
2015\end{array}$ \\
\hline
\end{tabular}

Notes: Sample of incorporated firms with positive payments for more than one factor and more than one employee. Baseline specification uses a balanced panel from 2009-2015, uses both export and import IVs, includes firm-year and factor fixed effects, and includes the extra controls consisting of year fixed effects interacted with the factor's exposure at $t_{0}$ to exports and imports. Observations weighted by initial factorfirm payments (winsorized at the 95th percetile). Standard errors in parentheses are clustered by factor.

from 2009-2015; we weight observations by initial factor-firm payments; and we take $t_{0}$ to be 2009-2011, so that initial shares in our IVs and controls are averaged over that period. This reduces the noise in the years right after the great trade collapse of 2008-2009.

The estimated value of $\hat{\eta}=2.09$ implies that factors of production are substitutes. ${ }^{27}$ This estimate is about twice as large as the Cobb-Douglas value of $\eta=1$ assumed in Deardorff and Staiger (1988). It is significantly higher than the U.S. plant-level elasticity of substitution between capital and labor of 0.3-0.5 in Oberfield and Raval (2021), but it is close to the range of existing estimates of the (aggregate) elasticity of substitution across educational groups surveyed in Acemoglu and Autor (2011). ${ }^{28}$

The remaining columns of Table 1 report estimates of $\eta$ obtained with alternative specifications. In column (2), we see that our estimate is almost identical when we ignore the additional controls capturing domestic shocks potentially correlated with the overall exposure of firms and factors to international trade. Columns (3) and (4) report estimates obtained when using IVs based only on export or import shocks. Although these point estimates are similar across both types of shock IVs, the first-stage strength differs, with export shocks being more important. In columns (5)-(6), we see that estimates are again similar when we restrict our sample to firms with at least five workers or based on an

\footnotetext{
${ }^{27}$ Standard errors are clustered by factor. This reflects the variation in our IVs while accounting for auto-correlation in residuals. Adao et al. (2019) point out that the correlation of residuals is a threat to the performance of traditional inference procedures in shift-share specifications. Implementing their standard error formulas is not feasible here because of the high number of fixed-effects and the impossibility of separately computing product exposure shares, due to the high-dimension of the input-output matrix $M$.

${ }^{28}$ We come back to the relationship between the aggregate implication of our model for factor prices and our estimates of micro-level elasticities in Section 6.2.
} 
unbalanced panel of firms. Lastly, in columns (7)-(8), we report our estimates when we restrict the sample period to years after 2011 that have not been used to compute the initial shares in the IVs. As we remove years, the first-stage tends to become weaker and standard errors larger. This is unsurprising given the reduced sample size.

\subsection{Elasticity of Substitution Between Goods}

Empirical Specification. To estimate $\sigma$, we turn to the final demand equation (4), which describes substitution between goods produced by different domestic firms $n$ within each sector $k$. This relates domestic expenditure, $D_{n, t}$, to the domestic price, $p_{n, t}$, via

$$
\ln D_{n, t}=(1-\sigma) \ln p_{n, t}+\zeta_{k, t}+\ln \theta_{n c, t}
$$

where $\zeta_{k, t} \equiv \ln \left(\alpha_{k, t} Y_{t} / \sum_{r \in \mathcal{N}_{k}} \theta_{r c} p_{r}^{1-\sigma}\right)$ now subsumes industry-year terms. In line with our estimation of the elasticity of substitution between factors, we let the good demand shock $\ln \theta_{n c, t}$ be a function of a firm-specific term, $\zeta_{n}$, a vector of observables, Controls ${ }_{n, t}$, to be described below, and a residual preference shock, $\epsilon_{n c, t}$. This leads to

$$
\ln D_{n, t}=(1-\sigma) \ln p_{n, t}+\zeta^{\prime} \text { Controls }_{n, t}+\zeta_{k, t}+\zeta_{n}+\epsilon_{n c, t} .
$$

The only conceptual difference between the estimation of $\eta$ and $\sigma$ is the measurement of prices: we lack data on domestic prices $p_{n, t}$. To address this issue, we use our model to relate $p_{n, t}$ to the domestic and foreign factor prices that we do observe in our dataset. As shown in Appendix A.6, equation (9) implies

$$
\ln p_{n, t}=\sum_{r \in \mathcal{N}} b_{r n, t}\left[\beta_{r, t} \ln \tilde{w}_{r, t}^{D}+x_{r, t}^{*} \ln w_{r, t}^{*}\right]+\rho_{n, t} .
$$

where $b_{r n, t}$ is an element of the Leontief inverse $B_{t}=\left(I-M_{t}\right)^{-1}$ associated with $M_{t} \equiv$ $\left\{x_{r v, t}\right\}_{(r, v) \in \mathcal{N} \times \mathcal{N}} ; \tilde{w}_{r, t}^{D}$ is a revealed measure of the CES price index for domestic factors in firm $r$ such that $\ln \tilde{w}_{r, t}^{D} \equiv \sum_{f \in \mathcal{F}} x_{f r, t}^{D}\left(\ln w_{f, t}+\frac{1}{\eta-1} \ln x_{f r, t}^{D}\right) ; w_{r, t}^{*}$ is the price of foreign factor services facing firm $r$, which we measure as $\ln w_{r, t}^{*}=\sum_{v \in \mathcal{P}} \theta_{v r, t_{0}}^{*} \ln p_{v, t}^{*}$, with $\theta_{v r, t_{0}}^{*}$ the average share of product $v$ in firm $r^{\prime}$ s imports in an initial period $t_{0}$ and with $\ln p_{v, t}^{*}$ the unit value of Ecuador's imports of product $v$ at year $t$; and $\rho_{n, t}$ is a cost shifter determined by firm $n$ 's technology parameters and those of its suppliers. ${ }^{29}$

\footnotetext{
${ }^{29}$ Our Ecuadorian firm-level customs transaction records are only available from 2009-2011, hence our choice to use $\theta_{v r, t_{0}}^{*}$ rather than $\theta_{v r, t}^{*}$ when computing the foreign factor prices faced by each firm.
} 
Substituting for domestic prices in (16) using (17), we finally obtain

$$
\ln D_{n, t}=(1-\sigma) \sum_{r \in \mathcal{N}} b_{r n, t}\left[\beta_{r, t} \ln \tilde{w}_{r, t}^{D}+x_{r, t}^{*} \ln w_{r, t}^{*}\right]+\zeta^{\prime} \operatorname{Controls}_{n, t}+\zeta_{k, t}+\zeta_{n}+\epsilon_{n, t}
$$

where $\epsilon_{n, t} \equiv \epsilon_{n c, t}+\rho_{n, t}$ is a combination of the firm-specific demand and cost shocks.

IV Strategy. For the same reason as in Section 5.1, OLS estimates of $\sigma$ suffer from simultaneity bias that can be addressed by developing IVs based on the differential exposure of firms to foreign shocks. Equation (18) suggests two types of instruments: price-shifters for the domestic factors used by different firms within each sector and analogous priceshifters for their foreign factors.

To construct domestic price-shifters, we propose to use firm-level averages of the two factor-specific instruments described in (14) and (15). The firm-level counterparts of the two previous export- and import-based instruments are

$$
\begin{aligned}
\hat{E}_{n, t} & =\sum_{f \in \mathcal{F}} x_{f n, t_{0}}^{D} \times \hat{E}_{f, t}, \\
\hat{I}_{n, t} & =\sum_{f \in \mathcal{F}} x_{f n, t_{0}}^{D} \times \hat{I}_{f, t},
\end{aligned}
$$

where the weights correspond to the initial spending shares across domestic factors in firm $n$ in period $t_{0}$. To construct foreign price-shifters, we simply use the average of product-level price shocks in the rest of the world weighted by firm $n$ 's initial import shares,

$$
\hat{w}_{n, t}^{*}=\sum_{v \in \mathcal{H} \mathcal{S}} \theta_{v n, t_{0}}^{*} \times(\text { Import Shock })_{v t} .
$$

Finally, we include in Controls $s_{n, t}$ the shares of firm $n^{\prime}$ s costs at $t_{0}$ spent on primary factors and imports, $\beta_{n, t_{0}}$ and $x_{n, t}^{*}$ interacted with time dummies. For our IVs to be valid, the three foreign shocks must therefore be uncorrelated with firms' preference and cost shocks, $\epsilon_{n c, t}$ and $\rho_{n, t}$, conditional on industry-time and firm fixed effects as well as differential initial exposures to changes in domestic and foreign factor prices.

Results. Table 2 reports the IV estimates of $\sigma$. Our baseline in column (1) uses the same balanced panel of incorporated firms and the same initial period as in Table 1, but weights observations by the initial final sales of each firm. Like in Section 5.1, the remainder of Table 2 documents the stability of our estimates to altering these and other considerations.

In column (1) our point estimate of $\hat{\sigma}=1.96$ contrasts sharply with the assumption of 
Table 2: Estimates of $\sigma$

\begin{tabular}{|c|c|c|c|c|c|c|c|c|}
\hline & \multirow{2}{*}{$\begin{array}{c}\text { Baseline } \\
(1)\end{array}$} & \multicolumn{7}{|c|}{ Alternative Specifications } \\
\hline & & (2) & (3) & (4) & (5) & (6) & (7) & (8) \\
\hline Estimate of $\sigma$ & $\begin{array}{c}1.96 \\
(0.57)\end{array}$ & $\begin{array}{c}1.98 \\
(0.55)\end{array}$ & $\begin{array}{c}1.76 \\
(0.19)\end{array}$ & $\begin{array}{c}1.91 \\
(0.57)\end{array}$ & $\begin{array}{c}1.84 \\
(0.63)\end{array}$ & $\begin{array}{c}2.86 \\
(0.70)\end{array}$ & $\begin{array}{c}1.48 \\
(0.48)\end{array}$ & $\begin{array}{c}1.51 \\
(0.72)\end{array}$ \\
\hline First-stage F statistic & 13.1 & 14.2 & 1.1 & 19.4 & 8.6 & 15.1 & 10.4 & 4.2 \\
\hline Firm-year obs. & 180,992 & 180,992 & 180,992 & 180,992 & 120,050 & 279,183 & 155,136 & 129,280 \\
\hline Number of firms & 25,856 & 25,856 & 25,856 & 25,856 & 17,150 & 47,413 & 25,856 & 25,856 \\
\hline Alternative: & $\begin{array}{l}- \\
-\end{array}$ & $\begin{array}{c}\text { Drop } \\
\text { extra } \\
\text { controls }\end{array}$ & $\begin{array}{c}\text { Export } \\
\text { IV } \\
\text { only }\end{array}$ & $\begin{array}{c}\text { Import } \\
\text { IV } \\
\text { only }\end{array}$ & $\begin{array}{c}\text { Firms } \\
\mathrm{w} />5 \\
\text { workers }\end{array}$ & $\begin{array}{c}\text { Un- } \\
\text { balanced } \\
\text { panel }\end{array}$ & $\begin{array}{l}\text { Years } \\
2010- \\
2015\end{array}$ & $\begin{array}{l}\text { Years } \\
2011- \\
2015\end{array}$ \\
\hline
\end{tabular}

Notes: Sample of incorporated firms with positive final sales and more than one employee. Baseline specification uses a balanced panel of observations from 2009-2015, uses both export and import IVs, includes firm and sector-year fixed effects, and includes the extra controls comprising of year fixed effects interacted with the firm's cost share spent on primary factors and imports. Observations are weighted by initial firm final sales (weights winsorized at the 95 percetile). Standard errors in parentheses are clustered by firm.

$\sigma=\infty$ in the original factor content approach of Deardorff and Staiger (1988). This value is also lower than the elasticity of substitution between U.S. firms in Hottman et al. (2016) who report a median elasticity of substitution between U.S. firms, within AC Nielsen product group categories, of 3.9. This is expected since such product groups are more narrowly defined than the 2-digit industries used in our specification. Our estimate of $\sigma$ is also lower than those indirectly inferred from average markups under the assumption of monopolistic competition, as in Oberfield and Raval (2021) and Blaum et al. (2018).

\section{Testing the Empirical Model of Domestic Factor Demand}

In Section 2, we have shown that in order to estimate the impact of trade on factor prices, knowledge of relative factor demand is sufficient. In Section 3, we have imposed specific parametric assumptions - on the primitives of tastes, technology, and product and factor market structures-that allow us to construct the aggregate relative factor demand $R D\left(w, w^{*}\right)$ by combining the rich micro data presented in Section 4 with the two elasticities of substitution, $\eta$ and $\sigma$, estimated in Section $5 .{ }^{30}$ Going from micro to macro in this way, however, begs the question of whether the "true" relative factor demand system in Ecuador looks anything like what our parametric model predicts. Before using our estimates of $R D\left(w, w^{*}\right)$ to conduct counterfactual analysis in Section 7 , we now test the predictions of our model, both at the micro- and macro-levels.

\footnotetext{
${ }^{30}$ Appendix A.7.1 shows that, as a formal matter, $R D\left(w, w^{*}\right)$ is identified once $\eta$ and $\sigma$ are known.
} 


\subsection{Micro-Level Tests}

Our micro-level tests focus on the Cobb-Douglas assumptions imposed on preferences and technology. In Section 3, we have arbitrarily set three elasticities to one: the elasticity of substitution between goods from different sectors in final demand $\left(\sigma_{\text {sector }}\right)$, that between domestic and foreign inputs in production $\left(\sigma_{\text {trade }}\right)$, and that between domestic inputs from different firms in production $\left(\sigma_{\text {input }}\right)$,

$$
\sigma_{\text {sector }}=\sigma_{\text {trade }}=\sigma_{\text {input }}=1
$$

One could consider instead a strictly more general nested CES model, where the previous elasticities are allowed to differ (in unique ways) from one and the associated expenditure shares are hence endogenous. Directly estimating this richer nested CES model is complicated by the fact that we do not directly observe domestic good prices, but rather infer them through the input-output structure of our model, as described in equation (17). Instead of a full structural estimation of these additional elasticities, we therefore propose to test our Cobb-Douglas assumptions by focusing on the following three specifications,

$$
\begin{aligned}
& \ln \frac{\sum_{n \in \mathcal{N}_{k}} D_{n, t}}{\sum_{n \in \mathcal{N}} D_{n, t}}=\beta_{\text {sector }} \ln \left(P_{k, t} / P_{t}\right)+\ln \alpha_{k, t}, \\
& \ln \frac{x_{n, t}^{*}}{\sum_{r \in \mathcal{N}} x_{r n, t}}=\beta_{\text {trade }} \ln \left(w_{n, t}^{*} / P_{n, t}^{D}\right)+\ln \left(\left(1-\Theta_{n, t}\right) / \Theta_{n, t}\right), \\
& \ln \frac{x_{m n, t}}{\sum_{r \in \mathcal{N}} x_{r n, t}}=\beta_{\text {input }} \ln \left(p_{m, t} / P_{n, t}^{D}\right)+\ln \theta_{m n, t},
\end{aligned}
$$

where the prices and price indices appearing on the right-hand side are all computed under the assumption that $\sigma_{\text {sector }}=\sigma_{\text {trade }}=\sigma_{\text {input }}=1$, as described in Appendix C.4. ${ }^{31}$ Under that null hypothesis, our model predicts that $\beta_{\text {sector }}=\beta_{\text {trade }}=\beta_{\text {input }}=0$.

Like in Section 5, prices may be correlated with demand shocks, potentially biasing OLS estimates. To solve this issue, we use again export and import shocks to construct IVs for prices, as described in Appendix C.4. Table 3 reports our estimates of $\beta_{\text {sector, }}$ $\beta_{\text {trade, }}$ and $\beta_{\text {input }}$. Despite fairly tight standard errors, we obtain a point estimate that is not statistically different from zero at conventional levels in all three cases. Hence, within our sample, we cannot reject the Cobb-Douglas assumptions imposed in Section 3. ${ }^{32}$

\footnotetext{
${ }^{31}$ The full structural estimation of $\sigma_{\text {sectors }}, \sigma_{\text {trade }}$, and $\sigma_{\text {inputs }}$ would instead require the computation of prices and price indices that are themselves consistent with the estimated values of these new elasticities.

${ }^{32}$ Unit-elasticities lie within the ranges of recent estimates obtained in other contexts. For example, using U.S. data, Oberfield and Raval (2021) estimate $\sigma_{\text {sector }}$ to lie between 0.77 and 1.14 at the 2-digit level (more aggregated than our sectors) and 1.19-2.12 at the 4-digit level (less so); whereas Bartelme et al. (2019) find $\sigma_{\text {sector }}=1.47$ across 2-digit manufacturing sectors in a cross-country sample. Antras et al. (2017b) estimate
} 
Table 3: Micro-Level Tests

\begin{tabular}{lccc}
\hline & \multicolumn{3}{c}{ Sensitivity of expenditure shares to relative prices across: } \\
\cline { 2 - 4 } & $\begin{array}{c}\text { sectors in } \\
\text { final demand } \\
(1)\end{array}$ & $\begin{array}{c}\text { imported and } \\
\text { domestic inputs }\end{array}$ & $\begin{array}{c}\text { domestic input } \\
\text { suppliers } \\
(3)\end{array}$ \\
\hline & -0.19 & -0.25 & 0.06 \\
P-value $\left(H_{0}: \beta=0\right)$ & $(0.32)$ & $(0.34)$ & $(0.26)$ \\
First-stage F statistic & {$[0.56]$} & {$[0.47]$} & {$[0.81]$} \\
Observations & 14.0 & 71.3 & 7.4 \\
Clusters & 448 & 19,575 & $1,476,055$ \\
\hline
\end{tabular}

Notes: Samples consist of: balanced panel with positive expenditure over 2009-2015; for columns (2) and (3), incorporated firms with more than one employee; and, for (3), transactions worth at least $1 \%$ of the buyer's purchases. Additional controls include year fixed effects as well as, in columns: (1) sector fixed effects; (2) firm fixed effects and year dummies interacted with the firm's cost share spent on primary factors and imports; (3) buyer-year and supplier fixed effects, and year dummies interacted with the supplier's cost share spent on primary factors and imports. Observations weighted (with weights winsorized at the 95 percetile) by initial sector final sales in column (1), initial firm final sales in (2), and initial buyer-seller transactions in (3). Standard errors clustered by sector in column (1), firm in (2), and seller in (3).

\subsection{Macro-Level Tests}

Our macro-level tests focus on potentially deeper departures from the assumptions imposed in Sections 2 and 3, such as imperfect competition in factor markets, imperfect competition in good markets, and imperfect factor mobility across firms or sectors. Though such imperfections may exist in Ecuador, the relevant question for the purposes of our analysis is whether they affect the ability of our empirical model to replicate the response of factor prices to foreign shocks observed in the data (since it is precisely from that response that we will build counterfactual distributions of earnings in the next section).

To address this question, we follow the same approach as in Proposition 2. Starting from any equilibrium at date $\tau-1$ and differentiating the factor market clearing condition in equation (2) implies that, up to a first-order approximation, changes in factor prices between date $\tau-1$ and any subsequent date $\tau$ can be expressed as

$$
\Delta \ln w_{\tau}=-\left(\frac{\partial \ln R D}{\partial \ln w}\right)_{\tau-1}^{-1}\left[\Delta \ln R E E_{\tau}+\left(\frac{\partial \ln R D}{\partial \ln w^{*}}\right)_{\tau-1} \Delta \ln w_{\tau}^{*}\right]+\epsilon_{\tau},
$$

$\sigma_{\text {trade }}=1.79$ for U.S. firms' cross-country sourcing behavior, Blaum et al. (2018) estimate this parameter to range from 1.71-2.38 for French importers, and Boehm et al. (2019) find an average estimate of 0.55 for U.S.-based firms' sourcing from Japan in the aftermath of a natural disaster. Finally, Atalay (2017) estimates $\sigma_{\text {input }}$ to be effectively zero in the case of cross-industry substitution of inputs in US manufacturing, whereas Huneeus (2018) estimates $\sigma_{\text {input }}=3.40$ for cross-domestic firm sourcing substitution in Chile. 
where $\Delta$ refers to changes between two consecutive periods, e.g. $\Delta \ln w_{\tau}=\ln w_{\tau}-$ $\ln w_{\tau-1}$, and the vector of structural demand shocks, $\epsilon_{\tau}$, comprises both relative supply and relative domestic demand shocks. ${ }^{33}$ Summing across all years between $t_{0}$ and $t$, we then obtain the domestic factor prices, $\ln w_{f, t}^{\text {model }}$, predicted by our model in response to a sequence of foreign shocks, $\left\{\Delta \ln R E E_{\tau}, \Delta \ln w_{\tau}^{*}\right\}_{\tau=t_{0}}^{t}$, between $t$ and $t_{0}$,

$$
\ln w_{f, t}^{\text {model }} \equiv \sum_{\tau=t_{0}}^{t}-\left(\frac{\partial \ln R D}{\partial \ln w}\right)_{\tau-1}^{-1}\left[\Delta \ln R E E_{\tau}+\left(\frac{\partial \ln R D}{\partial \ln w^{*}}\right)_{\tau-1} \Delta \ln w_{\tau}^{*}\right]+\ln w_{f, t_{0}}
$$

where $(\partial \ln R D / \partial \ln w)_{\tau-1}$ and $\left(\partial \ln R D / \partial \ln w^{*}\right)_{\tau-1}$ are constructed using our preferred estimates of the micro-level elasticities, $\hat{\eta}=2.09$ and $\hat{\sigma}=1.96$, from Section 5 .

To test our factor demand model, we can therefore estimate the testing specification

$$
\ln w_{f, t}=\beta_{\mathrm{fit}} \ln w_{f, t}^{\text {model }}+\epsilon_{f, t}
$$

where the fit coefficient $\beta_{\text {fit }}$ should be equal to one under the null that our model is correctly specified. ${ }^{34}$ Since the changes in relative export exposures $\Delta \ln R E E_{t}$ and foreign factor prices $\Delta \ln w_{t}^{*}$ that enter $\ln w_{f, t}^{\text {model }}$ may be correlated with domestic demand shocks $\epsilon_{f, t}$ in Ecuador, we build the following IV for $\ln w_{f, t}^{\text {model }}$,

$$
\ln \hat{w}_{f, t}^{\text {model }} \equiv \sum_{\tau=t_{0}+1}^{t}-\left(\frac{\partial \ln R D}{\partial \ln w}\right)_{t_{0}}^{-1}\left[\Delta \ln \widehat{R E E}_{t}+\left(\frac{\partial \ln R D}{\partial \ln w^{*}}\right)_{t_{0}} \Delta \ln \hat{w}_{t}^{*}\right],
$$

where $\widehat{R E E}_{t} \equiv\left\{\left[1-\left(\hat{E}_{0, t} / Y_{0, t_{0}}\right)\right] /\left[1-\left(\hat{E}_{f, t} / Y_{f, t_{0}}\right)\right]\right\}_{f \in \mathcal{F}}$ is the shifter of relative export exposure, with $\hat{E}_{f, t}$ given by equation (14), and $\hat{w}_{t}^{*} \equiv\left\{\hat{w}_{n, t}^{*}\right\}_{n \in \mathcal{N}_{t_{0}}}$ is the shifter of foreign factor price given by equation (21).

It may seem surprising that testing of this model is possible, given the inclusion of sufficient taste and technology heterogeneity to match all data points at the micro (and hence macro) level. The idea behind our test is that while one can always recover domestic residuals $\hat{\epsilon}_{f, t}$ such that equation (26) holds for $\beta_{\text {fit }}=1$, such recovered residuals do not

\footnotetext{
${ }^{33}$ Specifically, we have $\epsilon_{t} \equiv \Delta \ln \left(\bar{L}_{f, t} / \bar{L}_{0}\right)-(\partial \ln R D / \partial \ln w)_{t_{0}}^{-1}(\partial \ln R D / \partial \ln \bar{\Theta})_{t_{0}} \Delta \ln \bar{\Theta}_{t}$, with $\bar{\Theta}_{t} \equiv$ $\left\{\theta_{n c, t}, \theta_{f n, t}, \theta_{r n, t}, \Theta_{n, t}, \alpha_{n}, \beta_{n}, \varphi_{n}\right\}$ the full vector of preference and technological shifters.

${ }^{34}$ There is a long tradition of such "slope" tests in the field of international trade. For example, Davis and Weinstein (2001) use such a specification to test the predictions of the Heckscher-Ohlin-Vanek model, Costinot and Donaldson (2012) do so to test the predictions of the Ricardian model, Kovak (2013) does so to test a regional specific-factors model, and Adao et al. (2020) do so to test the ability of different spatial models to replicate observed responses of regional outcomes to trade shocks. A distinctive feature of our macro-level tests is that the foreign shocks, $\Delta \ln R E E_{\tau}$ and $\Delta \ln w_{\tau}^{*}$, are themselves endogenous objects that may be correlated with the structural error term, $\epsilon_{\tau}$.
} 
have to be orthogonal to our IV, $\ln \hat{w}_{f, t}^{\text {model }} .35$ The flip-side of this observation is that when imposing the orthogonality between $\ln \hat{w}_{f, t}^{\text {model }}$ and $\epsilon_{f, t}$, the estimated $\beta_{\text {fit }}$ does not have to equal one. So our test has power against the null.

Table 4 reports our estimates of the fit coefficient $\beta_{\text {fit }}$. Remarkably, as seen in column (1), despite the strong parametric restrictions imposed in Section 3, we obtain $\hat{\beta}_{\text {fit }}=1.08$. This implies that we fail to reject the null of $\beta_{\text {fit }}=1$ at standard levels $(p=0.61)$, a finding that continues to hold (though with a larger coefficient and standard error) when we control for initial levels of each factor's export and import exposure interacted with time dummies in column (2). Reassuringly, adding additional fixed effects (in columns 3-5) that probe the model's fit for different subsets of factors (across education groups, geographical groups, and capital relative to labor) causes $\hat{\beta}_{\text {fit }}$ to range from 0.86 to 1.25.

One remaining question is the extent to which this failure to reject the parametric model simply reflects a test that lacks power. That is, although we cannot reject the macrolevel predictions of our nested CES model using our preferred estimates of micro-level elasticities, $\hat{\eta}=2.09$ and $\hat{\sigma}=1.96$, the same tests conducted using any arbitrary values of $\eta$ and $\sigma$ might also be successful. Figures C.3 in Appendix C.5 show that this is not so. This analysis conducts the same macro tests as in Table 4 but at alternative values of $\eta$ and $\sigma$. These results clearly indicate that $\hat{\beta}_{\text {fit }}$ departs from one as we move away from our baseline estimates of $\eta$ and $\sigma$. At the $5 \%$ significance level, in specifications based on column (1), we typically reject specifications with $\eta>8$ or $\sigma>6$. Recall that, in contrast, the original factor content approach assumes $\sigma \rightarrow \infty$.

\section{The Overall Incidence of Trade on Earnings Inequality}

We have established that the magnitude of the factor price responses to foreign shocks predicted by our model are consistent with those observed in the data. This strengthens the credibility of our parametric assumptions and their quantitative implications, at least within the range of observed export and import shocks. With this in mind, we now turn to a full quantification of the distributional consequences of international trade. We solve for the changes between the observed distribution of earnings in Ecuador and the counterfactual distribution that would be observed if Ecuador were under autarky, as a result of both the export and import channels described in Proposition 2.

\footnotetext{
${ }^{35}$ Even though we have relied on the same exogenous source of variation to estimate our two micro-level elasticities, $\ln w_{f, t}^{\text {model }}$ is a non-linear function of $\hat{\eta}$ and $\hat{\sigma}$ that uses the full structure of the domestic factor system, $R D$, not just the linear component used in Section 5 to estimate $\eta$ and $\sigma$ within each CES nest.
} 
Table 4: Macro-Level Tests

\begin{tabular}{lccccc}
\hline & \multicolumn{5}{c}{$\Delta$ Log (observed factor price) } \\
\cline { 2 - 6 } & $(1)$ & $(2)$ & $(3)$ & $(4)$ & $(5)$ \\
\hline$\Delta$ Log (predicted factor price) & 1.08 & 1.60 & 1.25 & 1.02 & 0.86 \\
& $(0.15)$ & $(0.62)$ & $(0.63)$ & $(0.16)$ & $(0.20)$ \\
P-value of $H_{0}: \beta_{\text {fit }}=1$ & {$[0.61]$} & {$[0.33]$} & {$[0.69]$} & {$[0.92]$} & {$[0.47]$} \\
First-stage F statistic & 1840.4 & 195.4 & 180.6 & 290.1 & 122.7 \\
Factor-year observations & 525 & 525 & 525 & 525 & 518 \\
Number of factors & 75 & 75 & 75 & 75 & 74 \\
\hline Includes year indicators times: & & & & & \\
$\quad E E_{f, t_{0}}$ and $I E_{f, t_{0}}$ & & $\checkmark$ & $\checkmark$ & $\checkmark$ & $\checkmark$ \\
$\quad$ Capital factors indicator & & & $\checkmark$ & $\checkmark$ & $\checkmark$ \\
$\quad$ Province indicators & & & & $\checkmark$ & $\checkmark$ \\
$\quad$ Education level indicators & & & & & $\checkmark$ \\
\hline
\end{tabular}

Notes: Sample of 75 factors in 2009-2015. All specifications estimated with year and factor fixed effects. Observations weighted by initial factor payments (winsorized at the 95th percentile). Standard errors in parentheses clustered by factor.

\subsection{Baseline Results}

For our baseline results, we focus on the Ecuadorian economy at date $t=2012$, the midpoint of our sample. In order to quantify the overall impact of trade on inequality at that date, we apply Proposition 2 and compute $\left(\Delta \ln w_{t}\right)_{t r a d e}=\left\{\ln w_{f, t}-\ln \left(w_{f, t}\right)_{A}\right\}_{f \in \mathcal{F}}$, as well as the export and import channels, $\left(\Delta \ln w_{t}\right)_{\text {exports }}$ and $\left(\Delta \ln w_{t}\right)_{\text {imports }}$. This amounts to integrating over a sequence of small shocks to $R E E$ and $w^{*}$, just as in the macro test of Section 6.2, but now such that the shocks go from the initial equilibrium $\left(w^{*}=\right.$ $\left.w_{t}^{*}, R E E=R E E_{t}\right)$ to the autarky counterfactual equilibrium $\left(w^{*}=\infty, R E E=1\right)$ rather than to the values observed at a later year. ${ }^{36}$ Given changes in factor prices, the proportional changes in earnings of individual $i$ between trade and autarky, $\left(\Delta Y_{i, t}\right)_{\text {trade }} / Y_{i, t}=$ $\left[Y_{i, t}-\left(Y_{i, t}\right)_{A}\right] / Y_{i, t}$, as well as the changes in earnings associated with the export and import channels, $\left(\Delta Y_{i, t}\right)_{\text {exports }} / Y_{i, t}$ and $\left(\Delta Y_{i, t}\right)_{\text {imports }} / Y_{i, t}$, can be computed using the share of different factors $f$ in individual $i$ 's earnings in the initial equilibrium, $\omega_{f i, t} \equiv Y_{f i, t} / Y_{i, t} .{ }^{37}$

Figure 5 plots these counterfactual earnings changes for every percentile of income earner in our sample, always normalizing changes in the median income to zero. We

\footnotetext{
${ }^{36} \mathrm{~A}$ common issue in quantitative trade modeling concerns how to introduce trade imbalances in the context of a static economy. Following standard practices discussed in Costinot and Rodríguez-Clare (2014), we implicitly treat imbalances as lump-sum transfers between Ecuador and the rest of the world. Since preferences are homothetic and technology has constant returns in our empirical model, the magnitude of such transfers affects neither our estimates of Ecuador's relative factor demand nor our counterfactual
} 


\section{Figure 5: Trade and Earnings Inequality, Baseline Sample}

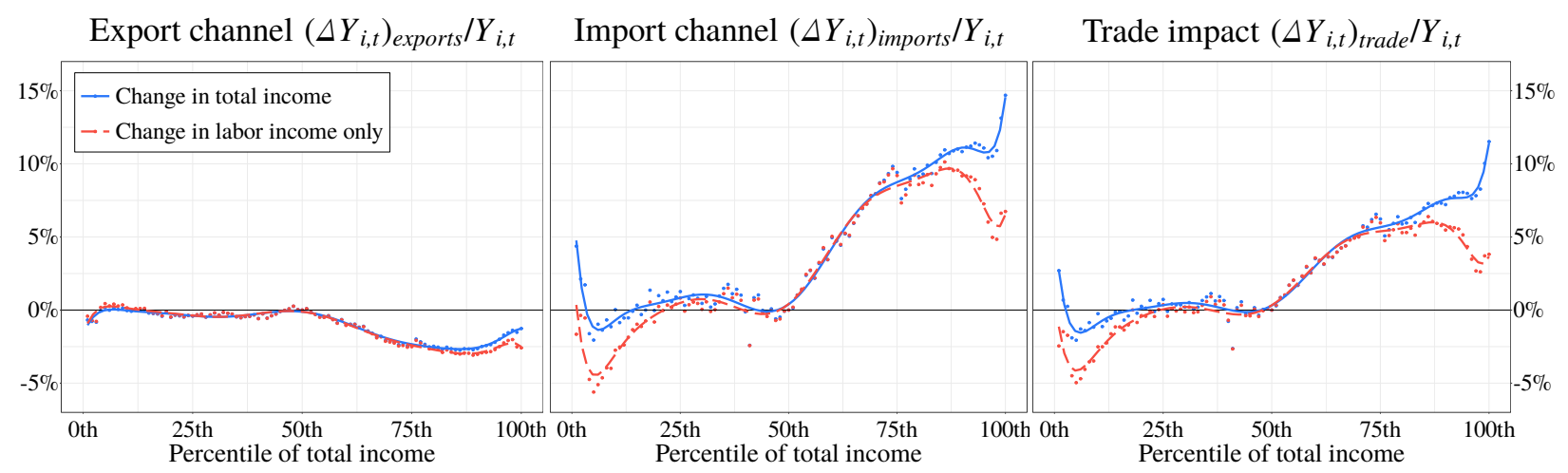

Notes: Blue dots correspond to the total (including both labor and capital) income change for each individual, averaged within each percentile and normalized to zero at the median percentile, between 2012 and the counterfactual autarkic equilibrium. Positive numbers therefore reflect larger gains from trade than at the median. Red dots do the same but for labor income only. In both cases the line indicates a fitted $10^{\text {th }}$-order polynomial. Trade impact is the sum of the export and import channels.

begin with the total (i.e. labor plus capital) gains from trade that individuals experience (the solid blue line). There is a clear tendency here for the export channel (left panel) to decrease inequality, especially in the upper-half of the income distribution, since exportchannel gains from trade are smaller for the rich than they are for the middle-class. By contrast, the import channel (middle panel) is broadly increasing throughout the income distribution, leading to higher inequality. The incidence of both channels on earnings inequality are very much in line with the pro-poor and anti-poor biases, respectively, of the export and import exposure measures displayed in Figures 3 and $4 .{ }^{38}$ The existence of these opposing forces means that, in the case of Ecuador, an empirical analysis that might focus on only one of these two channels would miss an important part of the distributional consequences of international trade.

The right-hand panel of Figure 5 combines the offsetting export and import channels. Evidently, it is the individuals in the top of Ecuador's income distribution who gain dis-

factor prices. The same is true for remittances from Ecuadorian migrants abroad.

${ }^{37}$ Appendix A.7.2 contains further details about the algorithm for calculating counterfactual factor price changes and Appendix A.7.3 does the same for changes in individual earnings.

${ }^{38}$ To explore systematically the connection between the exposure measures presented in Section 4 and the full impact of trade computed in this section, one can estimate the following linear regression

$$
\frac{\left(\Delta Y_{i, t}\right)_{\text {trade }}}{Y_{i, t}}=\beta+\beta^{E} E E_{i, t}+\beta^{I} I E_{i, t}+\eta_{i}
$$

where $E E_{i, t}$ and $I E_{i, t}$ are given by the expressions in (10) and (12). The results are reported in Table C.3 of Appendix C.6. We find that our exposure measures explain most of the variation in the full changes in earnings predicted by the full model, with a total $R^{2}$ of around 0.9 . 
proportionately more from trade since the import channel is larger in magnitude. Despite these offsetting effects, the magnitude of the net impact can be substantial. In the top half of the income distribution, our estimates imply income gains from trade that are $7 \%$ larger for individuals at the 90th percentile, compared to those at the median percentile, and $12 \%$ larger for those at the top percentile

Figure 5 also shows the distinction between total (in solid blue) and labor-only (in dashed red) earnings, which highlights the role played by inequalities in capital ownership. A substantial contribution to differences in gains from trade derives from the strong import channel that benefits the capitalists who are among Ecuador's richest individuals. By contrast, the return to highest-income labor is not particularly helped by trade.

\subsection{Sensitivity of Baseline Results to Inclusion of Informal Sector}

Our analysis so far has considered the impact of trade on inequality within Ecuador's formal sector-the firms and employees who appear in administrative tax, social security and ownership records. The impact of trade on inequality in Ecuador as a whole may be different, however, to the extent that the distribution and composition of earnings in the formal sector does not represent well that of the overall economy which also includes individuals in the informal sector.

In order to examine this possibility, we augment our original administrative dataset with a large survey (from 2011-12) that was designed to measure respondents' earnings from all of their activities, both formal and informal. Appendix B.4 describes the survey data in detail. It allows us to infer the share of earnings associated with the informal sector for individuals at different percentiles of the earnings distribution, as well as the industry and factor group associated with the source of the informal income of each individual. Compared to formal workers, we do not observe the specific firms making these informal payments. To fill this gap, we introduce, for each sector $k$, a representative informal firm that combines domestic factors in the same CES fashion as formal firms in the model of Section 3, does not purchase either domestic or foreign inputs, and sells only to final consumers. ${ }^{39}$ We then solve for counterfactual factor price changes under the assumption that formal and informal workers are perfect substitutes within each factor group, consistent with the treatment of informality in Meghir et al. (2015) and Ulyssea (2018). This assumption implies that, while we allow for arbitrary differences in the earnings of

\footnotetext{
${ }^{39}$ Formally, we assume that the production function of each sector's representative informal firm $n$ is given by $q_{n}=\varphi_{n}\left(\sum_{f \in \mathcal{F}} \theta_{f n}^{1 / \eta} l_{f n}^{(\eta-1) / \eta}\right)^{\eta /(\eta-1)}$, with $\eta$ set to 2.09 , the baseline value for formal firms, and the shifters $\varphi_{n}$ and $\theta_{f n}$ identified in the exact same way as we did for formal firms in Appendix A.7.1.
} 
Figure 6: Trade and Earnings Inequality, Augmented Sample with Informal Sector

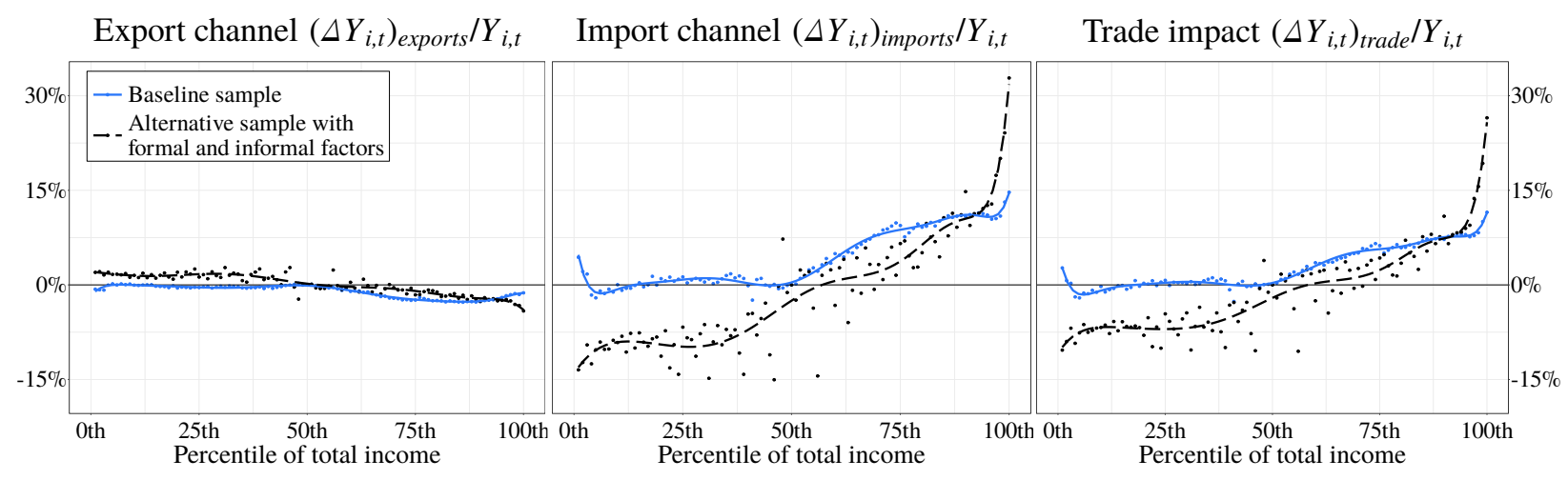

Notes: This figure reports the total income change for each individual, averaged within each percentile and normalized to zero at the median percentile, between 2012 and the counterfactual autarkic equilibrium. Positive numbers therefore reflect larger gains from trade than at the median. Blue dots correspond to income changes in our baseline sample based on the administrative dataset covering Ecuador's formal economy. Black dots report to the same variable when we account for the income of individuals that belong to Ecuador's informal economy. In both cases the line indicates a fitted $10^{\text {th }}$-order polynomial.

individuals employed in the formal and informal sectors, we impose that the impact of international trade shocks on the price of factor services is the same irrespective of the extent to which the factor is employed in the formal or informal sector.

The informal economy in Ecuador is large, with substantial differences in formalization rates across factors, as reported in Figures B.4 and B.5 of Appendix B.4. Figure 6, however, shows that the inclusion of informally-engaged individuals in our analysis (the black dashed line relative to the blue solid one) has little effect on our main qualitative conclusions: the export channel still benefits low-income individuals relative to highincome individuals, while the import channel does the opposite, and the overall impact of trade is pro-rich. The main impact of introducing an informal sector is quantitative. The export channel remains small, but the import channel is now significantly larger. As a result, the overall effect of trade on the 90th percentile relative to that on the 10th percentile is $18 \%$ rather than $8 \%$ in our baseline. The largest distinction is seen among top incomes, whose capital appears to benefit relatively more from the import channel once we introduce non-importing (but labor-intensive) informal firms. At the top percentile, individuals now experience gains from trade that are $27 \%$ larger than at the median.

\subsection{Trends in Earnings Inequality and Trade}

Up to now, we have focused on the difference between trade and autarky at a given point in time. We have concluded that international trade was a force towards greater 
Table 5: Changes in Earnings Inequality, 2009-2015

\begin{tabular}{lcc}
\hline & $\begin{array}{c}\text { Actual change } \\
\text { in open economy }\end{array}$ & $\begin{array}{c}\text { Counterfactual change } \\
\text { in closed economy }\end{array}$ \\
\hline$\Delta \ln (50-10$ income ratio) & -0.134 & -0.074 \\
$\Delta \ln (90-50$ income ratio) & -0.185 & -0.098 \\
$\Delta \ln (99-90$ income ratio) & -0.046 & -0.097 \\
\hline
\end{tabular}

Notes: All calculations are based on augmented sample with informal earnings included. "50-10 income ratio" (etc.) calculated from the ratio of the income of the 50th-percentile earner to that of the 10th-percentile earner, separately in each year and model scenario.

inequality, in the sense that the counterfactual distribution of earnings under autarky would be more equal than the actual distribution observed under trade. A distinct, but related, question is whether the trends in earnings inequality observed in Ecuador over time would have been different if the Ecuadorian economy had been subject to the same domestic shocks, but closed to international trade.

To address this question, it is sufficient to note that log-changes in factor prices between some initial period $t_{0}$ and any given date $t$ in the counterfactual autarkic equilibrium, $\ln \left(w_{f, t}\right)_{A}-\ln \left(w_{f, t_{0}}\right)_{A}$, can be expressed as

$$
\ln \left(w_{f, t}\right)_{A}-\ln \left(w_{f, t_{0}}\right)_{A}=\left[\ln w_{f, t}-\ln w_{f, t_{0}}\right]-\left[\left(\Delta \ln w_{t}\right)_{\text {trade }}-\left(\Delta \ln w_{t_{0}}\right)_{\text {trade }}\right] .
$$

We observe the first difference on the right-hand side directly in the data, whereas we can compute the second difference for each year (as we did for 2012 in Sections 7.1 and 7.2). Once counterfactual changes in factor prices $\ln \left(w_{f, t}\right)_{A}-\ln \left(w_{f, t_{0}}\right)_{A}$ have been obtained, changes in individual earnings can again be computed using information about the share of each factor $f$ owned by a given individual. We do this using the augmented sample with both formal and informal workers described in Appendix B.4.2.

Table 5 reports the changes in different ratios of percentiles of the distribution of earnings between 2009 and 2015, both under trade, i.e. as observed in our dataset over that time period, as well as in the counterfactual autarkic economy corresponding to each year. Except at the very top, we see that the decrease in inequality experienced by Ecuador would have been smaller in the absence of trade. This reflects the fact that although trade tends to increase inequality at all dates, it does so less and less in later years of our sample. Equivalently, this means that over the period Ecuador's economy was generating larger increases in gains from trade at the lower end of the income distribution. 


\section{Concluding remarks}

What is the overall impact of international trade on earnings inequality? Without the ability to observe a given economy both with and without access to global markets, answers to this question inherently draw on a combination of theory and empirics.

Inspired by the original factor content approach to trade and inequality, we have proposed to tackle this classical question as one of factor supply and factor demand. For any country, international trade amounts to a shock to the demand for its domestic factor services, either because foreign consumers and firms demand domestic factor services in different proportions than domestic consumers and firms do, an export channel, or because domestic consumers and firms change their demand for domestic factor services in response to the availability of foreign factor services, an import channel.

We have operationalized this decomposition through a novel structural relationship that relates domestic factor prices to two sufficient statistics of foreign shocks. It implies that individual-level exposure to exports and imports depends on the extent to which variation in these two statistics shifts the demand for their factor services. In the case of Ecuador, our measurements based on unique administrative data illustrate how export exposure is broadly pro-middle class, whereas import exposure is pro-rich.

We have then used this structural relationship to strengthen the credibility of our empirical model. Despite the parametric restrictions that we have imposed and the many real-word features of labor markets that we have abstracted from, we have shown that, within sample, our parsimonious model replicates well the observed response of domestic factor prices to our two sufficient statistics of foreign shocks.

Finally, we have used this structural relationship to conduct counterfactual analysis by taking the previous sufficient statistics to their autarkic limit values. In terms of incidence, the import channel is the dominant force linking trade to inequality in Ecuador, with gains from trade for individuals at the 90th percentile of the income distribution that are about $11 \%$ larger than the median-and up to $27 \%$ larger than the median for those at the top income percentile. However, our results also imply that the drop in inequality observed in Ecuador over the last decade would have been less pronounced in the absence of trade.

Needless to say, some of these conclusions may not carry over to other contexts. The fact that export exposure is more pronounced in the bottom half of Ecuador's income distribution, for instance, is more likely to hold in developing countries that, like Ecuador, specialize in low-skill-intensive goods, than in developed countries that do not. We hope, however, that the new factor content approach developed in this paper can prove useful in evaluating the overall impact of trade on inequality in other contexts as well. 


\section{References}

Acemoglu, Daron and David Autor, Skills, Tasks, and Technologies: Implications for Employment and Earnings, Vol. 4 of Handbook of Labor Economics, Elsevier, 2011.

Adao, Rodrigo, Arnaud Costinot, and Dave Donaldson, "Nonparametric Counterfactual Predictions in Neoclassical Models of International Trade," American Economic Review, 2017, 107 (3), 633-689.

_, Costas Arkolakis, and Federico Esposito, "General equilibrium effects in space: Theory and measurement," 2020. Working paper.

_ , Michal Kolesar, and Eduardo Morales, "Shift-Share Designs: Theory and Inference," The Quarterly Journal of Economics, 2019, 134 (4), 1949-2010.

Aghion, Philippe, Antonin Bergeaud, Matthieu Lequien, and Marc J Melitz, "The heterogeneous impact of market size on innovation: evidence from French firm-level exports," Technical Report, National Bureau of Economic Research 2018.

Amiti, Mary, Oleg Itskhoki, and Jozef Konings, "International shocks and domestic prices: how large are strategic complementarities?," Technical Report, National Bureau of Economic Research 2016.

Antras, Pol, Alonso de Gotari, and Oleg Itskhoki, "Globalization, Inequality and Welfare," Journal of International Economics, 2017, 108, 387-412.

_ , Teresa C. Fort, and Felix Tintelnot, "The Margins of Global Sourcing: Theory and Evidence from U.S. Firms," American Economic Review, 2017, 107 (9), 2514-64.

Artuc, E., S. Chaudhuri, and John McLaren, "Trade Shocks and Labor Adjustment: A Structural Empirical Approach," American Economic Review, 2010, 100 (3), 1008-1045.

Atalay, Enghin, "How Important Are Sectoral Shocks?," American Economic Journal: Macroeconomics, 2017, 9 (4), 254-280.

Atkin, David, Benjamin Faber, and Marco Gonzalez-Navarro, "Retail Globalization and Household Welfare: Evidence from Mexico," Journal of Political Economy, 2018, 126 (1), 1-73.

Attanasio, Orazio, Pinelopi Goldberg, and Nina Pavcnik, "Trade Reforms and Wage Inequality in Colombia," Journal of Development Economics, 2004, 74 (2), 331-366.

Autor, David, David Dorn, and Gordon Hanson, "The China syndrome: Local labor market effects of import competition in the United States," American Economic Review, 2013, 103, 21212168. 
_ , _ , _ , and Jae Song, "Trade Adjustment: Worker-Level Evidence," Quarterly Journal of Economics, 2014, 129 (4), 1799-1860.

Bartelme, Dominick, Arnaud Costinot, Dave Donaldson, and Andres Rodríguez-Clare, "The Textbook Case for Industrial Policy: Theory Meets Data," 2019. NBER Working Paper 26193.

Bernard, Andrew B. and J. Bradford Jensen, "Exceptional Exporter Performance: Cause, Effect, or Both," Journal of International Economics, 1999, 47, 1-25.

_ , Emmanuel Dhyne, Glenn Magerman, Kalina Manova, and Andreas Moxnes, "The Origins of Firm Heterogeneity: A Production Network Approach," 2019. NBER Working Paper 25441.

_, Stephen J. Redding, and Peter Schott, "Comparative Advantage and Heterogeneous Firms," Review of Economic Studies, 2007, 74 (1), 31-66.

Bernard, Andrew, Bradford Jensen, Steve Redding, and Peter J. Schott, "FIrms in International Trade," Journal of Economic Perspectives, 2007, 21 (3), 105-130.

Blaum, Joaquin, Claire Lelarge, and Michael Peters, "The Gains from Input Trade with Heterogeneous Importers," American Economic Journal: Macroeconomics, 2018, 10 (4), 77-127.

Boehm, Christoph E., Aaron Flaaen, and Nitya Pandalai-Nayar, "Input Linkages and the Transmission of Shocks: Firm-Level Evidence from the 2011 Tohoku Earthquake," Review of Economics and Statistics, 2019, 101 (1), 60-75.

Borjas, George J., Richard B. Freeman, and Lawrence F. Katz, On the labor market effects of immigration and trade, Vol. Immigration and the work force, University of Chicago Press and NBER, 1992.

_ , _ , and _ , "How much do immigration and trade affect labor market outcomes?," Brookings Papers on Economic Activity, 1997, 1, 1-90.

Borusyak, Kirill and Xavier Jaravel, "The Distributional Effects of Trade: Theory and Evidence from the United States," mimeo UCL, 2018.

_ , Peter Hull, and Xavier Jaravel, "Quasi-experimental shift-share research designs," Review of Economic Studies, 2021. Forthcoming.

Bowen, Harry P., Edward E. Leamer, and Leo Sveikauskas, “Multicountry, Multifactor Tests of the Factor Abundance Theory," American Economic Review, 1987, 77 (5), 791-809.

Burstein, Ariel and Jonathan Vogel, "International Trade, Technology, and the Skill Premium," Journal of Political Economy, 2017, 125 (5), 1356-1412. 
— , Javier Cravino, and Jonathan Vogel, "Importing Skill-Biased Technology," American Economic Journal: Macroeconomics, 2013, 5 (2), 32-71.

Costinot, Arnaud and Andres Rodríguez-Clare, "Trade Theory with Numbers: Quantifying the Consequences of Globalization," in Gita Gopinath, Elhanan Helpman, and Kenneth Rogoff, eds., Handbook of International Economics, Vol. 4, New York: Elsevier, 2014.

- and Dave Donaldson, "Ricardo's Theory of Comparative Advantage: Old Idea, New Evidence," American Economic Review, Papers and Proceedings, 2012, 102 (3), 453-458.

— and Ivan Werning, "Lerner Symmetry: A Modern Treatment," American Economic Review: Insights, 2019, 1 (1), 13-26.

- and Jonathan Vogel, "Matching and Inequality in the World Economy," Journal of Political Economy, 2010, 118 (4), 747-786.

Davis, Donald R. and David Weinstein, "An Account of Global Factor Trade," American Economic Review, 2001, 91 (5), 1423-1453.

Deardorff, Alan, "Factor Prices and the Factor Content of Trade Revisited: What's the Use?," Journal of International Economics, 2000, 50 (1), 73-90.

- and Robert Staiger, "An Interpretation of the Factor Content of Trade," Journal of International Economics, 1988, 24 (1), 93-107.

Demir, Banu, Ana Cecilia Fieler, Daniel Yi Xu, and Kelly Kaili Yang, "O-Ring Production Networks," 2020. Mimeo Bilkent University.

Dhyne, Emmanuel, Ayumu Ken Kikkawa, Magne Mogstad, and Felix Tintelnot, "Trade and Domestic Production Networks," Review of Economic Studies, 2021. Forthcoming.

Dix-Carneiro, Rafael and Brian K Kovak, "Trade Liberalization and Regional Dynamics," American Economic Review, 2017, 107 (10), 2908-46.

Faber, Benjamin and Thibault Fally, "Firm Heterogeneity in Consumption Baskets: Evidence from Home and Store Scanner Data," Review of Economic Studies, 2021. Forthcoming.

Fajgelbaum, Pablo and Amit Khandelwal, "Measuring the Unequal Gains from Trade," Quarterly Journal of Economics, 2016, 131, 1113-1180.

_, Gene M. Grossman, and Elhanan Helpman, "Income Distribution, Product Quality, and International Trade," Journal of Political Economy, 2011, 119 (4), 721 - 765.

Feenstra, Robert C., Offshoring in the global economy: microeconomic structure and macroeconomic implications, MIT Press, 2010. 
Fieler, Ana Cecilia, Marcela Eslava, and Daniel Yi Xu, “Trade, Quality Upgrading, and Input Linkages: Theory and Evidence from Colombia," American Economic Review, 2018, 108 (1), 109146.

Galle, Simon, Andres Rodríguez-Clare, and Moises Yi, "Slicing the Pie: Quantifying the Aggregate and Distributional Effects of Trade," 2017. NBER Working Paper 23737.

Goldberg, Penny and Nina Pavcnik, "Distributional Effects of Globalization in Developing Countries," Journal of Economics Literature, 2007, 45, 39-82.

Grossman, Gene M. and Esteban Rossi-Hansberg, "Trading Tasks: A Simple Theory of Offshoring," American Economic Review, 2008, 98 (5), 1978-1997.

_ , Elhanan Helpman, and Philipp Kircher, "Matching, Sorting, and the Distributional Effects of International Trade," Journal of Political Economy, 2017, 125 (1), 224-264.

Hanson, Gordon and Ann Harrison, "Trade Liberalization and Wage Inequality in Mexico," Industrial and Labor Relations Review, 1999, 52 (2), 271-288.

Harrigan, James and Ariell Reshef, "Skill-biased heterogeneous firms, trade liberalization and the skill premium," Canadian Journal of Economics, 2016, 48 (3), 1024-1066.

Harrison, Ann, John McLaren, and Margaret McMillan, "Recent Perspectives on Trade and Inequality," Annual Review of Economics, 2011, 3, 261-289.

Helpman, E., O. Itskhoki, and S. Redding, "Inequality and Unemployment in a Global Economy," Econometrica, 2010, 78 (4), 1239-1283.

Helpman, Elhanan, Globalization and Inequality, Harvard University Press, 2018.

Hottman, Colin, Steve Redding, and David Weinstein, "Quantifying the Sources of Firm Heterogeneity," Quarterly Journal of Economics, 2016, 131 (3), 1291-1364.

Hummels, David, Jakob R Munch, and Chong Xiang, "Offshoring and Labor Markets," Journal of Economic Literature, 2018, 56 (3), 981-1028.

_ , Rasmus Jørgensen, Jakob Munch, and Chong Xiang, “The Wage Effects of Offshoring: Evidence from Danish Matched Worker-Firm Data," American Economic Review, 2014, 104 (6), 15971629.

Huneeus, Federico, "Production Network Dynamics and the Propagation of Shocks," 2018. Mimeo Central Bank of Chile.

Katz, Lawrence and Kevin Murphy, “Changes in Relative Wages, 1963-1987: Supply and Demand Factors," Quarterly Journal of Economics, 1992, 107 (1), 35-78. 
Kovak, Brian K., "Regional Effects of Trade Reform: What Is the Correct Measure of Liberalization?," American Economic Review, 2013, 103 (5), 1960-76.

Krugman, Paul, “Technology, trade and factor prices," Journal of International Economics, 2000, 50, $51-71$.

Krusell, Per, Lee Ohanian, Jose-Victor Rios-Rull, and Giovanni Violante, "Capital-skill Complementarity and Inequality: A Macroeconomic Analysis," Econometrica, 2000, 68 (5), 1029-1053.

Leamer, Edward E., "What's the use of factor contents?," Journal of International Economics, 2000, $50,17-49$.

Leontief, Wassily, "Domestic production and foreign trade; the American capital position reexamined," Proceedings of the American Philosophical Society, 1953, pp. 332-349.

Matsuyama, Kiminori, “Beyond Icebergs: Towards a Theory of Biased Globalization," Review of Economic Studies, 2007, 74 (1), 237-253.

Meghir, Costas, Renata Narita, and Jean-Marc Robin, "Wages and Informality in Developing Countries," American Economic Review, 2015, 105 (4), 1509-1546.

Melitz, Marc J., "The Impact of Trade on Intra-Industry Reallocations and Aggregate Industry Productivity," Econometrica, 2003, 71 (6), 1695-1725.

Muendler, Marc-Andreas, "Trade, Technology, and Prosperity: An Account of Evidence from a Labor-market Perspective," 2017. WTO Staff Working Paper ERSD-2017-15.

Murphy, Kevin M. and Finis Welch, "The Role of International Trade in Wage Differentials," in M. Kosters, ed., Workers and their Wages, American Enterprise Institute, Washington DC, 1991.

Oberfield, Ezra and Devesh Raval, "Micro Data and Macro Technology," Econometrica, 2021. Forthcoming.

Ohnsorge, Franziska and Daniel Trefler, "Sorting It Out: International Trade with Heterogeneous Workers," Journal of Political Economy, 2007, 115 (5), 868-892.

Pavcnik, Nina, "The Impact of Trade on Inequality in Developing Countries," in "Proceedings of Jackson Hole Economic Symposium" 2017, pp. 61-114.

Pierce, Justin R. and Peter K. Schott, “The Surprisingly Swift Decline of US Manufacturing Employment," American Economic Review, 2016, 106 (7), 1632-62.

Piketty, Thomas and Emmanuel Saez, "Income Inequality in the United States, 1913-1998," Quarterly Journal of Economics, 2003, 118 (1), 1-39. 
_ , _ , and Gabriel Zucman, “Distributional National Accounts: Methods and Estimates for The United States," Quarterly Journal of Economics, 2018, 133 (2), 553-609.

Porto, Guido, "Using Survey Data to Assess the Distributional Effects of Trade Policy," Journal of International Economics, 2006, 70 (1), 140-160.

Sampson, Thomas, "Selection into Trade and Wage Inequality," American Economic Journal: Microeconomics, 2014, 6 (3), 157-202.

Smith, Matthew, Danny Yagan, Owen Zidar, and Eric Zwick, "Capitalists in the Twenty-First Century," Quarterly Journal of Economics, 2019, 134 (4), 1675-1745.

Stolper, Wolfgang F. and Paul A. Samuelson, "Protection and Real Wages," Review of Economic Studies, 1941, 9 (1), 58-73.

Trefler, Daniel, “International Factor Price Differences: Leontief Was Right!,” Journal of Political Economy, 1993, 101 (6), 961-987.

_ , "The Case of the Missing Trade and Other Mysteries," American Economic Review, 1995, 85 (5), 1029-46.

Ulyssea, Gabriel, "Firms, Informality, and Development: Theory and Evidence from Brazil," American Economic Review, 2018, 108 (8), 2015-2047.

Verhoogen, Eric, "Trade, Quality Upgrading and Wage Inequality in the Mexican Manufacturing Sector," Quarterly Journal of Economics, 2008, 123 (2), 489-530.

Wood, Adrian, North-South trade, employment, and inequality: Changing fortunes in a skill-driven world, Oxford University Press, 1995.

— , "Better-behaved Heckscher-Ohlin models through more consistent treatment of trade costs," 2012. QEH Working Paper No. 185.

Yeaple, Stephen Ross, “A Simple Model of Firm Heterogeneity, International Trade, and Wages," Journal of International Economics, January 2005, 65 (1), 1-20. 


\section{A Theoretical Appendix}

\section{A.1 Factor Market Equilibrium Under Perfect Competition}

The goal of this appendix is to describe how to go from primitive assumptions about preferences, technology, and market structure to the representation of the factor market equilibrium in terms of relative factor demand, relative export exposure, and relative factor supply given in Proposition 1. For expositional purposes, we start with the case of perfect competition in both goods and factor markets. We then move on to the case of perfect competition in factor markets, but imperfect competition in good markets in Section A.2.1. ${ }^{40}$

\section{A.1.1 Decentralized Equilibrium}

Consumers. Consumers are indexed by $i$. They live at Home, $i \in \mathcal{I}$, or in Foreign, $i \in \mathcal{I}^{*}$. They own local factors of production, $f \in \mathcal{F}$ or $f \in \mathcal{F}^{*}$, as well as shares of local firms, $n \in \mathcal{N}$ or $n \in \mathcal{N}^{*}$. Regardless of where they live, individuals consume goods produced by domestic firms, $g \in \mathcal{G}$, as well as goods produced by foreign firms, $g \in \mathcal{G}^{*}$.

Consumers living at Home choose their vector of consumption $c_{i} \equiv\left\{c_{g i}\right\}_{g \in \mathcal{G} \cup \mathcal{G}^{*}}$ in order to maximize their utility subject to budget constraint,

$$
\max _{c_{i}}\left\{u\left(c_{i} ; i\right) \mid \sum_{g \in \mathcal{G} \cup \mathcal{G}^{*}} p_{g} c_{g i}=\sum_{f \in \mathcal{F}} w_{f} \bar{l}_{f i}+\sum_{n \in \mathcal{N}} \pi_{n}\left(p, p^{*}, w\right) \vartheta_{n i}\right\}
$$

where $p \equiv\left\{p_{g}\right\}_{g \in \mathcal{G} \cup \mathcal{G}^{*}}$ is the vector of local good prices, $w \equiv\left\{w_{f}\right\}_{f \in \mathcal{F}}$ is the vector of local factor prices, $\bar{l}_{i} \equiv\left\{\bar{l}_{f i}\right\}_{f \in \mathcal{F}}$ is consumer $i$ 's vector of factor endowments, $\pi\left(p, p^{*}, w\right) \equiv\left\{\pi_{n}\left(p, p^{*}, w\right)\right\}_{n \in \mathcal{N}}$ is the vector of domestic firms' profits, to be described below, and $\vartheta_{i} \equiv\left\{\vartheta_{n i}\right\}_{n \in \mathcal{N}}$ are consumer $i^{\prime}$ s vector of domestic and foreign firms' shares. We let $\mathcal{C}\left(p, p^{*}, w ; i\right)$ denote the set of solutions to the utility maximization problem of consumer $i \in \mathcal{I}$.

Consumers living in Foreign face a similar problem. They choose their consumption $c_{i} \equiv$ $\left\{c_{g i}\right\}_{g \in \mathcal{G} \cup \mathcal{G}^{*}}$ taking local good prices $p^{*} \equiv\left\{p_{g}^{*}\right\}_{g \in \mathcal{G} \cup \mathcal{G}^{*}}$, local factor prices $w^{*} \equiv\left\{w_{f}\right\}_{f \in \mathcal{F}^{*} \text {, and the }}$ profits of foreign firms $\pi^{*}\left(p, p^{*}, w^{*}\right) \equiv\left\{\pi_{n}^{*}\left(p, p^{*}, w^{*}\right)\right\}_{n \in \mathcal{N}}$ as given. We let $\mathcal{C}^{*}\left(p, p^{*}, w^{*} ; i\right)$ denote the set of solutions to the utility maximization problem of consumer $i \in \mathcal{I}^{*}$.

Firms. Domestic firms $n \in \mathcal{N}$ produce at Home. They choose their vectors of output for Home consumers and firms, $y_{n} \equiv\left\{y_{g n}\right\}_{g \in \mathcal{G}}$, their vector of output for Foreign consumers and firms, $y_{n}^{*} \equiv\left\{y_{g n}^{*}\right\}_{g \in \mathcal{G}}$, their vector of intermediate inputs $m_{n} \equiv\left\{m_{g n}\right\}_{g \in \mathcal{G} \cup \mathcal{G}^{*}}$, and their vector of local

\footnotetext{
${ }^{40}$ For notational convenience, we ignore taxes and transfers, though those can be accommodated as well. Trade imbalances between countries, in particular, can be introduced as lump-sum transfers that enter households' budget constraints without further consequences for our analysis.
} 
factors $l_{n} \equiv\left\{l_{f n}\right\}_{f \in \mathcal{F}}$ in order to maximize their profits,

$$
\pi_{n}\left(p, p^{*}, w\right)=\max _{y_{n}, y_{n}^{*}, m_{n}, l_{n} \in \Omega_{n}} \sum_{g \in \mathcal{G}} p_{g} y_{g n}+\sum_{g \in \mathcal{G}} p_{g}^{*} y_{g n}^{*}-\sum_{g \in \mathcal{G} \cup \mathcal{G}^{*}} p_{g} m_{g n}-\sum_{f \in \mathcal{F}} w_{f} l_{f n}
$$

where $\Omega_{n}$ is firm $n^{\prime}$ s production set. We let $\mathcal{Z}\left(p, p^{*}, w ; n\right)$ denote the set of solutions to the profit maximization problem of firm $n \in \mathcal{N}$.

Foreign firms $n \in \mathcal{N}^{*}$ face a similar problem. They choose their output for Home and Foreign,

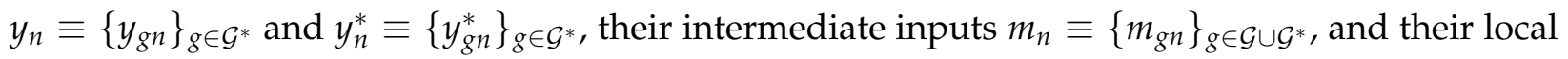
factors $l_{n} \equiv\left\{l_{f n}\right\}_{f \in \mathcal{F}^{*}}$ in order to maximize their profits $\pi_{n}^{*}\left(p, p^{*}, w^{*}\right)$ taking prices, $p, p^{*}$, and $w^{*}$, as given. We let $\mathcal{Z}^{*}\left(p, p^{*}, w^{*} ; n\right)$ denote the set of solutions to the profit maximization problem of firm $n \in \mathcal{N}^{*}$.

Market clearing. Goods and factor markets clear,

$$
\begin{aligned}
\sum_{n \in \mathcal{N}} y_{g n} & =\sum_{n \in \mathcal{N}} m_{g n}+\sum_{i \in \mathcal{I}} c_{g i}, \text { for all } g \in \mathcal{G}, \\
\sum_{n \in \mathcal{N}} y_{g n}^{*} & =\sum_{n \in \mathcal{N}^{*}} m_{g n}+\sum_{i \in \mathcal{I}^{*}} c_{g i}, \text { for all } g \in \mathcal{G}, \\
\sum_{n \in \mathcal{N}^{*}} y_{g n} & =\sum_{n \in \mathcal{N}} m_{g n}+\sum_{i \in \mathcal{I}} c_{g i} \text {, for all } g \in \mathcal{G}^{*}, \\
\sum_{n \in \mathcal{N}^{*}} y_{g n}^{*} & =\sum_{n \in \mathcal{N}^{*}} m_{g n}+\sum_{i \in \mathcal{I}^{*}} c_{g i}, \text { for all } g \in \mathcal{G}^{*}, \\
\sum_{n \in \mathcal{N}^{*}} l_{f n} & =\sum_{i \in \mathcal{I}_{f i}} \bar{l}_{f i} \text { for all } f \in \mathcal{F}, \\
\sum_{n \in \mathcal{N}^{*}} l_{f n} & =\sum_{i \in \mathcal{I}^{*}} \bar{l}_{f i}, \text { for all } f \in \mathcal{F}^{*} .
\end{aligned}
$$

Definition. An equilibrium with perfect competition in goods and factor markets corresponds to an allocation $\left(\left\{c_{i}\right\}_{i \in \mathcal{I} \cup \mathcal{I}^{*}},\left\{y_{n}, y_{n}^{*}, m_{n}, l_{n}\right\}_{n \in \mathcal{N} \cup \mathcal{N}^{*}}\right)$ and prices $\left(p, p^{*}, w, w^{*}\right)$ such that: $(i) c_{i} \in$ $\mathcal{C}\left(p, p^{*}, w ; i\right)$ if $i \in \mathcal{I}$ and $c_{i} \in \mathcal{C}^{*}\left(p, p^{*}, w^{*} ; i\right)$ if $i \in \mathcal{I}^{*} ;(i i)\left(y_{n}, y_{n}^{*}, m_{n}, l_{n}\right) \in \mathcal{Z}\left(p, p^{*}, w ; n\right)$ if $n \in \mathcal{N}$ and $\left(y_{n}, y_{n}^{*}, m_{n}, l_{n}\right) \in \mathcal{Z}^{*}\left(p, p^{*}, w^{*} ; n\right)$ if $n \in \mathcal{N}^{*}$; (iii) good markets clear, conditions (A.3)-(A.6); and (iv) factor markets clear, conditions (A.7)-(A.8).

\section{A.1.2 Factor Market Equilibrium}

For any vector of factor prices $\left(w, w^{*}\right)$, we define world factor demand as

$$
\begin{aligned}
& \mathcal{L}^{W}\left(w, w^{*}\right) \equiv\left\{\left\{L_{f}\right\}_{f \in \mathcal{F} \cup \mathcal{F}^{*}} \mid \exists\left(\left\{c_{i}\right\}_{i \in \mathcal{I} \cup \mathcal{I}^{*}},\left\{y_{n}, y_{n}^{*}, m_{n}, l_{n}\right\}_{n \in \mathcal{N} \cup \mathcal{N}^{*}}, p, p^{*}\right)\right. \text { such that } \\
&\left.\sum_{n \in \mathcal{N}} l_{f n}=L_{f} \text { for all } f \in \mathcal{F}, \sum_{n \in \mathcal{N}^{*}} l_{f n}=L_{f} \text { for all } f \in \mathcal{F}^{*} \text {, and conditions }(i) \text {-(iii) hold }\right\} .
\end{aligned}
$$


We let $\bar{L}_{f} \equiv \sum_{i \in \mathcal{I}} \bar{l}_{f i}$ denote the aggregate supply of any domestic factor $f \in \mathcal{F}$ and let $\bar{L}_{f} \equiv$ $\sum_{i \in \mathcal{I}^{*}} \bar{l}_{f i}$ denote the aggregate supply of any foreign factor $f \in \mathcal{F}^{*}$. Given our definition of a decentralized equilibrium, $\left(w_{T}, w_{T}^{*}\right)$ is an equilibrium vector of factor prices if and only if

$$
\bar{L} \in \mathcal{L}^{W}\left(w_{T}, w_{T}^{*}\right)
$$

where $\bar{L} \equiv\left\{\bar{L}_{f}\right\}_{f \in \mathcal{F} \cup \mathcal{F}^{*}}$ is the vector of world factor supply. In the special case where world factor demand is a function rather than a correspondence, $\mathcal{L}^{W}\left(w, w^{*}\right)=\left\{L^{W}\left(w, w^{*}\right)\right\}$, the previous condition simplifies to

$$
L^{W}\left(w_{T}, w_{T}^{*}\right)=\bar{L}_{f} \text { for all } f \in \mathcal{F} \cup \mathcal{F}^{*},
$$

as described in equation (1).

\section{A.1.3 Decomposition into Domestic and Foreign Factor Demand}

For any element $L^{W}\left(w, w^{*}\right) \in \mathcal{L}^{W}\left(w, w^{*}\right)$ and any associated allocation, $\left\{c_{i}\left(w, w^{*}\right)\right\}_{i \in \mathcal{I} \cup \mathcal{I}^{*}}$ and $\left\{y_{n}\left(w, w^{*}\right), y_{n}^{*}\left(w, w^{*}\right), m_{n}\left(w, w^{*}\right), l_{n}\left(w, w^{*}\right)\right\}_{n \in \mathcal{N} \cup \mathcal{N}^{*}}$, and good prices, $p\left(w, w^{*}\right)$ and $p^{*}\left(w, w^{*}\right)$, we can express the revenues associated with the production of each good within each firm as

$$
R_{g n}\left(w, w^{*}\right)=p_{g}\left(w, w^{*}\right) y_{g n}\left(w, w^{*}\right)+p_{g}^{*}\left(w, w^{*}\right) y_{g n}^{*}\left(w, w^{*}\right) \text { for all } g \in \mathcal{G} \cup \mathcal{G}^{*} \text { and } n \in \mathcal{N} \cup \mathcal{N}^{*},
$$

The share of a firm's revenue associated with each good is then given by

$$
r_{g n}\left(w, w^{*}\right)= \begin{cases}R_{g n}\left(w, w^{*}\right) / \sum_{l \in \mathcal{G}} R_{l n}\left(w, w^{*}\right) & \text { for all } n \in \mathcal{N} \text { and } g \in \mathcal{G}, \\ R_{g n}\left(w, w^{*}\right) / \sum_{l \in \mathcal{G}^{*}} R_{g^{\prime} n}\left(w, w^{*}\right) & \text { for all } n \in \mathcal{N}^{*} \text { and } g \in \mathcal{G}^{*} .\end{cases}
$$

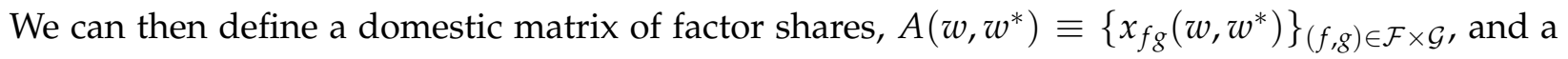
foreign matrix of factor shares, $A^{*}\left(w, w^{*}\right) \equiv\left\{x_{f g}\left(w, w^{*}\right)\right\}(f, g) \in \mathcal{F}^{*} \times \mathcal{G}^{*}$, with

$$
x_{f g}\left(w, w^{*}\right)= \begin{cases}\frac{\sum_{n \in \mathcal{N}} r_{g n}\left(w, w^{*}\right) w_{f} l_{f n}\left(w, w^{*}\right)}{\sum_{n \in \mathcal{N}} R_{g n}\left(w, w^{*}\right)} & \text { for all } f \in \mathcal{F} \text { and } g \in \mathcal{G}, \\ \frac{\sum_{n \in \mathcal{N}^{*}} r_{g n}\left(w, w^{*}\right) w_{f}^{*} l * k}{\sum_{n \in \mathcal{N}^{*}} R_{g n}\left(w, w, w^{*}\right)} & \text { for all } f \in \mathcal{F}^{*} \text { and } g \in \mathcal{G}^{*}\end{cases}
$$

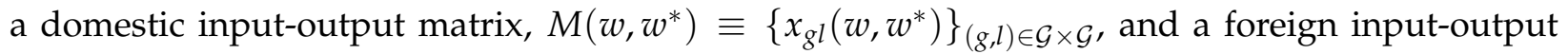
matrix, $M^{*}\left(w, w^{*}\right) \equiv\left\{x_{g l}\left(w, w^{*}\right)\right\}_{(g, l) \in \mathcal{G}^{*} \times \mathcal{G}^{*}}$, with

$$
x_{g l}\left(w, w^{*}\right)= \begin{cases}\frac{\sum_{n \in \mathcal{N}} r_{l n}\left(w, w^{*}\right) p_{g}\left(w, w^{*}\right) m_{g n}\left(w, w^{*}\right)}{\sum_{n \in \mathcal{N}^{*}} R_{\ln }\left(w, w^{*}\right)} & \text { for all } g, l \in \mathcal{G}, \\ \frac{\sum_{n \in \mathcal{N}^{*}} r_{l n}\left(w, w^{*}\right) p_{g}^{*}\left(w, w^{*}\right) m_{g n}\left(w, w^{*}\right)}{\sum_{n \in \mathcal{N}^{*}} R_{l n}\left(w, w^{*}\right)} & \text { for all } g, l \in \mathcal{G}^{*}\end{cases}
$$


a domestic vector of consumer expenditures on domestic goods, $D\left(w, w^{*}\right) \equiv\left\{D_{g}\left(w, w^{*}\right)\right\}_{g \in \mathcal{G}}$, and a foreign vector of consumer expenditures on foreign goods, $D^{*}\left(w, w^{*}\right) \equiv\left\{D_{g}^{*}\left(w, w^{*}\right)\right\}_{g \in \mathcal{G}^{*}}$, with

$$
\begin{aligned}
& D_{g}\left(w, w^{*}\right)=\sum_{i \in \mathcal{I}} p_{g}\left(w, w^{*}\right) c_{g i}\left(w, w^{*}\right), \text { for all } g \in \mathcal{G}, \\
& D_{g}^{*}\left(w, w^{*}\right)=\sum_{i \in \mathcal{I}^{*}} p_{g}^{*}\left(w, w^{*}\right) c_{g i}\left(w, w^{*}\right), \text { for all } g \in \mathcal{G}^{*} ;
\end{aligned}
$$

and a domestic vector of exports, $E\left(w, w^{*}\right) \equiv\left\{E_{g}\left(w, w^{*}\right)\right\}_{g \in \mathcal{G}}$, and a foreign vector of exports, $E^{*}\left(w, w^{*}\right) \equiv\left\{E_{g}^{*}\left(w, w^{*}\right)\right\}_{g \in \mathcal{G}^{*}}$, with

$$
\begin{aligned}
& E_{g}\left(w, w^{*}\right)=\sum_{i \in \mathcal{I}^{*}} p_{g}^{*}\left(w, w^{*}\right) c_{g i}\left(w, w^{*}\right)+\sum_{n \in \mathcal{N}^{*}} p_{g}^{*}\left(w, w^{*}\right) m_{g n}\left(w, w^{*}\right), \text { for all } g \in \mathcal{G}, \\
& E_{g}^{*}\left(w, w^{*}\right)=\sum_{i \in \mathcal{I}} p_{g}\left(w, w^{*}\right) c_{g i}\left(w, w^{*}\right)+\sum_{n \in \mathcal{N}} p_{g}\left(w, w^{*}\right) m_{g n}\left(w, w^{*}\right), \text { for all } g \in \mathcal{G}^{*}
\end{aligned}
$$

We can then express the value of domestic demand for domestic factors, $\left\{w_{f} L_{f}\left(w, w^{*}\right)\right\}_{f \in \mathcal{F}}$, and the value of foreign demand for domestic factors, $\left\{w_{f} L_{f}^{*}\left(w, w^{*}\right)\right\}_{f \in \mathcal{F}}$, as

$$
\begin{aligned}
& \left\{w_{f} L_{f}\left(w, w^{*}\right)\right\}_{f \in \mathcal{F}}=A\left(w, w^{*}\right) B\left(w, w^{*}\right) D\left(w, w^{*}\right), \\
& \left\{w_{f} L_{f}^{*}\left(w, w^{*}\right)\right\}_{f \in \mathcal{F}}=A\left(w, w^{*}\right) B\left(w, w^{*}\right) E\left(w, w^{*}\right),
\end{aligned}
$$

where $B\left(w, w^{*}\right) \equiv\left(I-M\left(w, w^{*}\right)\right)^{-1}$ is the Leontief inverse associated with the domestic inputoutput matrix, $M\left(w, w^{*}\right)$. By construction, we have

$$
\begin{aligned}
\left\{w_{f} L_{f}\left(w, w^{*}\right)+w_{f} L_{f}^{*}\left(w, w^{*}\right)\right\}_{f \in \mathcal{F}} & \\
=A\left(w, w^{*}\right) B\left(w, w^{*}\right)[ & \left.D\left(w, w^{*}\right)+E\left(w, w^{*}\right)\right] \\
& =\left\{w_{f} L_{f}^{W}\left(w, w^{*}\right)\right\}_{f \in \mathcal{F}}
\end{aligned}
$$

where the second equality uses the good market clearing conditions (A.3) and (A.4).

Likewise, we can express the value of domestic demand for foreign factors $\left\{w_{f}^{*} L_{f}\left(w, w^{*}\right)\right\}_{f \in \mathcal{F}^{*}}$ and the value of foreign demand for foreign factors $\left\{w_{f}^{*} L_{f}^{*}\left(w, w^{*}\right)\right\}_{f \in \mathcal{F}^{*}}$ as

$$
\begin{aligned}
& \left\{w_{f}^{*} L_{f}\left(w, w^{*}\right)\right\}_{f \in \mathcal{F}^{*}}=A^{*}\left(w, w^{*}\right) B\left(w, w^{*}\right) E^{*}\left(w, w^{*}\right) \\
& \left\{w_{f}^{*} L_{f}^{*}\left(w, w^{*}\right)\right\}_{f \in \mathcal{F}^{*}}=A^{*}\left(w, w^{*}\right) B^{*}\left(w, w^{*}\right) D^{*}\left(w, w^{*}\right) .
\end{aligned}
$$

where $B^{*}\left(w, w^{*}\right) \equiv\left(I-M^{*}\left(w, w^{*}\right)\right)^{-1}$ is the Leontief inverse associated with the domestic input- 
output matrix, respectively. By construction, it again satisfies

$$
\begin{aligned}
\left\{w_{f}^{*} L_{f}\left(w, w^{*}\right)+w_{f}^{*} L_{f}^{*}\left(w, w^{*}\right)\right\}_{f \in \mathcal{F}^{*}} & \\
=A^{*}\left(w, w^{*}\right) B^{*}\left(w, w^{*}\right) & {\left[D^{*}\left(w, w^{*}\right)+E^{*}\left(w, w^{*}\right)\right] } \\
& =\left\{w_{f} L_{f}^{W}\left(w, w^{*}\right)\right\}_{f \in \mathcal{F}^{*}}
\end{aligned}
$$

where the second equality uses the good market clearing conditions (A.5) and (A.6).

Using equations (A.9) and (A.10), we can rearrange equation (1) as

$$
L_{f}\left(w_{T}, w_{T}^{*}\right)+L_{f}^{*}\left(w_{T}, w_{T}^{*}\right)=\bar{L}_{f} \text { for all } f \in \mathcal{F} \cup \mathcal{F}^{*}
$$

Letting $R D_{f}\left(w, w^{*}\right) \equiv L_{f}\left(w, w^{*}\right) / L_{0}\left(w, w^{*}\right), E E_{f, T} \equiv L_{f}^{*}\left(w_{T}, w_{T}^{*}\right) / L_{f}^{W}\left(w_{T}, w_{T}^{*}\right), R E E_{f, T} \equiv(1-$ $\left.E E_{0, T}\right) /\left(1-E E_{f, T}\right)$, and $R S_{f} \equiv \bar{L}_{f} / \bar{L}_{0}$, we obtain

$$
R D_{f}\left(w_{T}, w_{T}^{*}\right) R E E_{f, T}=R S_{f} \text { for all } f \in \mathcal{F}, f \neq 0
$$

as described in Proposition 1.

\section{A.2 Factor Market Equilibrium Under Imperfect Competition}

\section{A.2.1 Decentralized Equilibrium}

We now describe the decentralized equilibrium with perfect competition in factor markets, but imperfect competition in goods markets. We follow the same strategy as in Costinot and Werning (2019). The utility maximization problem of consumers and the market clearing conditions are the same as in Section A.1. The profit maximization problem of firms, however, now takes into account the fact that while firms still take wages as given, they no longer face perfectly elastic residual demand curves for both final and intermediate goods.

Firms. For a given vector of wages $w$, each firm $n \in \mathcal{N} \cup \mathcal{N}^{*}$ chooses a correspondence $\sigma_{n} \in \Sigma_{n}$ that describes the set of quantities $\left(y_{n}, y_{n}^{*}, m_{n}, l_{n}\right)$ that it is willing to supply and demand at every price vector $\left(p, p^{*}\right)$. The feasible set $\Sigma(n)$ includes both the technological constraints faced by firm $n$ as well as the constraints on the way it may compete, e.g. firm $n$ may only choose one quantity for all prices, as in the case of Cournot competition, or one price for all quantities, as in the case of Bertrand competition.

For each strategy profile $\sigma \equiv\left\{\sigma_{n}\right\}_{n \in \mathcal{N} \cup \mathcal{N}^{*}}$, an auctioneer selects a price vector $\left(p(\sigma), p^{*}(\sigma)\right)$ 
and an allocation $\left(\left\{c_{i}(\sigma)\right\}_{i \in \mathcal{I} \cup \mathcal{I}^{*}},\left\{y_{n}(\sigma), y_{n}^{*}(\sigma), m_{n}(\sigma), l_{n}(\sigma)\right\}_{\mathcal{N} \cup \mathcal{N}^{*}}\right)$ such that:

$$
\begin{aligned}
& c_{i}(\sigma) \in \mathcal{C}\left(p(\sigma), p^{*}(\sigma), w ; i\right) \text { for all } i \in \mathcal{I} ; \\
& c_{i}(\sigma) \in \mathcal{C}^{*}\left(p(\sigma), p^{*}(\sigma), w^{*} ; i\right) \text { for all } i \in \mathcal{I}^{*} ; \\
& \sum_{n \in \mathcal{N}} y_{g n}(\sigma)=\sum_{n \in \mathcal{N}} m_{g n}(\sigma)+\sum_{i \in \mathcal{I}} c_{i}(\sigma) \text { for all } g \in \mathcal{G} ; \\
& \sum_{n \in \mathcal{N}} y_{g n}^{*}(\sigma)=\sum_{n \in \mathcal{N}^{*}} m_{g n}(\sigma)+\sum_{i \in \mathcal{I}^{*}} c_{i}(\sigma) \text { for all } g \in \mathcal{G} ; \\
& \sum_{n \in \mathcal{N}^{*}} y_{g n}(\sigma)=\sum_{n \in \mathcal{N}} m_{g n}(\sigma)+\sum_{i \in \mathcal{I}} c_{i}(\sigma) \text { for all } g \in \mathcal{G}^{*} ; \\
& \sum_{n \in \mathcal{N}^{*}} y_{g n}^{*}(\sigma)=\sum_{n \in \mathcal{N}^{*}} m_{g n}(\sigma)+\sum_{i \in \mathcal{I}^{*}} c_{i}(\sigma) \text { for all } g \in \mathcal{G}^{*} .
\end{aligned}
$$

Each firm $n \in \mathcal{N}$ then solves

$$
\max _{\sigma_{n} \in \Sigma_{n}} \sum_{g \in \mathcal{G}} p_{g} y_{g n}(\sigma)+\sum_{g \in \mathcal{G}} p_{g}^{*} y_{g n}^{*}(\sigma)-\sum_{g \in \mathcal{G} \cup \mathcal{G}^{*}} p_{g} m_{g n}(\sigma)-\sum_{f \in \mathcal{F}} w_{f} l_{n}(\sigma)
$$

taking the strategies of other firms $\left\{\sigma_{n^{\prime}}\right\}_{n^{\prime} \in \mathcal{N} \cup \mathcal{N}^{*}, n^{\prime} \neq n}$ as given, while each firm $n \in \mathcal{N}^{*}$ solves

$$
\max _{\sigma_{n} \in \Sigma_{n}} \sum_{g \in \mathcal{G}^{*}} p_{g} y_{g n}(\sigma)+\sum_{g \in \mathcal{G}^{*}} p_{g}^{*} y_{g n}^{*}(\sigma)-\sum_{g \in \mathcal{G} \cup \mathcal{G}^{*}} p_{g} m_{g n}(\sigma)-\sum_{f \in \mathcal{F}} w_{f}^{*} l_{f n}(\sigma),
$$

taking the strategies of other firms $\left\{\sigma_{n^{\prime}}\right\}_{n^{\prime} \in \mathcal{N} \cup \mathcal{N}^{*}, n^{\prime} \neq n}$ as given. We let $\Sigma^{e q}\left(w, w^{*}\right)$ denote the set of Nash equilibria of this game.

Definition. An equilibrium with perfect competition in factor markets and imperfect competition in good markets corresponds to an allocation $\left(\left\{c_{i}\right\}_{i \in \mathcal{I} \cup \mathcal{I}^{*}},\left\{y_{n}, y_{n}^{*}, m_{n}, l_{n}\right\}_{n \in \mathcal{N} \cup \mathcal{N}^{*}}\right)$ and prices $\left(p, p^{*}, w, w^{*}\right)$ such that: (i) firms play a Nash Equilibrium $\sigma^{e q} \in \Sigma^{e q}\left(w, w^{*}\right) ;(i i) c_{i}=c_{i}\left(\sigma^{e q}\right)$ for all $i \in \mathcal{I} \cup \mathcal{I}^{*} ;(i i i)\left(y_{n}, y_{n}^{*}, m_{n}, l_{n}\right)=\left(y_{n}\left(\sigma^{e q}\right), y_{n}^{*}\left(\sigma^{e q}\right), m_{n}\left(\sigma^{e q}\right), l_{n}\left(\sigma^{e q}\right)\right)$ for all $n \in \mathcal{N} \cup \mathcal{N}^{*} ;(i v)$ $\left(p, p^{*}\right)=\left(p\left(\sigma^{e q}\right), p^{*}\left(\sigma^{e q}\right)\right)$; and $(v)$ factor markets clear, conditions (A.7)-(A.8).

\section{A.2.2 Factor Market Equilibrium}

For any vector of factor prices $\left(w, w^{*}\right)$, we define world factor demand as

$$
\begin{aligned}
\mathcal{L}^{W}\left(w, w^{*}\right) \equiv\{ & \left\{L_{f}\right\}_{f \in \mathcal{F} \cup \mathcal{F}^{*}} \mid \exists\left(\left\{c_{i}\right\}_{i \in \mathcal{I} \cup \mathcal{I}^{*}},\left\{y_{n}, y_{n}^{*}, m_{n}, l_{n}\right\}_{n \in \mathcal{N} \cup \mathcal{N}^{*}}, p, p^{*}\right) \text { such that } \\
& \left.\sum_{n \in \mathcal{N}} l_{f n}=L_{f} \text { for all } f \in \mathcal{F}, \sum_{n \in \mathcal{N}^{*}} l_{f n}=L_{f} \text { for all } f \in \mathcal{F}^{*} \text {, and conditions }(i)-(i v) \text { hold }\right\} .
\end{aligned}
$$

Like in the case of perfect competition in the goods markets, $\left(w_{T}, w_{T}^{*}\right)$ is an equilibrium vector of factor prices if and only if

$$
\bar{L} \in \mathcal{L}^{W}\left(w_{T}, w_{T}^{*}\right)
$$


If world factor demand is a function rather than a correspondence, $\mathcal{L}^{W}\left(w, w^{*}\right)=\left\{L^{W}\left(w, w^{*}\right)\right\}$, the previous condition can be rearranged as equation (1).

\section{A.2.3 Decomposition into Domestic and Factor Demand}

For any element $L^{W}\left(w, w^{*}\right) \in \mathcal{L}^{W}\left(w, w^{*}\right)$, we can define domestic and foreign factor demand, $L\left(w, w^{*}\right)$ and $L^{*}\left(w, w^{*}\right)$, as we did in Section A.1. Substituting into equation (1) and rearranging, we again obtain equation (2), as described in Proposition 1.

\section{A.3 Proof of Proposition 2}

For any value of $w^{*} \equiv\left\{w_{f}^{*}\right\}_{f \in \mathcal{F}^{*}} \geq 0$ and $R E E \equiv\left\{\left(1-E E_{0}\right) /\left(1-E E_{f}\right)\right\}_{f \in \mathcal{F}}$, consider the vector of domestic factor prices $w \equiv\left\{w_{f}\right\}_{f \in \mathcal{F}} \geq 0$ that solves

$$
R D_{f}\left(w, w^{*}\right) R E E_{f}=R S_{f} \text { for all } f \in \mathcal{F}, f \neq 0 .
$$

Under the assumption $\ln R D$ is continuously differentiable with respect to $\left(w, w^{*}\right)$ and that the ma$\operatorname{trix} \partial \ln R D / \partial \ln w \equiv\left\{\partial \ln R D_{f} / \partial \ln w_{g}\right\}_{(f, g) \in \mathcal{F} \times \mathcal{F}}$ is invertible for all $\left(w, w^{*}\right)$, the Implicit Function Theorem implies the existence of a unique function $\tilde{w}\left(R E E, w^{*}\right)$ such that

$$
R D_{f}\left(\tilde{w}\left(R E E, w^{*}\right), w^{*}\right) R E E_{f}=R S_{f} \text { for all } f \in \mathcal{F}, f \neq 0 .
$$

Moreover, $\frac{\partial \ln \tilde{w}}{\partial \ln R E E} \equiv\left\{\partial \ln \tilde{w}_{f} / \partial \ln R E E_{g}\right\}_{(f, g) \in \mathcal{F} \times \mathcal{F}}$ and $\frac{\partial \ln \tilde{w}}{\partial \ln w^{*}} \equiv\left\{\partial \ln \tilde{w}_{f} / \partial \ln w_{g}^{*}\right\}_{(f, g) \in \mathcal{F} \times \mathcal{F} * \text { satisfy }}$

$$
\begin{aligned}
\frac{\partial \ln \tilde{w}}{\partial \ln R E E} & =-\left[\frac{\partial \ln R D}{\partial \ln w}\right]^{-1}, \\
\frac{\partial \ln \tilde{w}}{\partial \ln w^{*}} & =-\left[\frac{\partial \ln R D}{\partial \ln w}\right]^{-1} \frac{\partial \ln R D}{\partial \ln w^{*}}
\end{aligned}
$$

where $\frac{\partial \ln R D}{\partial \ln w_{f}^{*}} \equiv\left\{\partial \ln R D_{f} / \partial \ln w_{g}^{*}\right\}_{(f, g) \in \mathcal{F} \times \mathcal{F}^{*}}$. In the trade and autarkic equilibria, we know that

$$
\begin{array}{r}
R D_{f}\left(w_{T}, w_{T}^{*}\right) \times R E E_{f, T}=R S_{f}, \\
R D_{f}\left(w_{A}, \infty\right) \times 1=R S_{f} .
\end{array}
$$

Let $u \equiv\left\{\ln R E E_{f}\right\}_{f \in \mathcal{F}}$ and $v \equiv\left\{\ln w_{f}^{*}\right\}_{f \in \mathcal{F}^{*}}$. Integrating equations (A.11) and (A.12) between $(u=0, v=\infty)$ and $\left(u=\ln R E E_{T}, v=\ln w_{T}^{*}\right)$, we obtain

$$
\ln w_{T}-\ln w_{A}=-\int_{(u=0, v=\infty)}^{\left(u=\ln R E E_{T}, v=\ln w_{T}^{*}\right)}\left(\left[\frac{\partial \ln R D}{\partial \ln w}\right]^{-1} d u+\left[\frac{\partial \ln R D}{\partial \ln w}\right]^{-1} \frac{\partial \ln R D}{\partial \ln w^{*}} d v\right) .
$$


This can be rearranged as $(\Delta \ln w)_{\text {trade }}=(\Delta \ln w)_{\text {exports }}+(\Delta \ln w)_{\text {imports }}$ with

$$
\begin{aligned}
& (\Delta \ln w)_{\text {exports }}=-\int_{\left(u=0, v=\ln w_{T}^{*}\right)}^{\left(u=\ln R E E_{T}, v=\ln w_{T}^{*}\right)}\left[\frac{\partial \ln R D}{\partial \ln w}\right]^{-1} d v, \\
& (\Delta \ln w)_{\text {imports }}=-\int_{(u=0, v=\infty)}^{\left(u=0, v=\ln w_{T}^{*}\right)}\left[\frac{\partial \ln R D}{\partial \ln w}\right]^{-1}\left[\frac{\partial \ln R D}{\partial \ln w^{*}}\right] d u .
\end{aligned}
$$

\section{A.4 Proof of Proposition 3}

In Section 3.2, we have already established that

$$
\begin{aligned}
R D_{f}\left(w, w^{*}\right) & =\left(\frac{w_{f}}{w_{0}}\right)^{-\eta} \frac{\sum_{m \in \mathcal{N}} \theta_{f m} Z_{m}\left(w, w^{*}\right)}{\sum_{m \in \mathcal{N}} \theta_{0 m} Z_{m}\left(w, w^{*}\right)} \\
Z_{m}\left(w, w^{*}\right) & =\beta_{m}\left(w_{n}^{D}(w)\right)^{\eta-1} \sum_{k} \sum_{r \in \mathcal{N}_{k}} b_{m r}\left(\frac{p_{r}\left(w, w^{*}\right)}{P_{k}\left(w, w^{*}\right)}\right)^{1-\sigma} \alpha_{k} \theta_{r c} .
\end{aligned}
$$

Differentiating the two previous expressions with respect to $w_{n}^{*}$ we get

$$
\begin{aligned}
\frac{\partial \ln R D_{f}}{\partial \ln w_{n}^{*}} & =\sum_{m \in \mathcal{N}}\left(r_{f m}-r_{0 m}\right) \frac{\partial \ln Z_{m}\left(w, w^{*}\right)}{\partial \ln w_{n}^{*}} \\
\frac{\partial \ln Z_{m}\left(w, w^{*}\right)}{\partial \ln w_{n}^{*}} & =\sum_{k} \sum_{r \in \mathcal{N}_{k}} z_{m r}(1-\sigma)\left(\frac{\partial \ln p_{r}\left(w, w^{*}\right)}{\partial \ln w_{n}^{*}}-\frac{\partial \ln P_{k}\left(w, w^{*}\right)}{\partial \ln w_{n}^{*}}\right)
\end{aligned}
$$

with the shares $r_{f m}$ and $z_{m r}$ given by

$$
\begin{aligned}
& r_{f m} \equiv \frac{\theta_{f m} Z_{m}\left(w, w^{*}\right)}{\sum_{n \in \mathcal{N}} \theta_{f n} Z_{n}\left(w, w^{*}\right)}=\frac{x_{f m}\left(\sum_{k} \sum_{r \in \mathcal{N}_{k}} b_{m r} D_{r}\right)}{\sum_{n \in \mathcal{N}} x_{f n}\left(\sum_{k} \sum_{r \in \mathcal{N}_{k}} b_{n r} D_{r}\right)} \\
& z_{m r} \equiv \frac{b_{m r}\left(w, w^{*}\right)\left(\frac{p_{r}\left(w, w^{*}\right)}{P_{k}\left(w, w^{*}\right)}\right)^{1-\sigma} \alpha_{k} \theta_{r c}}{\sum_{k} \sum_{n \in \mathcal{N}_{k}} b_{m n}\left(w, w^{*}\right)\left(\frac{p_{n}\left(w, w^{*}\right)}{P_{k}\left(w, w^{*}\right)}\right)^{1-\sigma} \alpha_{k} \theta_{n c}}=\frac{b_{m r} D_{r}}{\sum_{k} \sum_{n \in \mathcal{N}_{k}} b_{m n} D_{n}} .
\end{aligned}
$$

We know that

$$
\begin{aligned}
& p_{r}\left(w, w^{*}\right)=\phi_{r}\left(\sum_{f \in \mathcal{F}} \theta_{f r} w_{f}^{1-\eta}\right)^{\frac{\beta_{r}}{1-\eta}}\left(\left(\prod_{m \in \mathcal{N}}\left(p_{m}\left(w, w^{*}\right)\right)^{\theta_{m r}}\right)^{\Theta_{r}}\left(w_{r}^{*}\right)^{1-\Theta_{r}}\right)^{1-\beta_{r}}, \\
& P_{k}\left(w, w^{*}\right)=\left(\sum_{n \in \mathcal{N}_{k}} \theta_{n c} p_{n}^{1-\sigma}\left(w, w^{*}\right)\right)^{\frac{1}{1-\sigma}} .
\end{aligned}
$$


Differentiating the two previous expressions with respect to $w_{n}^{*}$ we get

$$
\begin{aligned}
& \frac{\partial \ln p_{r}\left(w, w^{*}\right)}{\partial \ln w_{n}^{*}}=\sum_{m \in \mathcal{N}} x_{m r} \frac{\partial \ln p_{m}\left(w, w^{*}\right)}{\partial \ln w_{n}^{*}}+\mathbb{1}_{\{n=r\}} x_{n}^{*}, \\
& \frac{\partial \ln P_{k}\left(w, w^{*}\right)}{\partial \ln w_{n}^{*}}=\sum_{m \in \mathcal{N}_{k}} d_{m k} \frac{\partial \ln p_{m}\left(w, w^{*}\right)}{\partial \ln w_{n}^{*}} .
\end{aligned}
$$

In vector and matrix notation, we can rearrange equation (A.15) as

$$
\frac{\partial \ln p\left(w, w^{*}\right)}{\partial \ln w_{n}^{*}}=M^{\prime} \frac{\partial \ln p\left(w, w^{*}\right)}{\partial \ln w_{n}^{*}}+x_{n}^{*} I_{n}
$$

where $I_{n}$ denotes the column vector with entry one in row $n$ and zero in all other entries. This implies

$$
\frac{\partial \ln p\left(w, w^{*}\right)}{\partial \ln w_{n}^{*}}=x_{n}^{*}\left(I d-M^{\prime}\right)^{-1} I_{n} .
$$

Noting that $\left(I d-M^{\prime}\right)^{-1}=\left[(I d-M)^{-1}\right]^{\prime}$, we obtain

$$
\frac{\partial \ln p_{r}\left(w, w^{*}\right)}{\partial \ln w_{n}^{*}}=b_{n r} x_{n}^{*}
$$

Substituting into equation (A.16) further implies

$$
\frac{\partial \ln P_{k}\left(w, w^{*}\right)}{\partial \ln w_{n}^{*}}=\sum_{m \in \mathcal{N}_{k}} d_{m k} b_{n m} x_{n}^{*} .
$$

Proposition 3 directly follows from equations (A.13), (A.14), (A.17), and (A.18).

\section{A.5 Proof of Proposition 4}

The same algebra as in the proof of Proposition 3 now implies

$$
\begin{aligned}
\frac{\partial \ln R D_{f}}{\partial \ln w_{g}} & =-\eta \mathbb{1}_{g}(f)+\sum_{m \in \mathcal{N}}\left(r_{f m}-r_{0 m}\right) \frac{\partial \ln Z_{m}\left(w, w^{*}\right)}{\partial \ln w_{g}}, \\
\frac{\partial \ln Z_{m}\left(w, w^{*}\right)}{\partial \ln w_{g}} & =(\eta-1) \frac{x_{g m}}{\sum_{f \in \mathcal{F}} x_{f m}} \\
& +\sum_{k} \sum_{r \in \mathcal{N}_{k}} z_{m r}(1-\sigma)\left(\frac{\partial \ln p_{r}\left(w, w^{*}\right)}{\partial \ln w_{g}}-\frac{\partial \ln P_{k}\left(w, w^{*}\right)}{\partial \ln w_{g}}\right),
\end{aligned}
$$


as well as

$$
\begin{aligned}
& \frac{\partial \ln p_{r}\left(w, w^{*}\right)}{\partial \ln w_{g}}=\sum_{m \in \mathcal{N}} x_{m r} \frac{\partial \ln p_{m}\left(w, w^{*}\right)}{\partial \ln w_{g}}+x_{g r}, \\
& \frac{\partial \ln P_{k}\left(w, w^{*}\right)}{\partial \ln w_{g}}=\sum_{m \in \mathcal{N}_{k}} d_{m k} \frac{\partial \ln p_{m}\left(w, w^{*}\right)}{\partial \ln w_{g}} .
\end{aligned}
$$

In vector and matrix notation, the first of the two previous equations can now be rearranged as

$$
\frac{\partial \ln p\left(w, w^{*}\right)}{\partial \ln w_{g}}=\left(I d-M^{\prime}\right)^{-1} x_{g}
$$

with $x_{g} \equiv\left\{x_{g r}\right\}_{r \in \mathcal{N}}$, leading to

$$
\begin{aligned}
& \frac{\partial \ln p_{r}\left(w, w^{*}\right)}{\partial \ln w_{g}}=\sum_{n \in \mathcal{N}} b_{n r} x_{g n} \\
& \frac{\partial \ln P_{k}\left(w, w^{*}\right)}{\partial \ln w_{g}}=\sum_{m \in \mathcal{N}_{k}} d_{m k} \sum_{n \in \mathcal{N}} b_{n m} x_{g n} .
\end{aligned}
$$

Proposition 4 directly follows from equations (A.19), (A.20), (A.21), and (A.22).

\section{A.6 Derivation of Equation (17)}

Denote the CES factor price index of firm $r$ at date $t$ as $w_{r, t}^{D} \equiv\left[\sum_{f \in \mathcal{F}} \theta_{f r, t} w_{f, t}^{1-\eta}\right]^{\frac{1}{1-\eta}}$. For an arbitrary factor $f$, equation (13) implies

$$
\ln w_{r, t}^{D}=\ln w_{f, t}+\frac{1}{\eta-1} \ln x_{f r, t}^{D}+\frac{1}{1-\eta} \ln \theta_{f r, t} .
$$

Averaging the previous expression across factors and using firm $v^{\prime}$ s factor cost shares as weights, we get

$$
\ln w_{r, t}^{D}=\ln \tilde{w}_{r, t}^{D}+\xi_{r, t}
$$

with $\ln \tilde{w}_{r, t}^{D} \equiv \sum_{f \in \mathcal{F}} x_{f r, t}^{D}\left(\ln w_{f, t}+\frac{1}{\eta-1} \ln x_{f r, t}^{D}\right)$ and $\xi_{r, t} \equiv \frac{1}{1-\eta} \sum_{f \in \mathcal{F}} x_{f r, t}^{D} \ln \theta_{f r, t}$. Substituting for the $\log$ of the CES factor price index in equation (9) implies

$$
\ln p_{n, t}=\sum_{r \in \mathcal{N}} b_{r n, t}\left[\beta_{r, t} \ln \tilde{w}_{r, t}^{D}+x_{r, t}^{*} \ln w_{r, t}^{*}\right]+\rho_{n, t}
$$

with $\rho_{n, t} \equiv \sum_{r \in \mathcal{N}} b_{r n, t}\left(\xi_{r, t}+\ln \phi_{r, t}\right)$. 


\section{A.7 Counterfactual Analysis}

\section{A.7.1 Identification of Relative Domestic Factor Demand}

We set units of account for domestic goods so that all prices in at date $t$ are equal to one,

$$
p_{n, t}=1 \text { for all } n \in \mathcal{N} \text {. }
$$

We now show that under this normalization, relative factor demand is identified.

Building on the analysis of Section 3.2, we can rearrange relative factor demand as

$$
R D_{f, t}\left(w, w^{*}\right)=\frac{\sum_{n \in \mathcal{N}: X_{f n, t}>0} \frac{\beta_{n, t} \theta_{f n, t} w_{f}^{1-\eta}}{\sum_{g \in \mathcal{F}: X_{g n, t}>0} \theta_{g n, t} z w_{g}^{1-\eta}} \sum_{k} \sum_{r \in \mathcal{N}_{k}: D_{r, t}>0} b_{n r, t} \frac{\alpha_{k, t} \theta_{r c, t} p_{r, t}^{1-\sigma}\left(w, w^{*}\right)}{\sum_{m \in \mathcal{N}_{k}: D_{m, t}>0} \theta_{m c, t} p_{m, t}^{1-\sigma}\left(w, w^{*}\right)}}{\sum_{n \in \mathcal{N}: X_{0 n, t}>0} \frac{\beta_{n, t} \theta_{0 n, t} w_{0}^{1-\eta}}{\sum_{g \in \mathcal{F}: X_{g n, t}>0} \theta_{g n, t} w_{g}^{1-\eta}} \sum_{k} \sum_{r \in \mathcal{N}_{k}: D_{r, t}>0} b_{n r, t} \frac{\alpha_{k, t} \theta_{r, t} p_{r, t}^{1-\sigma}\left(w, w w^{*}\right)}{\sum_{m \in \mathcal{N}_{k}: D_{m, t}>0} \theta_{m c, t} p_{m, t}^{1-\sigma}\left(w, w^{*}\right)}},
$$

where $p_{n, t}\left(w, w^{*}\right)$ is given by (9),

$$
\ln p_{n, t}\left(w, w^{*}\right)=\sum_{r \in \mathcal{N}} b_{r n, t}\left(\ln \phi_{r, t}+\frac{\beta_{r, t}}{1-\eta} \ln \left(\sum_{f \in \mathcal{F}: X_{f r, t>0}} \theta_{f r, t} w_{f}^{1-\eta}\right)+x_{r, t}^{*} \ln w_{r, t}^{*}\right),
$$

and $b_{n r, t}$ is an element of the Leontief inverse associated with $M_{t} \equiv\left\{x_{n r, t}\right\}_{(n, r) \in \mathcal{N} \times \mathcal{N}}$.

By equation (6), we know that $\left\{x_{n r, t}\right\}_{(n, r) \in \mathcal{N} \times \mathcal{N}}$ and hence $\left\{b_{n r, t}\right\}_{(n, r) \in \mathcal{N} \times \mathcal{N}}$ are independent of $\left(w, w^{*}\right)$. We have already discussed the identification of $\left\{\beta_{n, t}\right\}_{n \in \mathcal{N}}$ and $\left\{\alpha_{k, t}\right\}_{k \in \mathcal{K}}$ in Section 4.1. We have also shown how to identify $\eta$ and $\sigma$ using instrumental variables in Section 5 . To show that $R D_{f}(\cdot, \cdot)$ is identified for all $f \in \mathcal{F}$, it remains to show that: $(i) \theta_{m c, t} / \theta_{r c, t}$ is identified for all $k \in \mathcal{K}, m, r \in \mathcal{N}_{k}$ such that $D_{m, t}, D_{r, t}>0 ;(i i) \theta_{g n, t} / \theta_{f n, t}$ is identified for all $n \in \mathcal{N}, g, f \in \mathcal{F}$ such that $X_{g n, t}, X_{f n, t}>0$; and (iii) $\phi_{r, t}$ is identified for all $r \in \mathcal{N}$. Under (A.24), equation (4) implies

$$
\frac{\theta_{m c, t}}{\theta_{r c, t}}=\frac{D_{m, t}}{D_{r, t}} \text { for all } k \in \mathcal{K}, m, r \in \mathcal{N}_{k} \text { s.t. } D_{m, t}, D_{r, t}>0
$$

Equation (5) implies

$$
\frac{\theta_{g n, t}}{\theta_{f n, t}}=\frac{x_{g n, t}}{x_{f n, t}}\left(\frac{w_{g}}{w_{f}}\right)^{\eta-1} \text { for all } n \in \mathcal{N}, f \in \mathcal{F} \text { s.t. } X_{g n, t}, X_{f n, t}>0
$$

Finally, under (A.24), equation (A.26) implies

$$
\phi_{r, t}=\frac{1}{\left(\sum_{f \in \mathcal{F}: X_{f r, t>0}} \theta_{f r, t} w_{f}^{1-\eta}\right)^{\frac{\beta_{r, t}}{1-\eta}}\left(w_{r, t}^{*}\right)^{x_{r, t}^{*}}} \text { for all } r \in \mathcal{N}
$$

At this point, we have established that conditions $(i)-($ iii $)$ hold. Thus, $\left\{p_{n, t}(\cdot, \cdot)\right\}_{n \in \mathcal{N}}$ is identified 
by (9) and, in turn, $\left\{R D_{f, t}(\cdot, \cdot)\right\}_{f \in \mathcal{F}}$ is identified by(A.25).

\section{A.7.2 Algorithm}

In this appendix, we describe how we compute the log changes in domestic factor prices $\Delta \ln w$ associated with an arbitrary counterfactual change from $\left(w^{*}=w_{t}^{*}, R E E=R E E_{t}\right)$ to $\left(w^{*}=\right.$ $\left.\left(w^{*}\right)^{\prime}, R E E=R E E^{\prime}\right) . \quad(\Delta \ln w)_{\text {autarky }}$ corresponds to the special case $\left(\left(w^{*}\right)^{\prime}=\infty, R E E^{\prime}=1\right)$, whereas $(\Delta \ln w)_{\text {exports }}$ corresponds to the special case $\left(\left(w^{*}\right)^{\prime}=w_{t_{0}}^{*}, R E E=1\right)$.

Our algorithm constructs discretized versions of the integrals in Proposition 2. Consider a sequence $j=0, \ldots, J$ of foreign prices $w_{(j)}^{*}$ such that

$$
\ln w_{n,(j)}^{*}-\ln w_{n,(j-1)}^{*}=\frac{1}{1-\sigma} \frac{\ln \left(w_{n, J}^{*}\right)^{1-\sigma}-\ln \left(w_{n, t_{0}}^{*}\right)^{1-\sigma}}{J} \text { for all } n \in \mathcal{N} \text { and } j \geq 1 \text {, }
$$

and relative export exposures $R E E_{(j)}$ such that

$$
\ln R E E_{f,(j)}-\ln R E E_{f,(j-1)}=\frac{\ln R E E_{f, J}-\ln R E E_{f, t_{0}}}{J} \text { for all } f \in \mathcal{F} \text { and } j \geq 1 \text {. }
$$

By construction, $w_{(J)}^{*}=\left(w^{*}\right)^{\prime}$ and $R E E_{(J)}=R E E^{\prime}$. Below we let $\hat{w}_{(j)}^{*} \equiv\left\{\ln w_{n,(j)}^{*} / w_{n,(j-1)}^{*}\right\}_{n \in \mathcal{N}}$ and $R \hat{E} E_{(j)} \equiv\left\{\ln R E E_{f,(j)} / R E E_{f,(j-1)}\right\}_{f \in \mathcal{F}}$ denote the vector of foreign price and relative export exposure shock.

Without loss of generality, we set units of account for domestic factors and domestic goods so that the following initial conditions hold: $\ln w_{f,(0)}=0$ for all $f \in \mathcal{F} ; \ln p_{n,(0)}=0$ for all $n \in \mathcal{N}$; $x_{m n,(0)}=x_{m n, t}$ for all $m, n \in \mathcal{N} ; x_{f n,(0)}=x_{f n, t}$ for all $f \in \mathcal{F}$ and $n \in \mathcal{N} ; d_{n k,(0)}=d_{n k, t}$ for all $k \in \mathcal{K}$ and $n \in \mathcal{N}_{k}$; and $x_{n,(0)}^{*}=x_{n, t}^{*}$ for all $n \in \mathcal{N}$. At each step $j=1, \ldots, J$, given step- $(j-1)$ prices and expenditure shares, we then construct step- $(j)$ new equilibrium variables as follows:

i. New domestic factor prices $w_{(j)} \equiv\left\{w_{f,(j)}\right\}_{f \in \mathcal{F}}$ are such that

$$
\ln w_{(j)}=\ln w_{(j-1)}-\left[\frac{\partial \ln R D}{\partial \ln w}\right]_{(j-1)}^{-1}\left[R \hat{E} E_{(j)}+\left(\frac{\partial \ln R D}{\partial \ln w^{*}}\right)_{(j-1)} \hat{w}_{(j)}^{*}\right],
$$

with $(\partial \ln R D / \partial \ln w)_{(j-1)}$ and $\left(\partial \ln R D / \partial \ln w^{*}\right)_{(j-1)}$ given by Propositions 3 and 4 and step$(j-1)$ expenditure shares;

ii. New domestic good prices $p_{(j)} \equiv\left\{p_{n,(j)}\right\}_{n \in \mathcal{N}}$ are such that

$$
\ln p_{n,(j)}=\sum_{r \in \mathcal{N}} b_{r n, t}\left(\ln \phi_{r, t}+\frac{\beta_{r, t}}{1-\eta} \ln \left(\sum_{f \in \mathcal{F}: X_{f r, t>0}} \theta_{f r, t} w_{f,(j)}^{1-\eta}\right)+x_{r, t}^{*} \ln w_{r,(j)}^{*}\right) ;
$$


iii. New expenditure shares are such that

$$
\begin{aligned}
& x_{f n,(j)}= \begin{cases}\frac{\beta_{n, t} \theta_{f n, t} w_{f,(j)}^{1-\eta}}{\sum_{g \in \mathcal{F}} \theta_{g n, t} w_{g,(j)}^{1-\eta}} & \text { for all } f \in \mathcal{F} \text { and } n \in \mathcal{N} \text { s.t. } X_{f n, t}>0, \\
0 & \text { otherwise; }\end{cases} \\
& d_{n k,(j)}= \begin{cases}\frac{\theta_{n c, t} t_{n,(j)}^{1-\sigma}}{\sum_{r \in \mathcal{N}_{k}} \theta_{r c, t} p_{r, j(j)}^{1-\sigma}} & \text { for all } k \in \mathcal{K} \text { and } n \in \mathcal{N}_{k} \text { s.t. } D_{n k, t}>0, \\
0 & \text { otherwise. }\end{cases}
\end{aligned}
$$

By construction, as $J$ goes to infinity, $\ln w_{(J)}-\ln w_{(0)}$ converges to $\Delta \ln w$.

\section{A.7.3 Individual Earnings}

Consider an individual $i$ with factor endowments $\bar{l}_{i} \equiv\left\{\bar{l}_{f i}\right\}_{f \in \mathcal{F}}$. In the initial equilibrium, individual $i^{\prime}$ s earnings are given by $Y_{i, t}=\sum_{f \in \mathcal{F}} \bar{l}_{f i} w_{f, t}$. In the counterfactual autarkic equilibrium, they are given by $\left(Y_{i, t}\right)_{A}=\sum_{f \in \mathcal{F}} \bar{l}_{f i}\left(w_{f, t}\right)_{A}$. We therefore have

$$
\frac{\left(\Delta Y_{i, t}\right)_{\text {trade }}}{Y_{i, t}}=1-\frac{\left(Y_{i, t}\right)_{A}}{Y_{i, t}}=1-\sum_{f} \frac{Y_{f i, t}}{Y_{i, t}} \frac{\left(w_{f, t}\right)_{A}}{w_{f, t}}=1-\sum_{f} \omega_{f i, t} \exp \left(-\left(\Delta \ln w_{f, t}\right)_{\text {trade }}\right),
$$

with $\omega_{f i, t} \equiv Y_{f i, t} / Y_{i, t}$.

Let $\left(\Delta Y_{i, t}\right)_{\text {exports }}=Y_{i, t}-\left(Y_{i, t}\right)_{N E}$ and $\left(\Delta Y_{i, t}\right)_{\text {imports }}=\left(Y_{i, t}\right)_{N E}-\left(Y_{i, t}\right)_{A}$ where $\left(Y_{i, t}\right)_{N E}$ are the counterfactual earnings associated with the counterfactual equilibrium without differences in relative export exposure, $\left(w^{*}=w_{t}^{*}, R E E=1\right)$. Similarly, we have

$$
\begin{aligned}
& \frac{\left(\Delta Y_{i, t}\right)_{\text {exports }}}{Y_{i, t}}=1-\frac{\left(Y_{i, t}\right)_{N E}}{Y_{i, t}}=1-\sum_{f} \frac{Y_{f i, t}}{Y_{i, t}} \frac{\left(w_{f, t}\right)_{N E}}{w_{f, t}}=1-\sum_{f} \omega_{f i, t} \exp \left(-\left(\Delta \ln w_{f, t}\right)_{\text {exports }}\right), \\
& \frac{\left(\Delta Y_{i, t}\right)_{\text {imports }}}{Y_{i, t}}=\frac{\left(Y_{i, t}\right)_{N E}}{Y_{i, t}}-\frac{\left(Y_{i, t}\right)_{A}}{Y_{i, t}}=\left[1-\sum_{f} \omega_{f i, t} \exp \left(-\left(\Delta \ln w_{f, t}\right)_{\text {imports }}\right)\right] \exp \left(-\left(\Delta \ln w_{f, t}\right)_{\text {exports }}\right) .
\end{aligned}
$$




\section{B Data Appendix}

In this appendix we provide further details about the data construction described in Section 4.1, as well as additional descriptive statistics not reported in the main text.

\section{B.1 Firm-level Data}

This section describes our methodology for constructing firm-level variables (available from 2009 to 2015). Our sample of firms $\mathcal{N}$ includes the full sample of firm IDs constructed from groups of tax IDs in the data that share the same ownership structure (in a particular sense described below). This set also considers a residual firm that we construct to create the accounting identities in our model. We consider the tax IDs that either file income tax forms or are named as the seller in the itemized VAT purchase annexes filed by entities filing income tax forms. All incorporated firms (and all branches of government and state-owned firms) file a detailed tax form (F101) and are required to submit monthly purchase annexes independent of their revenues and or costs. Unincorporated firms (largely self-employed individuals) file a simplified tax form (F102) if their annual revenue exceeds the standardized deduction $(\$ 10,000)$. They are obligated to keep accounting records and file monthly purchase annexes if they have yearly revenues greater than $\$ 100,000$, or yearly costs and expenses greater than $\$ 80,000$, or begin economic activities with a capital of at least $\$ 60,000{ }^{41}$ All other self-employed individuals (the vast majority) do not file purchase annexes.

\section{B.1.1 Transaction Data}

We use the information in the purchase annex to measure transactions between tax IDs. For each transaction, the data contains information on the tax ID of the buyer, the tax ID of the seller, the amount of the transaction, the VAT paid, whether the transaction was subject to a tax rate of $12 \%$ or $0 \%$, and the transaction's date. In each year, we compute the annual transactions between tax ID pairs based on the registered date. We only consider transactions that are not subject to future amendments. We manually exclude 40 transactions that are above 1 billion dollars and are more than three times larger than the total cost reported in the buyer's tax form since these appear to reflect data entry errors.

We implement three adjustments to the transaction data in order to minimize reporting errors. First, we drop monthly transactions whose values are more than $10 \%$ higher than the buyer's total annual cost as reported in its tax form. Second, we drop all transactions associated with tax IDs that do not file a tax form but do file a purchase annex. Third, we assume that sellers who appear in the purchase annex of other firms but who do not have a tax filing themselves must

\footnotetext{
${ }^{41}$ Many firms that fall below these thresholds do voluntarily file purchase annexes, but for such smaller firms (whose aggregate presence in the economy is limited, by nature) the records on intermediate purchases may be incomplete.
} 
have an annual revenue below the minimum filing threshold; we therefore exclude all transactions associated with non-tax filing sellers whose total transaction sales are above a threshold (which we set at $\$ 20,000$ to be conservative).

Table B.1 reports the number and value of the transactions dropped in each of these three steps (after excluding the transactions above one billion dollars). These steps retain approximately $85-90 \%$ of the (buyer-seller-year aggregated) transactions in each year, which corresponds to around $75 \%$ of the total transaction value in the original sample.

Table B.1: Summary Statistics, Transactions Data

\begin{tabular}{lccccccc}
\hline & 2009 & 2010 & 2011 & 2012 & 2013 & 2014 & 2015 \\
\hline Initial number of transactions & $8,677,539$ & $9,364,890$ & $8,613,648$ & $11,523,376$ & $13,082,687$ & $14,056,320$ & $13,639,626$ \\
Share deleted: & & & & & & & \\
$\quad$ due to criterion 1 & 0.032 & 0.023 & 0.018 & 0.038 & 0.030 & 0.029 & 0.034 \\
$\quad$ in addition, due to criterion 2 & 0.100 & 0.101 & 0.123 & 0.085 & 0.077 & 0.074 & 0.106 \\
$\quad$ in addition, due to criterion 3 & 0.009 & 0.008 & 0.030 & 0.006 & 0.008 & 0.008 & 0.014 \\
Share deleted due to 1, 2 or 3 & 0.141 & 0.132 & 0.171 & 0.129 & 0.115 & 0.111 & 0.155 \\
$\quad$ as share of total value & 0.229 & 0.229 & 0.302 & 0.282 & 0.265 & 0.251 & 0.256 \\
Valid transactions & $7,455,195$ & $8,128,498$ & $7,136,558$ & $10,034,442$ & $11,575,909$ & $12,502,489$ & $11,528,448$ \\
\hline
\end{tabular}

Notes: The reported number of transactions is that obtained after first summing up all transactions that occurred within each buyer-seller pair (separately by year).

\section{B.1.2 Grouping Tax IDs Into Firms}

We start by grouping corporate tax IDs into firms based on their ownership structure. This draws on a unique ownership annex that every incorporated firm must file, which reports the personal and corporate tax IDs of each owner of the filing tax ID, as well as their corresponding ownership shares of each owner. ${ }^{42}$ We merge a tax ID into a parent tax ID whenever the parent tax ID owns more than $50 \%$ of the tax ID's shares. For each firm group, we compute all financial variables by summing the values of the same variable across all tax IDs in the firm group. We assume that the firm's ownership structure, as well as the firm's sector and location, is given by that of the highest-level holding firm.

Over the entire period, there are 14,029 corporate tax IDs in firm groups with multiple tax IDs, which amounts to $0.33 \%$ of the total number of corporate tax IDs in our data. Table B.2 shows that, in each year, more than $50 \%$ of the firm groups have only two tax IDs. This procedure yields a dataset with 4,201,722 unique firm IDs (the vast majority of which reflect self-employment, as we discuss below) that are active at least once between 2009 and 2015, which is 7,957 fewer than before the grouping process.

\footnotetext{
${ }^{42}$ For unincorporated firms, the firm's tax ID corresponds to the personal tax ID of the owner.
} 
Table B.2: Summary Statistics, Corporate Tax ID Grouping

\begin{tabular}{lccccccc}
\hline & 2009 & 2010 & 2011 & 2012 & 2013 & 2014 & 2015 \\
\hline $\begin{array}{l}\text { Grouping sample } \\
\text { Group size distribution }\end{array}$ & & & & & & & \\
$\quad 50^{\text {th }}$ percentile & 2 & 2 & 2 & 2 & 2 & 2 & 2 \\
$\quad 75^{\text {th }}$ percentile & 3 & 3 & 3 & 3 & 3 & 3 & 3 \\
$\quad 90^{\text {th }}$ percentile & 5 & 5 & 5 & 5 & 5 & 5 & 5 \\
Unique corporate tax IDs & 8,113 & 8,113 & 8,113 & 5,197 & 5,426 & 5,706 & 5,874 \\
Unique firm IDs & 2,784 & 2,784 & 2,784 & 2,450 & 2,594 & 2,735 & 2,830 \\
\hline Full sample & & & & & & & \\
Unique corporate tax IDs & $1,192,781$ & $1,294,552$ & $1,253,628$ & $1,607,954$ & $1,703,784$ & $1,717,315$ & $1,759,767$ \\
Unique firm IDs & $1,187,452$ & $1,289,223$ & $1,248,299$ & $1,605,207$ & $1,700,952$ & $1,714,344$ & $1,756,723$ \\
Difference & 5,329 & 5,329 & 5,329 & 2,747 & 2,832 & 2,971 & 3,044 \\
\hline
\end{tabular}

Notes: The "grouping sample" comprises the sample of corporate tax IDs that are part of a firm ID group of at least size 2. The "full sample" contains all corporate tax IDs and firm IDs in our final dataset.

\section{B.1.3 Construction of Firm-level Variables}

We now describe our procedure to create the revenue and cost variables of each firm in a given year. Our goal is to combine the information in the tax forms and purchase annexes in order to create revenue and cost variables that are consistent with our theory. Specifically, we assume that a firm's revenue $R_{n}$ is the sum of its exports $E_{n}$, its final sales $D_{n}$, and its intermediate sales to other domestic firms $\sum_{m \in \mathcal{N}, m \neq n} M_{n m}$ :

$$
R_{n}=E_{n}+D_{n}+\sum_{m \in \mathcal{N}, m \neq n, R} M_{n m}+M_{n R}
$$

where $M_{n R}$ are sales to a consolidated residual firm that we use to account for inconsistencies in the data.

We construct the firm's cost items in such a way as to equalize revenues and (full factor) costs. The firm's total cost is the sum of the firm's profit $\Pi_{n}$, its labor cost $W_{n}$, its imports $X_{n}^{*}$, and its input purchases from other domestic suppliers $\sum_{m \in \mathcal{N}, m \neq n} M_{m n}$ :

$$
R_{n}=\Pi_{n}+W_{n}+X_{n}^{*}+\sum_{m \in \mathcal{N}, m \neq n, R} M_{m n}
$$

This treats the firm's profits as a "cost" that is simply its payments to its owners (i.e. to a capital factor).

To construct each of these variables, we classify firms in into four categories according to the 
type of information available: (1) firms reporting positive corporate revenue and/or cost in their F101 or F102, (2) firms only reporting personal revenue and costs in their F102, (3) firms that are identified as sellers in the purchase annex of a buying firm and do not themselves file tax forms or a purchase annex, and (4) two consolidated firms that contain the financial and public sectors, respectively, because these sectors have different tax reporting requirements. We now describe our procedure for constructing the revenue and cost structure in the economy for each of these four firm types.

Firms of Type 1 and 2. We start by defining the items in the firm's revenue stream in (B.1). For each firm ID, we compute the sum across the firm's tax IDs of their reported (on forms F101/2) total revenue $R_{n}^{t a x}$ and exports $E_{n}^{t a x}$. We use the purchase annex to compute sales of firm ID $n$ to each other firm ID $m, M_{n m}^{P A}$. We then compute the variables as follows. First, we specify exports and intermediate sales as reported in the tax form and purchase annex: $E_{n}=E_{n}^{\operatorname{tax}}$ and $M_{n m}=M_{n m}^{P A}$ for all $n \in \mathcal{N}$ and $n \neq R$. Second, we attribute any residual revenue to final sales:

$$
D_{n} \equiv \max \left\{0, R_{n}^{t a x}-E_{n}^{t a x}-\sum_{m \in \mathcal{N}, m \neq R} M_{n m}^{P A}\right\}
$$

We then construct the items in the firm's cost structure in (B.2). For each firm ID, we specify the firm's payroll and imports using the sum across the firm's tax IDs of the values reported in their tax forms of wage bill and imports: $W_{n}=W_{n}^{\operatorname{tax}}$ and $X_{n}^{*}=X_{n}^{\operatorname{tax}, * 43}$. We then use the definitions (B.1) and (B.2) to compute revenue, profits and sales to the residual firm such that the firm at least breaks even. Specifically, we define

$$
\tilde{\Pi}_{n} \equiv E_{n}^{t a x}+D_{n}+\sum_{m \in \mathcal{N}, m \neq n, R} M_{n m}^{P A}-\left(W_{n}^{t a x}+X_{n}^{t a x, *}+\sum_{m \in \mathcal{N}, m \neq n, R} M_{m n}^{P A}\right),
$$

and define

$$
\begin{array}{cccc}
\Pi_{n}=\tilde{\Pi}_{n} \text { and } M_{n R}=0 & \text { if } & \tilde{\Pi}_{n}>0 \\
\Pi_{n}=0 \text { and } M_{n R}=-\tilde{\Pi}_{n} & \text { if } & \tilde{\Pi}_{n} \leq 0, W_{n}+X_{n}^{*}>0 \\
\Pi_{n}=\epsilon \text { and } \quad M_{n R}=-\tilde{\Pi}_{n}+\epsilon & \text { if } & \tilde{\Pi}_{n} \leq 0, W_{n}+X_{n}^{*}=0
\end{array}
$$

where $\epsilon$ denotes a small positive constant. ${ }^{44}$ Finally, we compute $R_{n}$ using the accounting relation in (B.1).

To understand these expressions, consider a firm whose revenue from domestic and foreign

\footnotetext{
${ }^{43}$ For the case of the single (and state-owned) oil producer in Ecuador, we obtain this wage bill, export, and import information from the social security and customs datasets due to this firm's incomplete cost information on its own tax filing early in our sample period. Further, in 2010 and 2011, because of the firm's restructuring process, we do not observe a reliable value for the firm's final sales so we set this to zero; such sales are a small share of the firm's total sales in other years.

${ }^{44}$ In practice, because of numerical rounding, we set $\epsilon$ to $\$ 10$ if the maximum of revenue and costs is less than or equal to $\$ 5$, or $\epsilon$ equal to $0.1 \%$ of the maximum of revenue and costs otherwise.
} 
sales is strictly above its costs from labor, imports and intermediates. In this case, profits are defined as the difference between revenue and costs, implying sales to the residual firm of zero. Whenever the difference between revenue and costs is negative, we create additional sales to the residual firm, so that profits are zero if $W_{n}+X_{n}^{*}>0$ or $\epsilon$ if $W_{n}+X_{n}^{*}=0$. This adjustment is necessary to guarantee the existence of the Leontief inverse, $B \equiv(I-M)^{-1}$, by imposing the requirement that the share of the firm's costs from intermediate inputs is strictly below one, $\sum_{m \in \mathcal{N}, m \neq n, R} x_{m n}<1$ for all $n$.

Firms of Type 3. Since firms of type 3 file neither a tax form nor a purchase annex, we do not have all the cost and revenue items described above for firms of type 1 or 2 . Thus, for every firm $n$ of type 3 , we specify $E_{n}=D_{n}=X_{n}^{*}=0$ and $M_{m n}=0$ for all $m \in \mathcal{N}$. In addition, we define the firm's labor cost $W_{n}$ as the sum across all the firm's tax IDs of their wage bill in the social security database. We set labor payments to zero if none of the firm's tax IDs can be found in the social security database. This implies that $\tilde{\Pi}_{n} \equiv \sum_{m \in \mathcal{N}, m \neq n, R} M_{n m}^{P A}-W_{n}$. We then compute profits and residual sales using the procedure in (B.4) and revenue using the accounting relation in (B.1).

Additional Firms (Type 4, Residual). We construct one consolidated firm for public institutions and another for financial institutions. The consolidated financial firm consists of all tax IDs reporting their main activity to be in the financial sector. The consolidated public firm consists of all tax IDs flagged as state-owned (including branches of government that, for example, procure goods from private firms and hence file purchase annexes) in the tax data. Because Ecuador's state-owned oil firm accounts for all of its oil exports, we exclude it from the consolidated public firm and treat it as an ordinary firm (though one without an owner). For both of these consolidated firms, we construct the firm's revenue and cost following the same procedure as that adopted for the firms of type 1 and 2.

Lastly, we compute outcomes for the residual firm. We compute the intermediates purchases of the residual firm using $M_{n R}$ as implied by the procedure above. In order to guarantee that this firm breaks even, we specify that its final sales cover intermediate purchases, $D_{n}=\epsilon+\sum_{n \in \mathcal{N}} M_{n R}$.

\section{B.1.4 Summary Statistics}

Sample of Firms We now present simple summary statistics about our sample of firms, $\mathcal{N}$, that includes firms of types 1-3 as well as the three consolidated firms (public, financial, and residual). Table B.3 reports the counts of these firm types (by year), with shares broken down by singleperson firms (those that correspond to self-employed individuals working in their own firm). ${ }^{45}$ In addition, Figure B.1 illustrates how several of our key variables (revenues, costs, imports, exports,

\footnotetext{
${ }^{45}$ We define define single-person firms as either (a) firms with labor cost of zero and no entries in the social security database, or (b) those firms with a single employee in the social security database where employee is also registered as the firm's owner.
} 
labor payments, and capital payments/profits) are distributed across three broad types of firm: (i) single-person firms; (ii) the three consolidated firms; and (iii) corporate firms, which comprise all other firms. These findings indicate how incorporated firms of type 1 account for only $7 \%$ of firm tax IDs, but are responsible for more than $75 \%$ of the aggregate revenue in our sample. Such firms also account for essentially all of Ecuador's exports and imports. On the other hand, the vast majority of firms in our sample are of types 2 and 3. These firms are predominantly self-employed individuals. Depending on the year, about half of the incorporated firms filing tax forms (type 2), and $96-98 \%$ of the firms not filing tax forms (type 3), are single-person firms. Such firms account for a tiny share of exports, imports and a small share of total revenue; however, they are responsible for a slightly higher share of final sales and profits.

Table B.3: Summary Statistics of Firm Counts, by Firm Type

\begin{tabular}{lccccccc}
\hline & 2009 & 2010 & 2011 & 2012 & 2013 & 2014 & 2015 \\
\hline $\begin{array}{l}\text { Panel A: Firms of type 1 } \\
\text { Number of firms }\end{array}$ & 84,795 & 88,200 & 94,796 & 115,718 & 121,735 & 127,801 & 118,461 \\
$\quad$ Share that are single-person firms & $30 \%$ & $27 \%$ & $24 \%$ & $25 \%$ & $23 \%$ & $23 \%$ & $23 \%$ \\
\hline $\begin{array}{l}\text { Panel B: Firms of type 2 } \\
\quad\end{array}$ & 390,319 & 422,932 & 368,193 & 625,678 & 640,306 & 686,209 & 648,257 \\
$\quad \begin{array}{l}\text { Number of firms } \\
\text { Share that are single-person firms }\end{array}$ & $62 \%$ & $58 \%$ & $50 \%$ & $46 \%$ & $46 \%$ & $44 \%$ & $42 \%$ \\
\hline $\begin{array}{l}\text { Panel C: Firms of type 3 } \\
\quad \text { Number of firms }\end{array}$ & 711,352 & 777,117 & 784,281 & 863,263 & 938,359 & 899,804 & 989,389 \\
$\quad$ Share that are single-person firms & $98 \%$ & $98 \%$ & $96 \%$ & $98 \%$ & $97 \%$ & $97 \%$ & $97 \%$ \\
\hline
\end{tabular}

Notes: Firms of type 1 are those reporting corporate revenues or costs in their tax forms. Firms of type 2 are those only reporting personal revenues or costs in their tax forms. Firms of type 3 are those not filing tax forms but mentioned as sellers in the purchase annex of other firms. Single-person firms are either (i) firms with labor cost of zero and no entry in the social security database, or (ii) firms where the sole listed employee is the firm's owner itself.

Firm Revenues and Costs. Table B.4 reports the distribution of revenue and cost characteristics for firms of different types (for the pooled sample of firm-year combinations). Evidently, the revenue distribution is very skewed for all firm types. Firms of type 1 are larger and obtain a higher share of their revenue from final sales. These firms account for all the exports and imports, but this is concentrated in just a few firms - for instance, more than $90 \%$ of the firms of type 1 do not export or import. For firms of types 2 and 3, most of the revenues come from intermediate sales. These firms also have costs that are comprised heavily of profits (i.e. capital payments, as around half are self-employed individuals that do not have any reported input purchases). 


\section{Figure B.1: Aggregate Outcomes by Firm Category}
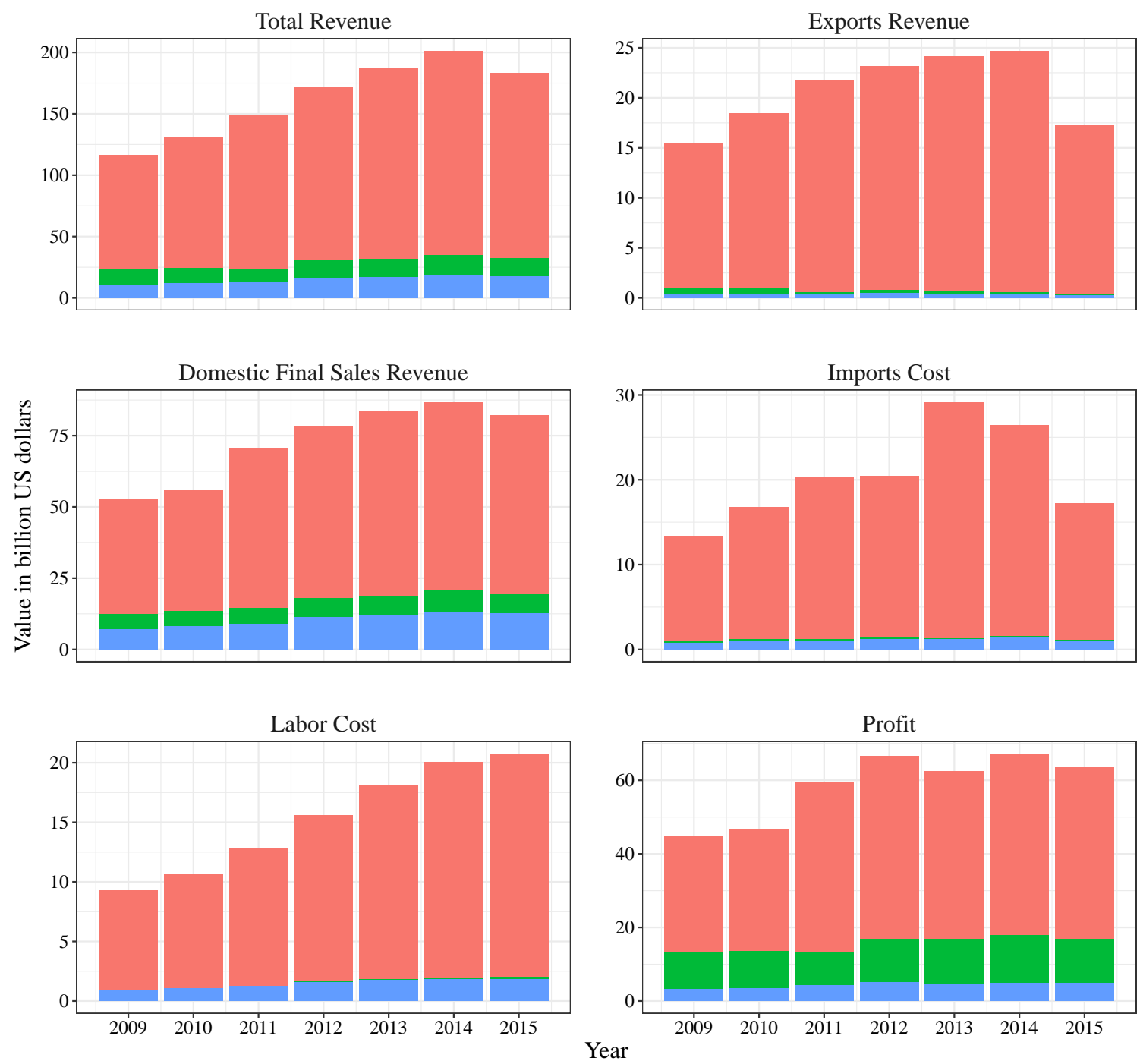

Corporate Firms $\_$Single-person Firms $\quad$ Other Firms

Notes: Single-person firms are either (i) firms with labor cost of zero and no entry in the social security database, or (ii) firms where the sole listed employee is the firm's owner him/herself. Corporate firms are all firm IDs not classified as single-person firms. "Other firms" consists of the consolidated financial firms, the consolidated residual firms, and the consolidated public firms. 
Table B.4: Summary Statistics, Firm-level Data

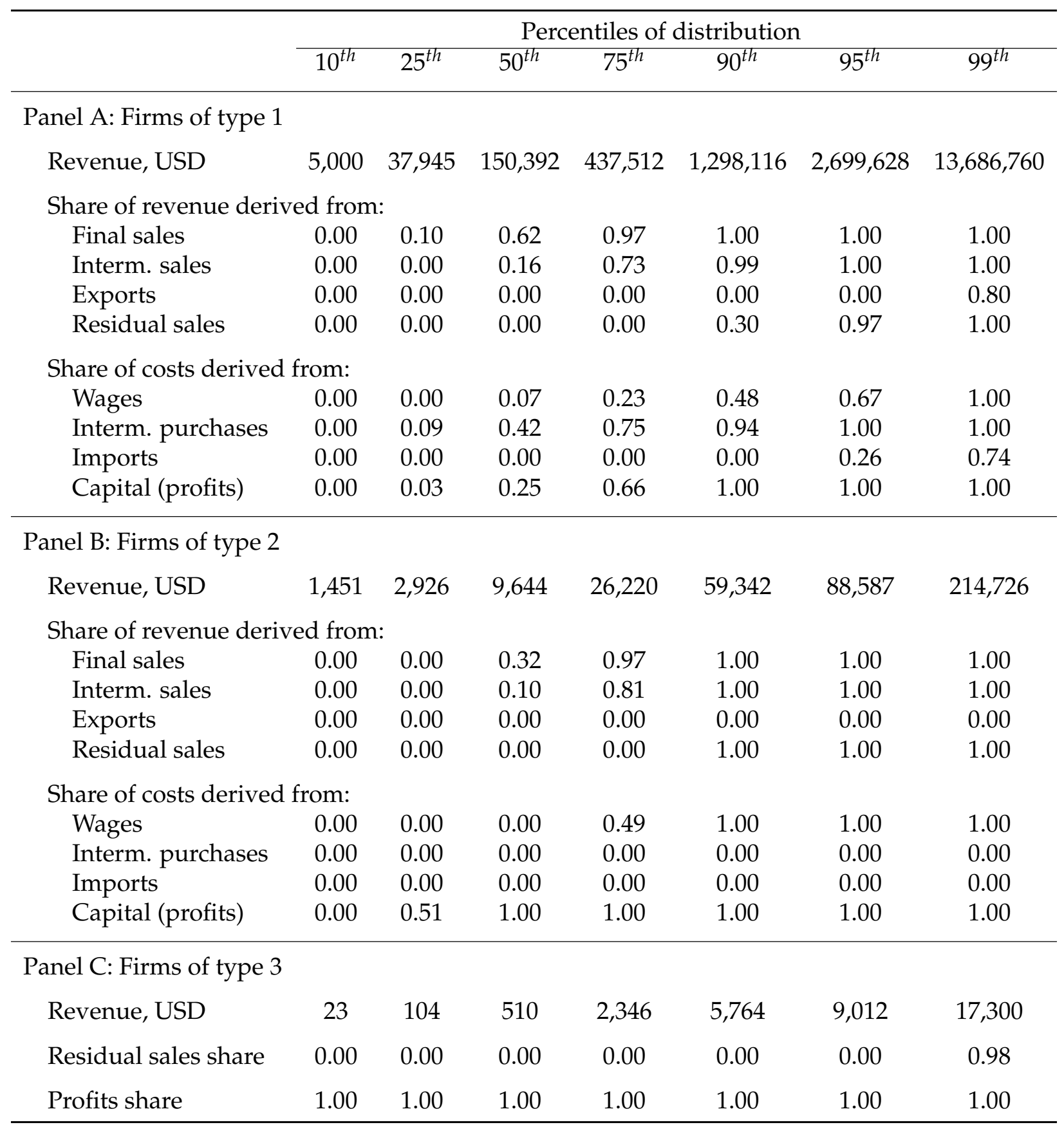

Notes: Each row reports features of the distribution (pooling across all firm-year observations that appear in the tax data, for the given firm type) of the indicated variable. Firms of type 1 are those reporting corporate revenues or costs in their tax forms. Firms of type 2 are those only reporting personal revenues or costs in their tax forms. Firms of type 3 are those not filing tax forms but mentioned as sellers in the purchase annex of other firms. 


\section{B.2 Payments to Factors and Individuals}

In order to connect firm payments to factors of production and individual factor endowments, we use two databases: the social security employer-employee database (IESS) that allows us to match workers to each firm, and the ownership survey that allows us to match owners to each firm. Our sample of individuals $\mathcal{I}$ includes all individuals with positive income in the social security and ownership dataset that are associated with a firm in our sample (excluding the consolidated financial, residual and public firms). We assign workers to provinces based on the location of their main employer defined as the firm ID from which the individual earns most of her income. ${ }^{46} \mathrm{We}$ also create a residual agent that receives labor and capital payments that certain firms make to entities (foreign owners or the government) that are not individuals in our sample.

\section{B.2.1 Data Construction}

Firm Shares of Payments to Individuals. We start by constructing firm payments to labor factors as follows. For every individual $i \in \mathcal{I}$, we define the firm's labor payment share to $i$ as $x_{i n}^{L}=W_{i n}^{I E S S} / W_{n}^{I E S S}$, where $W_{i n}^{I E S S}$ is the value of annual earnings reported by firm $n$ in the social security database for $i$, and $W_{n}^{I E S S}$ is firm $n^{\prime}$ s total payroll reported in the IESS. A fraction of such individuals cannot be matched to the Civil Registry, which contains the demographic indicators that we later require, so we assign such individuals to a residual labor agent as $x_{R n}^{L}=1-\sum_{i \in \mathcal{I}} x_{i n}^{L}$ where $\mathcal{I}$ denotes individuals in the Civil Registry. The payment share $x_{R n}^{L}$ is also set equal to one for firms that have positive labor payments in their tax firms but no employees in the social security dataset, as well as for the three consolidated firms in our sample. We consider every single-person firm $n$ to be a self-employed individual and reclassify the firm's profits as labor payments to the individual-owner; that is, $W_{n}=\Pi_{n}, \Pi_{n}=0$, and $x_{i n}^{L}=1$ for the individualowner $i$. Finally, we construct the matrix of share of firm-individual labor payment shares as $x^{L} \equiv\left\{x_{i n}^{L}\right\}_{(i, n) \in \mathcal{I} \times \mathcal{N}}$.

We then proceed similarly for the case of capital payments to individuals. For every individual $i \in \mathcal{I}$, we measure $\vartheta_{n i}$ as the ownership share of individual $i$ in firm $n$. For a single-person firm, we set $\vartheta_{n i}=1$ for the individual-owner. We compute the ownership share of the residual agent as $\vartheta_{n R}=1-\sum_{i \in \mathcal{I}} \vartheta_{n i}$. These capital ownership shares yield the matrix of shares of capital payments to different individuals in our sample, $\vartheta \equiv\left\{\vartheta_{n i}\right\}_{(i, n) \in \mathcal{I} \times \mathcal{N}}$.

Firm Shares of Payments to Factors. We define labor factors in terms of education-province pairs, and an additional residual labor type. We compute the firm's payments to each factor using the personal information of its employees in the Civil Registry. Specifically, we define $D_{f i}^{L}$ as a

\footnotetext{
${ }^{46}$ The firm's location (as reported in its tax filing) will reflect that of its headquarters, which may not correspond to the location of every establishment in a multi-establishment firm. Section B.4.1 compares factor payments derived from the administrative data discussed here to that in a nationally representative earnings survey, which provides reassurance that such measurement error is unlikely to be large.
} 
dummy variable that equals one if individual $i$ belongs to the group associated with factor $f$ and the row vector with the dummy variable for different individuals as $D_{f}^{L} \equiv\left\{D_{f i}^{L}\right\}_{i \in \mathcal{I}}$. For the residual type, the vector has entries equal to one for all individuals in our sample with missing personal information in either the Civil Registry or IESS, as well as the residual agent $i=R$. We then compute the firm payment shares to each labor factor as $\left\{x_{f n}\right\}_{n \in \mathcal{N}}=D_{f}^{L} x^{L} \operatorname{diag}\left(\left\{W_{n} / R_{n}\right\}_{n \in \mathcal{N}}\right)$ for each $f \in \mathcal{F}^{L}$.

Similarly, we compute the firm payments to different capital types. For each firm $n$, we compute $D_{s n}^{K}=1$ if firm $n$ is in sector $s$, and define the row vector containing this dummy for all firms as $D_{s}^{K} \equiv\left\{D_{s n}^{K}\right\}_{n \in \mathcal{N}}$. We consider two sectors s: Oil and Non-Oil. Finally, we compute firm payment shares to each capital factor as $\left\{x_{f n}\right\}_{n \in \mathcal{N}}=D_{f}^{K} \operatorname{diag}\left(\left\{\Pi_{n} / R_{n}\right\}_{n \in \mathcal{N}}\right)$ for each $f \in \mathcal{F}^{K}$.

Individual Factor Earnings. The last step is to construct individuals' earnings and earnings from each factor service that they supply. Let $Y_{f i}$ denote $i$ 's income associated with factor $f$, and $Y_{i}$ be $i^{\prime}$ s total income $Y_{i}=\sum_{f \in \mathcal{F}} Y_{f, i}$. For labor factors $f \in \mathcal{F}^{L}, Y_{f}=\left\{Y_{f, i}\right\}_{i \in \mathcal{I}}$ is simply the vector of individual labor payments times the dummy vector indicating which individuals are associated with each group defining factor $f$ (education-province pair or residual): $Y_{f}=$ $D_{f}^{L} \operatorname{diag}\left(x^{L}\left\{W_{n}\right\}_{n \in \mathcal{N}}\right)$. For capital factors $f \in \mathcal{F}^{K}, Y_{f}=\left\{Y_{f, i}\right\}_{i \in \mathcal{I}}$ is the product of the matrix of payments individuals get from different firms, $\vartheta \operatorname{diag}\left(\left\{\Pi_{n}\right\}_{n \in \mathcal{N}}\right)$, and the dummy vector indicating whether firms are associated with the oil or the non-oil sectors, $D_{f}^{K}: Y_{f}=D_{f}^{K} \operatorname{diag}\left(\left\{\Pi_{n}\right\}_{n}\right)(\vartheta)^{\prime}$. Finally, we compute, for each individual, the income share associated with each factor, $\omega_{f, i} \equiv$ $Y_{f, i} / Y_{i}$

\section{B.2.2 Summary Statistics}

We now present summary statistics regarding our sample of individuals and factors. In the first part of Table B.5, we report the number of individuals in our sample. Across years, the number of individuals in our sample grows reflecting mostly the increase in formalization rates in Ecuador. In 2012, the administrative dataset has approximately 3 million individuals with positive income, accounting for approximately half of Ecuador's employed and/or business-owning population (according to the 2011-12 earnings survey that we describe in Section B.4). We have information on education and province for roughly $90 \%$ of the individuals with strictly positive income. The second panel displays statistics for our baseline sample of individuals with strictly positive income and whose labor income can be mapped to an education-province pair. In 2012, there are 2.6 million such individuals in our baseline sample, with $30 \%$ of them employed in single-person firms. The last part of the table reports the annual income at different parts of the distribution. In 2012, the median income was around $\$ 4,900$. The earnings distribution in this administrative dataset contains many individuals with very low apparent earnings (e.g. $10 \%$ with $\$ 276$ or less in 2012), but this is largely driven by single-person firms and likely reflects a part-time or seasonal involvement in such activities. The earnings distribution derived from survey data reflecting all 
types of earnings, described in Section B.4, does not have this same feature.

Figure B.2 reports the share of payments to different factor types by income percentile. It shows that the capital income share is especially important at the top of the distribution, accounting for $38 \%$ and $64 \%$ of income in the 95 and 99 percentiles, respectively. The plot also shows that individuals with higher education levels are more likely to be at higher income percentiles. Excluding capital income, low-education individuals correspond to $10 \%-15 \%$ of income above the 90th percentile of the distribution, but they account for almost $50 \%$ of the income below the 10th percentile. For high-education individuals this pattern is reversed: this group generates less than $10 \%-15 \%$ of income in the bottom 10 percentiles and almost $50 \%$ of income in the top 10 percentiles.

Table B.5: Summary Statistics of Sample Characteristics Across Individuals

\begin{tabular}{|c|c|c|c|c|c|c|c|}
\hline & 2009 & 2010 & 2011 & 2012 & 2013 & 2014 & 2015 \\
\hline \multicolumn{8}{|c|}{ Panel A: Full sample of individuals in administrative dataset } \\
\hline Total number of individuals & $2,414,839$ & $2,659,772$ & $2,892,445$ & $3,321,591$ & $3,519,453$ & $3,643,140$ & $3,614,968$ \\
\hline with positive income & $\begin{array}{c}2,256,513 \\
(93 \%)\end{array}$ & $\begin{array}{c}2,460,699 \\
(93 \%)\end{array}$ & $\begin{array}{c}2,678,308 \\
(93 \%)\end{array}$ & $\begin{array}{c}3,002,078 \\
(90 \%)\end{array}$ & $\begin{array}{c}3,194,608 \\
(91 \%)\end{array}$ & $\begin{array}{c}3,298,603 \\
(91 \%)\end{array}$ & $\begin{array}{c}3,287,431 \\
(91 \%)\end{array}$ \\
\hline with complete information & $\begin{array}{c}2,009,715 \\
(83 \%)\end{array}$ & $\begin{array}{c}2,211,525 \\
(83 \%)\end{array}$ & $\begin{array}{c}2,362,355 \\
(82 \%)\end{array}$ & $\begin{array}{c}2,676,243 \\
(81 \%)\end{array}$ & $\begin{array}{c}2,718,062 \\
(77 \%)\end{array}$ & $\begin{array}{c}2,720,276 \\
(75 \%)\end{array}$ & $\begin{array}{c}2,580,246 \\
(71 \%)\end{array}$ \\
\hline \multicolumn{8}{|c|}{ Panel B: Baseline sample of individuals } \\
\hline Total number of individuals & $1,981,214$ & $2,150,372$ & $2,291,093$ & $2,612,867$ & $2,669,436$ & $2,681,576$ & $2,565,771$ \\
\hline in single-person firms & $\begin{array}{c}696,101 \\
(35 \%)\end{array}$ & $\begin{array}{c}728,293 \\
(34 \%)\end{array}$ & $\begin{array}{c}587,872 \\
(26 \%)\end{array}$ & $\begin{array}{c}789,889 \\
(30 \%)\end{array}$ & $\begin{array}{c}777,024 \\
(29 \%)\end{array}$ & $\begin{array}{c}720,956 \\
(27 \%)\end{array}$ & $\begin{array}{c}713,160 \\
(28 \%)\end{array}$ \\
\hline \multicolumn{8}{|c|}{ Panel C: Percentiles of income in baseline sample $\left(Y_{i}\right)$, USD } \\
\hline $10^{\text {th }}$ & 280 & 286 & 306 & 276 & 269 & 306 & 218 \\
\hline $50^{t h}$ & 4,025 & 4,224 & 4,466 & 4,874 & 5,350 & 5,795 & 6,003 \\
\hline $90^{t h}$ & 22,043 & 22,900 & 23,252 & 25,991 & 26,916 & 28,225 & 28,443 \\
\hline $99^{\text {th }}$ & 166,190 & 165,239 & 224,958 & 187,165 & 180,949 & 180,741 & 177,894 \\
\hline
\end{tabular}

Notes: Panel A is based on all individuals in our administrative dataset. Panels B and C are based on our baseline sample of individuals in the administrative dataset who have strictly positive income and whose labor income can be mapped to an education-pronvince pair.

\section{B.3 International Trade Data}

We rely on two sources of international trade data. The first is Ecuador's custom records, which measure firm-level exports and imports in each HS6 product and by the partner country of desti- 
Figure B.2: Share of Aggregate Factor Payments by Factor Category, 2012

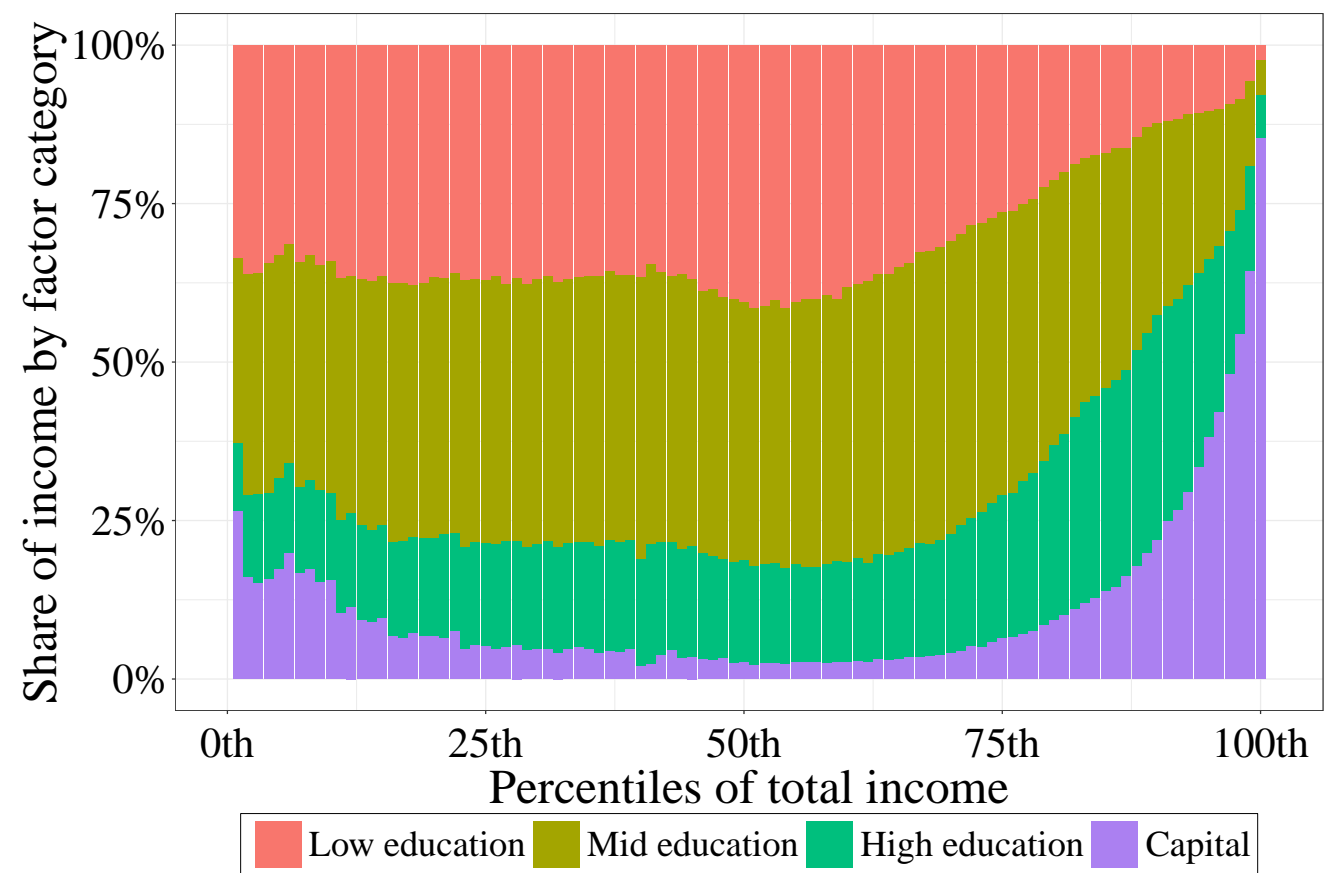

Notes: Based on baseline sample of individuals in the administrative dataset who have strictly positive income and whose labor income can be mapped to an education-pronvince pair.

nation or origin. ${ }^{47}$ This dataset covers the universe of Ecuador's exports and imports in 2009-2011. We focus on Ecuador's trade with its 50 largest trade partners, and aggregate all other countries into a group representing the rest of the world. Figure B.3 describes the composition of Ecuador's exports and imports in 2009-2011, based on this customs database.

Our second source of trade data is CEPII's BACI dataset, which reports bilateral trade flows worldwide (for 2009-15 and beyond) at the HS6 level. We use this dataset to construct proxies for foreign shocks in export demand and import prices, as described in Section 5. Specifically, for each HS6 product and year, we compute the total value and average unit value of the imports of all countries in the dataset, excluding Ecuador as both importer and exporter. The log of total world imports is our measure of the product export shock, and the average of the log import unit value is our measure of the import price shock.

\section{B.4 Earnings Survey Data}

This subsection describes the earnings survey data that we use to supplement our baseline analysis. Section B.4.1 describes Ecuador's National Survey of Income and Expenditures from Urban

\footnotetext{
${ }^{47}$ Ecuador's custom records track products using the 6-digit NANDINA system, which is similar to the 2007 HS 6-digit classification system. We drop trade flows in the case of the $1.4 \%$ of NANDINA codes that we cannot match to HS codes.
} 


\section{Figure B.3: Composition of Ecuador's Exports and Imports, 2009-2011}

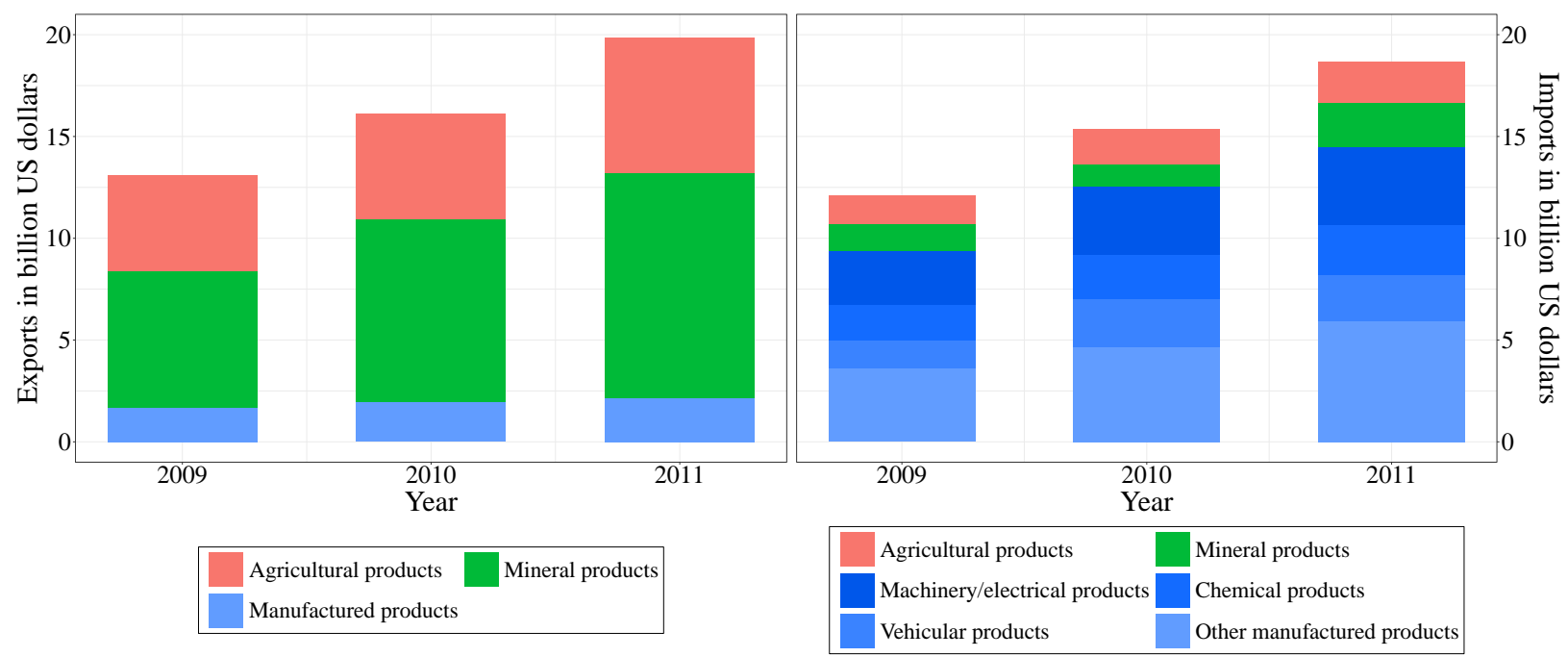

Notes: Trade flows by product category computed from firm-level custom records in 2009-2011.

and Rural Households (ENIGHUR), a detailed survey carried out in 2011-2012 that we incorporate into our analysis in Section 7.2. Section B.4.2 describes Ecuador's National Employment, Unemployment and Underemployment Survey (ENEMDU), a shorter survey that was carried out quarterly throughout 2009-2015, which we use in Section 7.3. Both surveys were administered by Ecuador's National Institute of Statistics and Censuses (INEC).

\section{B.4.1 ENIGHUR Survey}

Ecuador's ENIGHUR survey, collected information from 39,617 households during the period between April 2011 and March 2012. Its objective was to measure the distribution, amount and structure of household income and expenses. This dataset is representative at the national level and covers Ecuador's formal and informal economy. It has information about 153,444 respondents, who resemble Ecuador's total population (15.24 and 15.47 million in 2011 and 2012, respectively) when we take into account the frequency sampling weights available in the survey. ${ }^{48}$ We limit our sample to the group of respondents that were 15 years or older at the moment of being surveyed, and keep only those with positive earnings who are currently working. ${ }^{49}$ This results in a sample size of 60,465 respondents, representative of around 6 million working individuals in Ecuador.

Importantly, the survey reports each respondent $i$ 's demographics, monthly earnings, and

\footnotetext{
${ }^{48}$ In what follows, all aggregate statistics that we employ are weighted by these sampling weights.

${ }^{49} \mathrm{~A}$ respondent is defined as currently working if s/he either: (i) worked (as an employee or in the operation of a business that the respondent wholly or partially owns) at least one hour last week; (ii) did not work last week but did an activity to help the household (like helping in a family business); or (iii) did not work last week, but had a job or business to which s/he was surely going to return after a temporary absence (such as an illness or vacation).
} 
workplace characteristics for each occupation $o$ (including both employment, self-employment, and operating a business that the respondent owns a share of) in which they were engaged during the week prior to their survey week. ${ }^{50}$ We classify each occupation $o$ for each respondent $i$ as formal in the following cases: when $o(i)$ refers to employment at a firm (not a domicile), if that firm either has a taxpayer ID (a Registro Único de Contribuyentes, or RUC) or has more than 100 employees, and $i$ reports receiving some social security contributions from their employer; when $o(i)$ refers to employment in domestic work, if the respondent reports receiving some social security contributions from their employer; when $o(i)$ refers to employment in a branch of government; and when $o(i)$ refers to operating a firm in which the respondent is a partial owner, if that firm has a RUC or has more than 100 employees. Otherwise, we classify $o(i)$ as informal.

We then classify $o(i)$ according to its factor group $f$ in the same way as in the baseline administrative data. If $o(i)$ refers to either employment at a firm, or self-employment at respondent $i$ 's own firm but where $i$ hires no paid employees, then we classify the factor type as labor of the type corresponding to the respondent's education-province. Otherwise, if $o(i)$ refers to the operation of a firm that the respondent partially or wholly owns, and that hires employees, we classify the factor type as oil or non-oil capital depending on the sector in which the firm operates. The survey has 544 original (i.e. unweighted) respondents in the median factor group, 138 respondents in the smallest, and 4,049 in the largest.

Based on these definitions and the information on annualized earnings by occupation, we denote $Y_{i, f, F}$ as individual $i$ 's total annual earnings, summed across all occupations $o(i)$, from each factor type $f$ and formality status $F .^{51}$ Then we calculate total earnings as $Y_{i} \equiv \sum_{f, F} Y_{i, f, F}$ and factor earnings shares as $\omega_{i, f, F} \equiv Y_{i, f, F} / Y_{i}$. Finally, we calculate the total informal factor earnings within each sector. These ingredients enter the counterfactual calculations reported in Section 7.2.

While our analysis in Section 7.2 uses data on formality from the administrative database and data on informality from the ENIGHUR survey, it is useful to compare their measures of the formal earnings of each factor. Figure B.4 does this for 73 factor groups (72 labor groups plus Non-oil capital, since Oil capital is never represented in the survey) using the 2011 administrative data. The fit among the labor groups is high (the $R^{2}$ from the line of best-fit for Figure B.4 is 0.78), so it appears that, despite the possibility of survey misreporting and sampling errors, the administrative and survey datasets are capturing similar notions of formal earnings across the labor factor distribution. However, the capital point is a clear outlier, with far more total capital earnings in the administrative dataset than in the (formal earnings segment of the) ENIGHUR survey. This

\footnotetext{
${ }^{50}$ The survey questionnaire asks all of the details we require about the respondent's "main" and "secondary" occupation. For "all other occupations" (of which fewer than 1\% report having any) the questionnaire does not allow us to classify the occupation(s) as formal or informal, so we code these as informal.

${ }^{51}$ Employment earnings include (annualized rates of) wages, overtime and bonuses in the past month as well as total amounts of additional payments (paid leave, retroactive payments, etc.) received in the past year. The earnings of business owners are calculated as the firm's profits (over the past year for agricultural businesses, and over the past half-year for non-agricultural businesses) adjusted for the respondent's ownership share.
} 


\section{Figure B.4: Comparison of Administrative and Survey Factor Earnings}

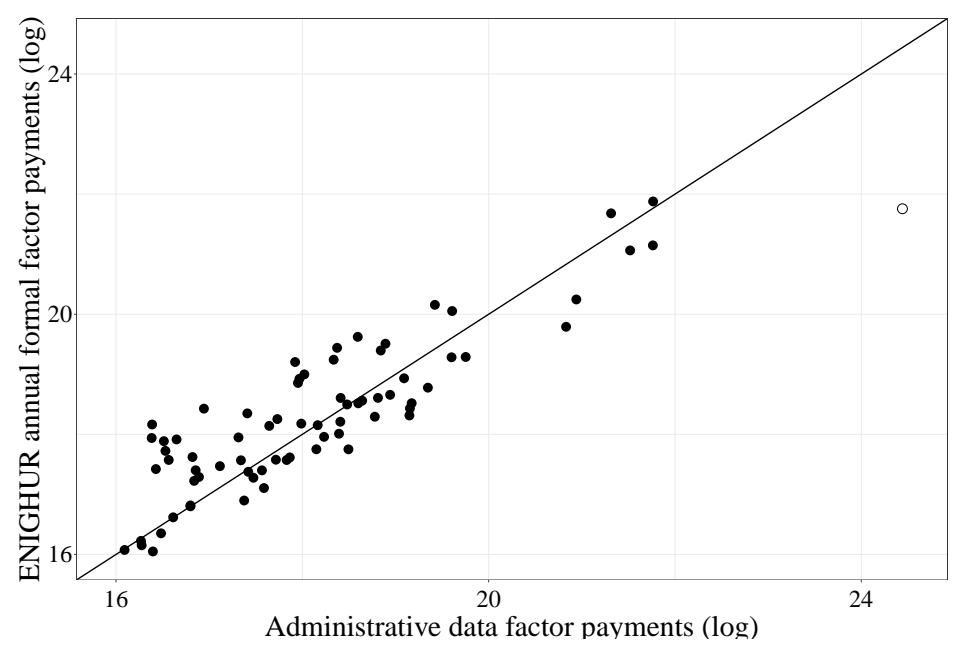

Notes: Filled dots correspond to labor factor groups (education-province pairs) while the empty dot represents the non-oil capital factor, and the black line indicates $y=x$. The $\mathrm{x}$-axis reports the $(\log )$ value of total earnings in each factor group (i.e. $Y_{f}=\sum_{i \in \mathcal{I}} Y_{i, f}$ ) as measured in the administrative data in 2011. The $y$-axis reports the analogous measurement from the ENIGHUR survey in regards to formal earnings.

should be expected given the active definition of capital earnings that is implicit in the earnings survey, as well as the likelihood of a survey failing to capture top earnings, especially among capital owners.

Finally, Figure B.5 reports the share of earnings within each factor group that is earned from the formal economy. The median factor group derives earnings that are $60.4 \%$ formal, but there is considerable dispersion across factors in their formal income shares (the minimal share is $7.1 \%$ and the maximum is $87.1 \%$ ). There is no systematic relationship between a factor's total (that is, formal plus informal) survey earnings and its formal income share. However, Figure B.5 shows that there does exist a clear (positive) relationship when the formal income share is compared to per capita earnings across factor groups. ${ }^{52}$

\section{B.4.2 ENEMDU Survey}

While the ENEMDU survey was conducted quarterly, its fourth quarter editions were more explicitly designed to be representative at the province level (and typically larger) than those in the rest of the year, so we use only the fourth quarter information. This results in a number of respondents (with positive earnings, over the age of 15) ranging from 25,712 to 42,017 depending on the year.

This survey shares many features with the ENIGHUR survey described above, so we discuss here only any differences that have implications for our analysis. First, all ENEMDU respondents report their earnings in the past month. Second, unlike the ENIGHUR survey, the ENEMDU

\footnotetext{
${ }^{52}$ We calculate per capita factor group earnings on the basis of survey respondents' main occupations.
} 


\section{Figure B.5: Formal Share of Earnings by Factor Group}

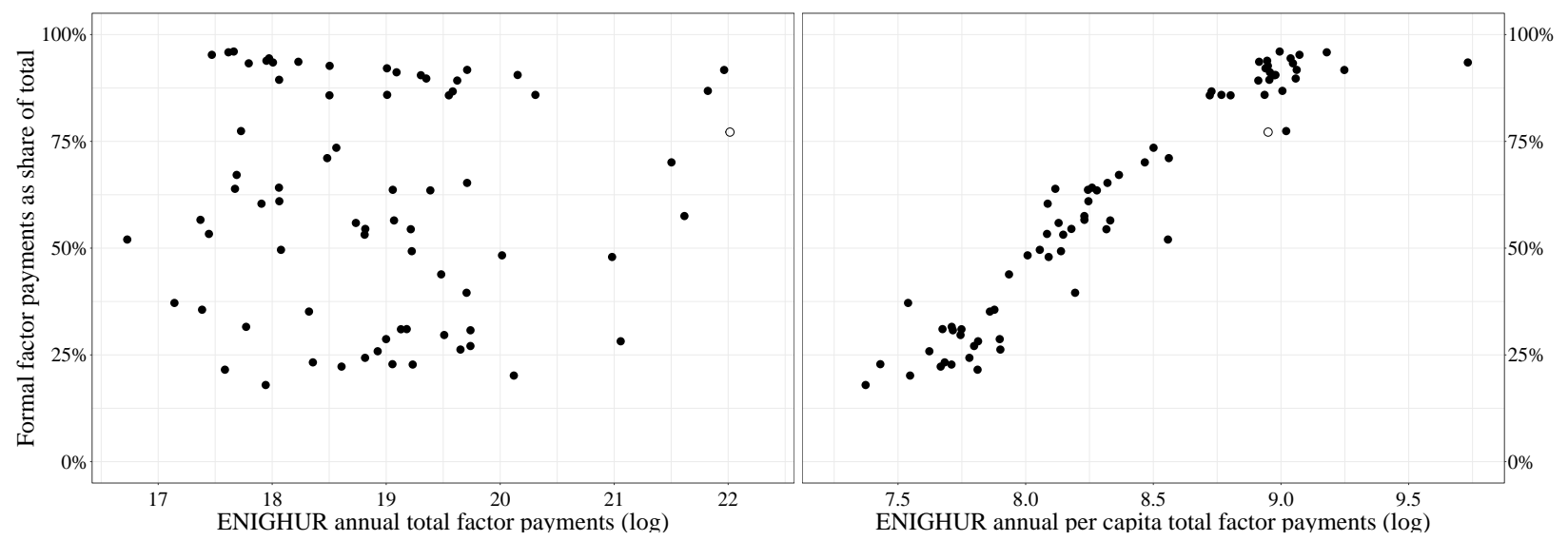

Notes: Filled dots correspond to labor factor groups (education-province pairs) while the empty dot represents the non-oil capital factor. The figure on the left reports on the x-axis the $(\log )$ value of total earnings in each factor group (i.e. $Y_{f}=\sum_{i \in \mathcal{I}} Y_{i, f}$ ) as measured in the survey data, whereas the one on the right reports the $(\log )$ per capita earnings in each factor group (i.e. $Y_{f}$ divided by the frequency-weighted number of respondents whose main occupation corresponds to factor group $f$ ) as measured in the survey data. The common $y$-axis reports the share of the factor group's total earnings that are obtained formally.

survey does not disaggregate business costs so we cannot use reports of positive wage costs to identify businesses that hire employees (and hence are owned by a capital factor); we use the respondent's occupation description instead. ${ }^{53}$ Third, the ENEMDU survey does not report the ownership share of business owners, so we assume that they earn all of their firm's profits. ${ }^{54}$ Finally, ENEMDU provides slightly less information with which to classify employee income as formal or informal. ${ }^{55}$

While these differing survey characteristics may result in differing measures of factor earnings in ENEMDU and ENIGHUR, we find that such differences are minimal in practice. Across factor groups, the correlation between total earnings inferred from the 2011 ENEMDU survey and those from the 2011-12 ENIGHUR survey is 0.96. Similarly, the correlation between the two surveys' inferred number of individuals whose primary occupation lies within each factor group is 0.97 . And the correlation between their inferred share of factor earnings that is formal is 0.96 .

${ }^{53}$ That is, when the occupation is categorized as "patron" the survey questionnaire intends this to refer to a business that typically hires others. By contrast, when the occupation is listed as "self-employed" this refers to a business that has no salaried employees.

${ }^{54}$ In the ENIGHUR survey, which does report ownership shares, the share of total profits accruing to the respondent, aggregating across all respondents and occupations, is $96 \%$.

55 For employee occupations our previous formality classification requires that both the employee's firm has formal characteristics and that the employee appears to be enrolled in the social security system. Information on the latter is incomplete in ENEMDU. In particular, for main occupations only the total amount of employer deductions (due to social security payments, income tax payments, etc.) is reported, so we assume that any positive total amount implies social security enrollment. For secondary occupations no such information is reported, so we remove the social security requirement from our formality classification in such cases. 


\section{Empirical Appendix}

\section{C.1 Summary Statistics}

Table C.1 reports summary statistics of the distribution of capital income shares, export exposure and import exposures across individuals in Ecuador from 2009-2015.

Table C.1: Summary Statistics of Income and Exposure Across Individuals

\begin{tabular}{|c|c|c|c|c|c|c|c|}
\hline & \multirow[b]{2}{*}{ Mean } & \multicolumn{5}{|c|}{ Percentiles of distribution } \\
\hline & & & $10^{\text {th }}$ & $50^{t h}$ & $90^{t h}$ & $99^{\text {th }}$ & $99.9^{t h}$ \\
\hline \multirow{3}{*}{2009} & Capital income share & 0.078 & 0.000 & 0.000 & 0.003 & 1.000 & 1.000 \\
\hline & Export exposure $\left(E E_{i}\right)$ & 0.158 & 0.088 & 0.138 & 0.281 & 0.455 & 0.455 \\
\hline & Import exposure $\left(I E_{i}\right)$ & 0.041 & 0.014 & 0.031 & 0.097 & 0.111 & 0.122 \\
\hline \multirow{3}{*}{2010} & Capital income share & 0.082 & 0.000 & 0.000 & 0.020 & 1.000 & 1.000 \\
\hline & Export exposure $\left(E E_{i}\right)$ & 0.169 & 0.088 & 0.142 & 0.287 & 0.479 & 0.479 \\
\hline & Import exposure $\left(I E_{i}\right)$ & 0.045 & 0.011 & 0.032 & 0.105 & 0.128 & 0.148 \\
\hline \multirow{3}{*}{2011} & Capital income share & 0.088 & 0.000 & 0.000 & 0.121 & 1.000 & 1.000 \\
\hline & Export exposure $\left(E E_{i}\right)$ & 0.164 & 0.095 & 0.139 & 0.292 & 0.445 & 0.445 \\
\hline & Import exposure $\left(I E_{i}\right)$ & 0.043 & 0.003 & 0.028 & 0.105 & 0.127 & 0.139 \\
\hline \multirow{3}{*}{2012} & Capital income share & 0.110 & 0.000 & 0.000 & 0.770 & 1.000 & 1.000 \\
\hline & Export exposure $\left(E E_{i}\right)$ & 0.155 & 0.084 & 0.128 & 0.258 & 0.474 & 0.474 \\
\hline & Import exposure $\left(I E_{i}\right)$ & 0.038 & 0.011 & 0.027 & 0.087 & 0.108 & 0.123 \\
\hline \multirow{3}{*}{2013} & Capital income share & 0.112 & 0.000 & 0.000 & 0.799 & 1.000 & 1.000 \\
\hline & Export exposure $\left(E E_{i}\right)$ & 0.150 & 0.073 & 0.133 & 0.274 & 0.586 & 0.586 \\
\hline & Import exposure $\left(I E_{i}\right)$ & 0.036 & 0.013 & 0.028 & 0.082 & 0.101 & 0.112 \\
\hline \multirow{3}{*}{2014} & Capital income share & 0.116 & 0.000 & 0.000 & 0.862 & 1.000 & 1.000 \\
\hline & Export exposure $\left(E E_{i}\right)$ & 0.158 & 0.076 & 0.142 & 0.292 & 0.577 & 0.577 \\
\hline & Import exposure $\left(I E_{i}\right)$ & 0.030 & 0.006 & 0.018 & 0.073 & 0.093 & 0.099 \\
\hline \multirow{3}{*}{2015} & Capital income share & 0.118 & 0.000 & 0.000 & 0.898 & 1.000 & 1.000 \\
\hline & Export exposure $\left(E E_{i}\right)$ & 0.154 & 0.070 & 0.144 & 0.280 & 0.590 & 0.590 \\
\hline & Import exposure $\left(I E_{i}\right)$ & 0.023 & -0.002 & 0.012 & 0.070 & 0.086 & 0.095 \\
\hline
\end{tabular}

Notes: Baseline sample of individuals with strictly positive income. Capital income share refers to total capital earnings. 


\section{C.2 Export and Import Exposure Across Years}

Figure C.1 illustrates the distribution of individual-level export exposure $\left(E E_{i}\right)$, as in Figure 3, for all years, 2009-2015. Figure C.2 does the same for import exposure $\left(I E_{i}\right)$ as in Figure 4.

Figure C.1: Distribution of Export Exposure $\left(E E_{i}\right)$ Across Individuals, 2009-2015
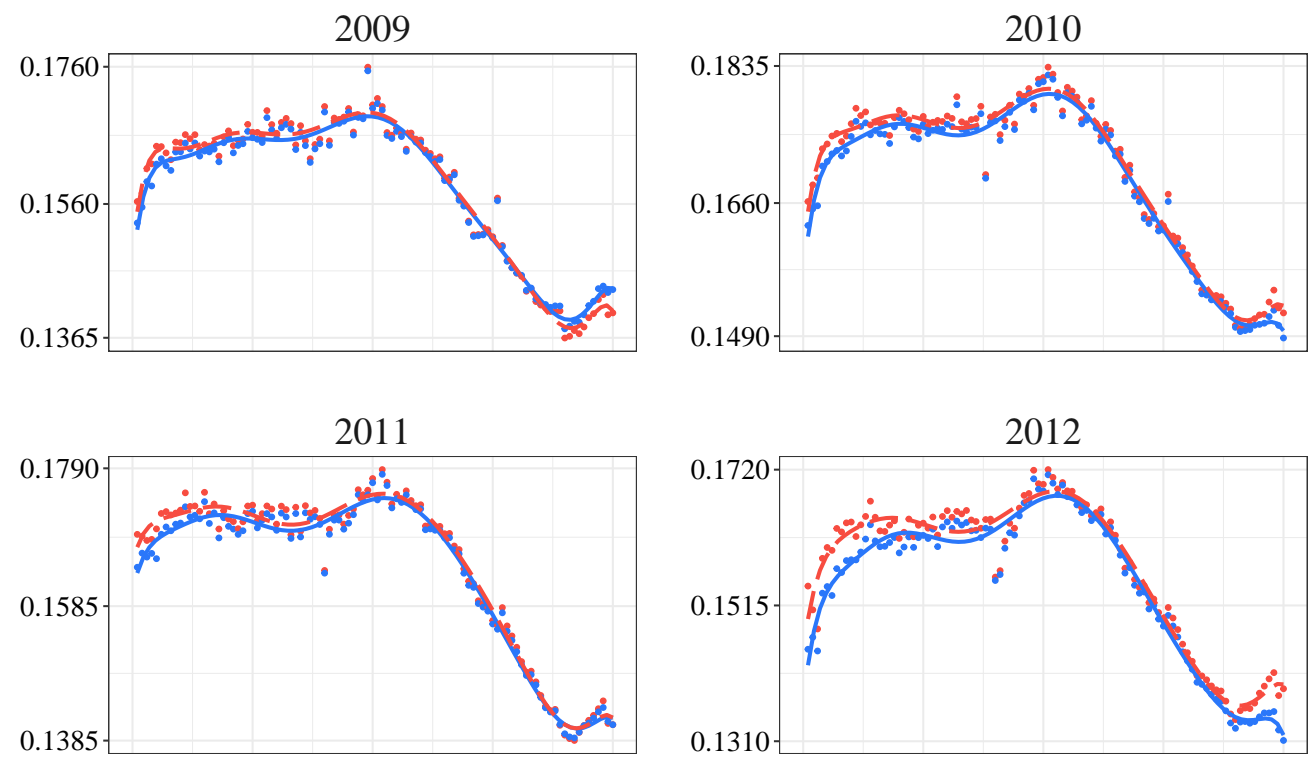

$E E_{i}$
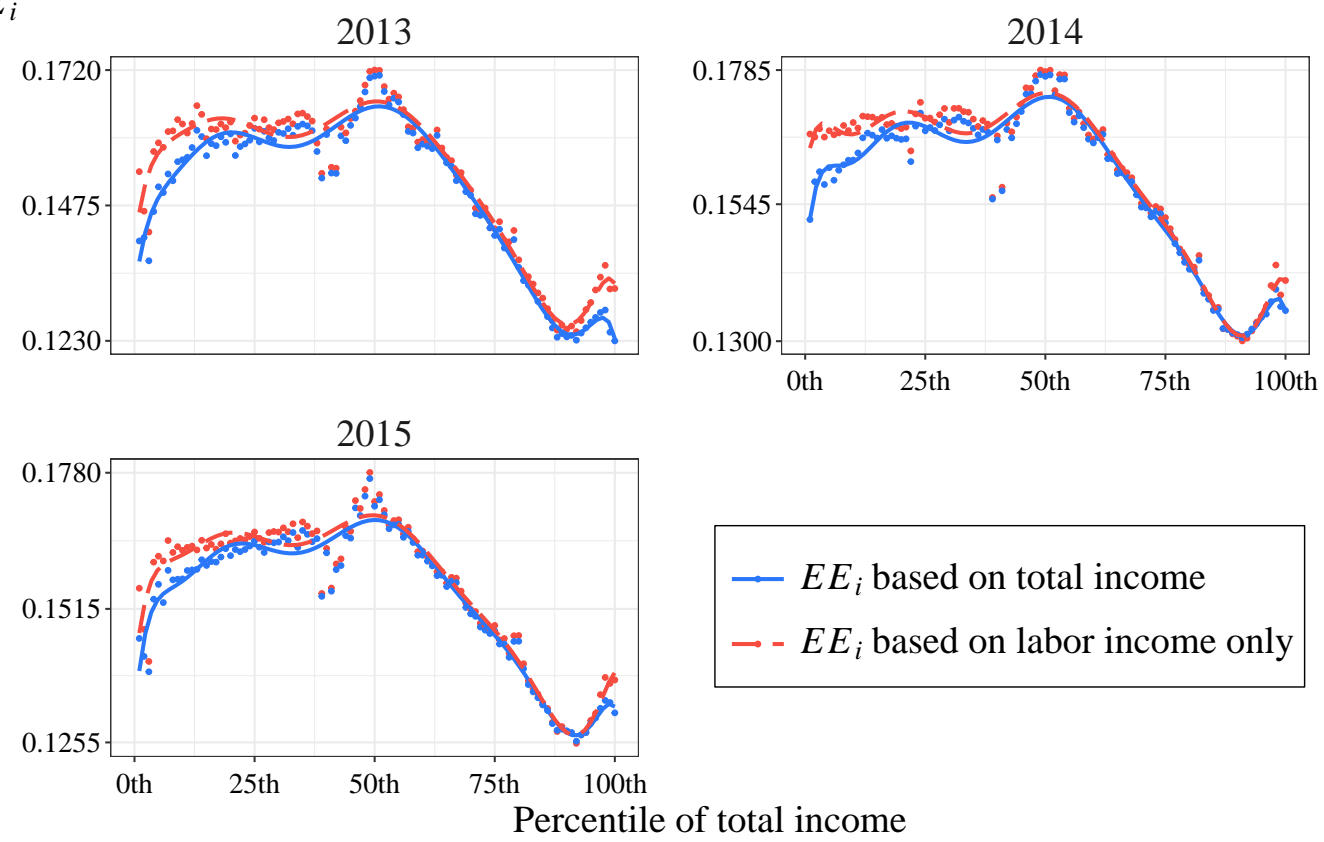
Figure C.2: Distribution of Import Exposure $\left(I E_{i}\right)$ Across Individuals, 2009-2015
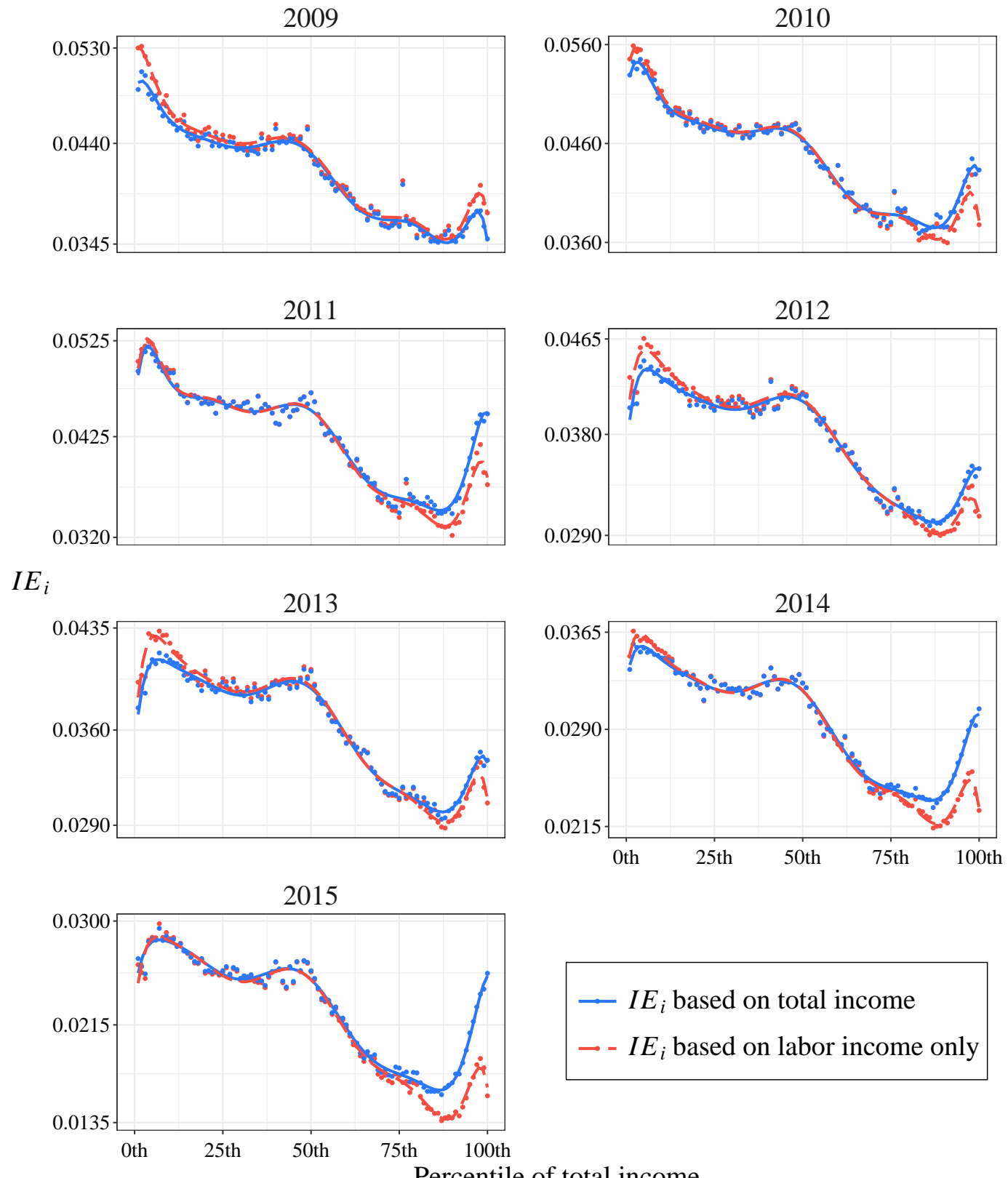

$-I E_{i}$ based on total income

- - $I E_{i}$ based on labor income only 


\section{C.3 Estimation of Micro-Level Elasticities: Zeroth-Stage Regression}

The logic of the IVs in Section 5 relies on product-level export and import shocks in the rest of the world, (Export Shock) $)_{v t}$ and (Import Shock) ${ }_{v t}$, having a positive effect on the log of Ecuador's total export value and import unit value, (Export Ecuador) $)_{v t}$, and (Import Ecuador) $)_{v t}$, respectively. We now evaluate whether this is the case through the following zeroth-stage regression:

$$
Y_{v, t}^{E c u a d o r}=\beta Y_{v, t}^{W}+\zeta_{v}+\delta_{t}+\epsilon_{v, t}
$$

with $Y_{v, t}^{\text {Ecuador }}=(\text { Export Ecuador })_{v t}(\text { Import Ecuador })_{v t}, Y_{v, t}^{W}=(\text { Export Shock })_{v t},(\text { Import Shock })_{v t}$, and $\zeta_{v}$ and $\delta_{t}$ are product and year fixed-effects. In this specification, the coefficient $\beta$ captures the pass-through of foreign shocks to Ecuadorian variables. We estimate this pass-through using the sample of product-year pairs for which we observe positive exports and imports for Ecuador between 2009 and 2015.

Table C. 2 reports the results of this exercise for the total export value in Panel A and the import unit value in Panel B. For both exports and imports, column (1) shows that a foreign shock of $1 \%$ causes an increase of roughly $0.2 \%$ in Ecuador's export total value and import unit value. Columns (2) and (3) indicate that the pass-through coefficient is positive for both manufacturing and non-manufacturing products.

Table C.2: Impact of World Shocks on Ecuadorian Trade

(3)

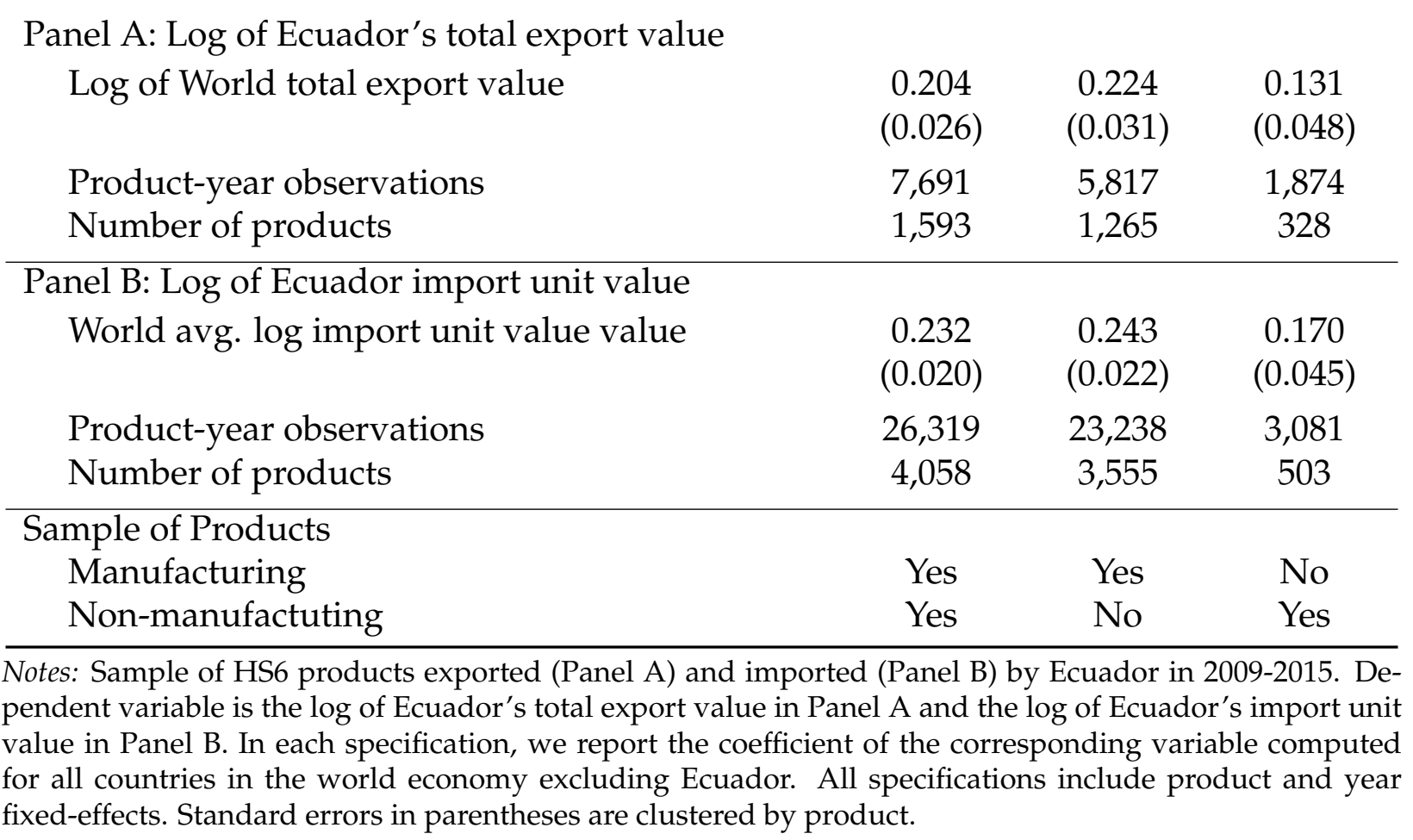




\section{C.4 Micro-Level Test: Specification Details}

This section presents the details of the empirical specifications used to estimate $\beta_{\text {sector }}, \beta_{\text {trade, }}$, and $\beta_{\text {input }}$ in Section 6.1.

\section{C.4.1 Estimation of $\beta_{\text {sector }}$}

Empirical Specification. Like in Section 5, we allow the demand residual $\alpha_{k, t}$ to be a function of a sector-specific term $\zeta_{k}$, a year-specific term $\zeta_{t}$ that includes both the aggregate spending and the aggregate price index, and an unobserved preference shock $\epsilon_{k, t}$. Thus, equation (22) implies

$$
\ln \left(\sum_{n \in \mathcal{N}_{k}} D_{n, t}\right)=\beta_{\text {sector }} \ln P_{k, t}+\zeta_{k}+\zeta_{t}+\epsilon_{k c, t} .
$$

The estimation of this specification requires measures of the CES price index in each sector, $P_{k, t}$. We follow the same strategy used in Section 5.2 to measure the CES price index for domestic factors in each firm. For any firm $n$ in sector $k$, inverting final demand in (4) implies that

$$
\ln P_{k, t}=\ln p_{n, t}+\frac{1}{\sigma-1} \ln \left(d_{n k, t} / \theta_{n c, t}\right) .
$$

Averaging this expression across firms using shares of final sales in sector $k$ as weights, we obtain

$$
\ln P_{k, t}=\ln \tilde{P}_{k, t}+\xi_{k, t}
$$

with $\ln \tilde{P}_{k, t} \equiv \sum_{n \in \mathcal{N}_{k, t}} d_{n k, t}\left(\ln p_{n, t}+\frac{1}{\sigma-1} d_{n k, t} \ln d_{n k, t}\right)$ and $\xi_{k, t} \equiv \frac{1}{1-\sigma} \sum_{n \in \mathcal{N}_{k, t}} d_{n k, t} \ln \theta_{n c, t}$. The combination of (C.1) and (C.2) yields our estimating equation

$$
\ln \left(\sum_{n \in \mathcal{N}_{k}} D_{n, t}\right)=\beta_{\text {sector }} \ln \tilde{P}_{k, t}+\zeta_{k}+\zeta_{t}+\epsilon_{k, t}
$$

with $\epsilon_{k, t} \equiv \epsilon_{k c, t}+\xi_{k, t}$.

IV Strategy. To circumvent the simultaneity bias in the estimation of $\beta_{\text {sector }}$ in (C.3), we use three IVs constructed from the sectoral average of the firm-level cost shifters used in the estimation of $\sigma$ in Section 5.2. These are

$$
\hat{E}_{k, t}=\sum_{n \in \mathcal{N}_{k, t_{0}}} d_{n k, t_{0}} \hat{E}_{n, t}, \quad \hat{I}_{k, t}=\sum_{n \in \mathcal{N}_{k, t_{0}}} d_{n k, t_{0}} \hat{I}_{n, t}, \quad \hat{w}_{k, t}^{*}=\sum_{n \in \mathcal{N}_{k, t_{0}}} d_{n k, t_{0}} \hat{w}_{n, t}^{*},
$$

where $d_{n k, t_{0}}$ is the share of firm $n$ in total final spending in sector $k$ at the initial year $t_{0}$. The validity of these IVs relies on the assumption that, conditional on sector and time fixed effects, global export and import shocks are orthogonal to shocks in the final demand for the products of different firms and sectors. 


\section{C.4.2 Estimation of $\beta_{\text {trade }}$}

Empirical Specification. Like in Section 5, we allow the firm's relative demand for imported inputs, $\ln \left(\left(1-\Theta_{n, t}\right) / \Theta_{n, t}\right)$, to be a function of a firm-specific term $\zeta_{n}$, a year-specific term $\zeta_{t}$, a control set Controls $s_{n, t}$, and an unobserved technology shock $\epsilon_{n, t}$. Equation (23) therefore implies

$$
\ln \frac{x_{n, t}^{*}}{\sum_{n \in \mathcal{N}} x_{n, t}}=\beta_{\text {trade }} \ln \left(w_{n, t}^{*} / P_{n, t}^{D}\right)+\zeta^{\prime} \operatorname{Controls}_{n, t}+\zeta_{n}+\zeta_{t}+\epsilon_{n, t},
$$

where $w_{n, t}^{*}$ is the same measure of the price of foreign factor services facing firm $n$ used in Section 5.2; $P_{n, t}^{D}$ is the price index of domestic inputs for firm $n$, which we measure as $\ln P_{n, t}^{D}=$ $\sum_{m \in \mathcal{N}} \theta_{m n} \ln p_{m, t}$ using the values of $p_{m, t}$ implied by (17); and the vector of controls Controls ${ }_{n, t}$ include the same variables as in Section 5.2: time dummies interacted with the share of the firm's costs spent on primary factors and imported inputs.

IV Strategy. In the estimation of (C.5), we use the global shock to the cost of firm $n$ 's imported inputs, $\hat{w}_{n, t}^{*}$ in equation (21), as IV. Again, the validity of this instrument requires foreign shocks to the price of imported products to be orthogonal to technology shocks in Ecuador.

\section{C.4.3 Estimation of $\beta_{\text {input }}$}

Empirical Specification. We allow the firm's demand for inputs from different suppliers, $\ln \theta_{m n, t}$, to be a function of a supplier-specific term $\zeta_{m}$, a buyer-year term $\zeta_{n, t}$ that absorbs the buyer's input price index, a control set for each supplier Controls ${ }_{m, t}$, and an unobserved input demand shock $\epsilon_{m n, t}$. Thus, equation (24) implies

$$
\ln x_{m n, t}=\beta_{\text {input }} \ln p_{m, t}+\zeta^{\prime} \operatorname{Controls}_{m, t}+\zeta_{n, t}+\zeta_{m}+\epsilon_{m n, t}
$$

where $p_{m, t}$ is still measured using (17) and Controls $s_{m, t}$ again includes time dummies interacted with the share of the supplier's cost spent on primary factors and imported inputs.

IV Strategy. We address the simultaneity bias in the estimation of (C.6) by instrumenting $\ln p_{m, t}$ with the same firm-level IVs used in Section 5.2: $\hat{E}_{n, t}, \hat{I}_{n, t}$ and $\hat{w}_{n, t}^{*}$ in equations (19)-(21). This strategy is valid under the same assumptions necessary for the estimation of $\sigma$. 


\section{C.5 Macro-Level Test Under Alternative Micro-Level Elasticities}

Figure C.3 describes how estimates of $\hat{\beta}_{\text {fit }}$ vary when alternative values of $\sigma$ and $\eta$ are used to construct $\ln w_{f, t}^{\text {model }}$.

\section{Figure C.3: Macro-Level Test Under Alternative Values of Micro-Level Elasticities}
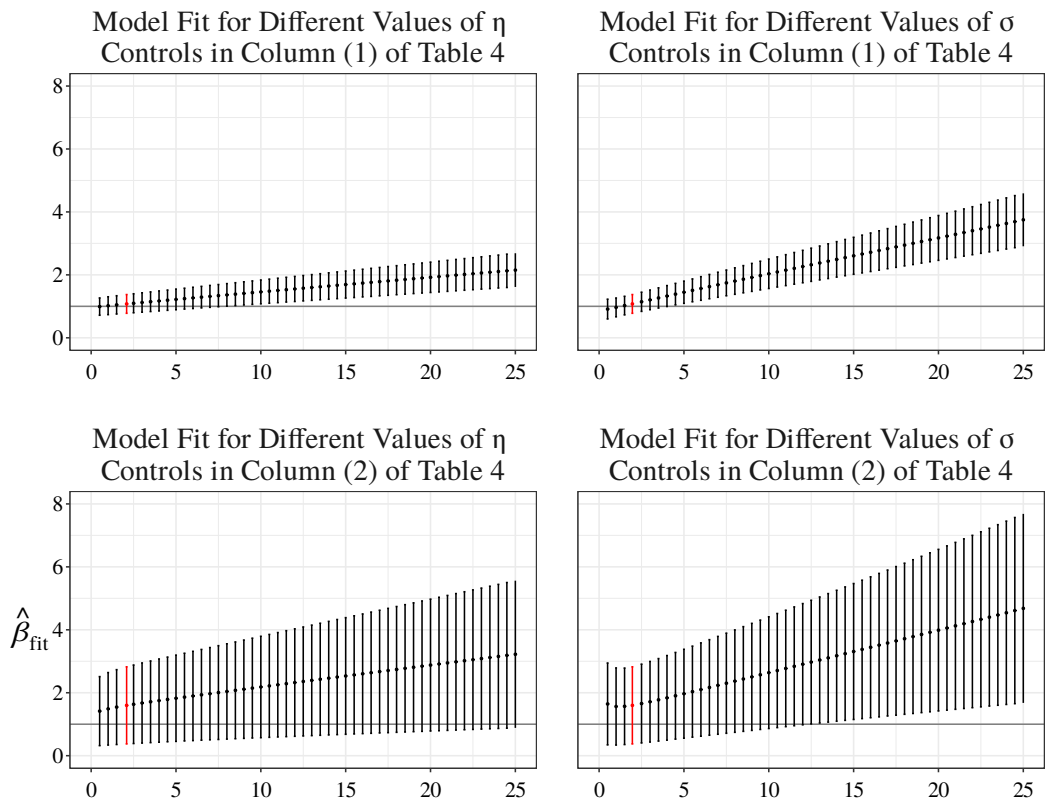

Model Fit for Different Values of o Controls in Column (2) of Table 4

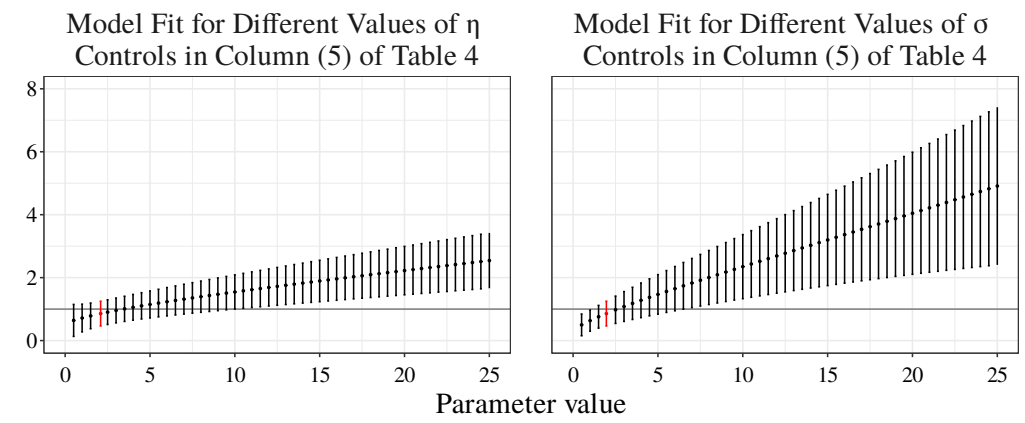

Notes: Each panel reports the fit coefficient $\hat{\beta}_{\text {fit }}$ and the $95 \%$ confidence interval implied by the estimation of (26) with $\ln \hat{w}_{f, t}^{\text {model }}$ computed under alternative values of the elasticity of substitution across factors in production, $\eta$, and the elasticity of substitution across firms in consumption, $\sigma$. The left-hand panels vary $\eta$ at $\sigma=1.96$, and the right-hand panels vary $\sigma$ at $\eta=2.09$, the baseline parameter values used in Table 4 . Red points denote those same baseline values. Based on sample of 75 factors in 2009-2015. All specifications include year and factor fixed effects. Observations are weighted by initial factor payments (with weights winsorized at the 95 percentile). Standard errors clustered by factor. 


\section{C.6 Connecting Exposure Measures to Counterfactual Responses}

We now aim to assess how the export and import exposure measures from Section $4, E E_{i, t}$ and $I E_{i, t}$, relate to the counterfactual changes in earnings predicted for each individual, $\left(\Delta Y_{i, t}\right)_{t r a d e} / Y_{i, t}$. We do this by means of the linear regression

$$
\frac{\left(\Delta Y_{i}\right)_{\text {trade }}}{Y_{i}}=\beta+\beta^{E} E E_{i}+\beta^{I} I E_{i}+v_{i}
$$

using the sample of all individuals $i$ (in 2012). Table C.3 reports our estimates, beginning in column (1) with the regression coefficients corresponding to total income. Both exposure measures have signs that are in line with the local predictions of Proposition 2 and Proposition 3 (for $\sigma>1$ ) and the total contribution of the two exposure measures is high (with an $R^{2}=0.90$ ). The same is true for labor income on its own, reported in column (3). In order to explore the relative explanatory contributions of $E E_{i, t}$ and $I E_{i, t}$ to this high overall fit, columns (2) and (4) report the Shapley decomposition of the $R^{2}$ in columns (1) and (3), respectively. It is clear, in both cases, that significantly more fit can be accounted for in this sense by the import exposure measure.

Table C.3: Distribution of the Gains from Trade and Individual Exposure, 2012

\begin{tabular}{|c|c|c|c|c|}
\hline & \multicolumn{2}{|c|}{$\begin{array}{l}\text { Proportional change } \\
\text { in total income }\end{array}$} & \multicolumn{2}{|c|}{$\begin{array}{c}\text { Proportional change } \\
\text { in labor income }\end{array}$} \\
\hline & $\begin{array}{c}\text { Coefficient } \\
\text { estimates } \\
\text { (1) }\end{array}$ & $\begin{array}{c}\text { Shapley } \\
\% R^{2} \\
\text { (2) }\end{array}$ & $\begin{array}{c}\text { Coefficient } \\
\text { estimates } \\
\text { (3) }\end{array}$ & $\begin{array}{c}\text { Shapley } \\
\text { \% } R^{2} \\
\text { (4) }\end{array}$ \\
\hline Export exposure $(E E)$ & $\begin{array}{c}1.228 \\
(0.001)\end{array}$ & $7.5 \%$ & $\begin{array}{c}1.319 \\
(0.001)\end{array}$ & $8.1 \%$ \\
\hline Import exposure $(I E)$ & $\begin{array}{l}-8.161 \\
(0.002)\end{array}$ & $92.5 \%$ & $\begin{array}{l}-8.216 \\
(0.001)\end{array}$ & $91.9 \%$ \\
\hline$R^{2}$ & 0.90 & $100.0 \%$ & 0.93 & $100.0 \%$ \\
\hline Obs. & $2,612,867$ & & $2,413,683$ & \\
\hline
\end{tabular}

Notes: Columns (1) and (3) report the results of the estimation of (C.7) for the changes, between the trade and the counterfactual autarkic equilibrium, in total and labor income, respectively. Columns (2) and (4) report the Shapley decomposition of the $R^{2}$ for each specification. Robust standard errors in parentheses. 